Erwin Tramontini Grau

\title{
Filogenia Molecular e Biogeografia: Jacus e Jacutingas (Cracidae)
}

São Paulo 


\section{Erwin Tramontini Grau}

\section{Filogenia Molecular e Biogeografia: Jacus e Jacutingas (Cracidae)}

Tese apresentada ao Instituto de Biociências, Universidade de São Paulo, para a obtenção de Título de Doutor em Ciências, na Área de Biologia (Genética).

Orientadora: Profa. Dra. Anita Wajntal

São Paulo

2008 
Grau, Erwin Tramontini

Filogenia Molecular e Biogeografia: Jacus e Jacutingas (Cracidae)

138 páginas

Tese - Doutorado

Instituto de Biociências da

Universidade de São Paulo.

Departamento de Genética e Biologia Evolutiva.

1. Cracidae; 2. Aburria; 3. Penelope;

I. Universidade de São Paulo. Instituto de Biociências.

Departamento de Genética e Biologia Evolutiva.

Comissão Julgadora

$\operatorname{Prof}(a) . \operatorname{Dr}(a)$.

$\operatorname{Prof(a).} \operatorname{Dr}(a)$.
$\operatorname{Prof}(a) . \operatorname{Dr}(a)$

$\operatorname{Prof}(a) . \operatorname{Dr}(a)$

Profa. Dra. Anita Wajntal

Orientadora 
Aos meus pais. 
À minha orientadora, Anita Wajntal, pelo apoio incondicional e por toda a compreensão durante estes oito anos de convivência.

À minha família e à Andréia pela compreensão pela minha ausência em momentos importantes.

Ao Sérgio Luiz Pereira e a Cristina Miyaki pelo apoio constante.

Ao João Morgante pelo importante apoio no início da minha pesquisa.

Ao Allan Baker pela oportunidade de desenvolver parte dos experimentos em seu laboratório.

Um agradecimento especial à Lucilene, sempre disposta a me ajudar.

Aos colegas Fábio Raposo Sarubi, Erika Sendra Tavares, Camila Ribas, Luís Fábio Silveira e a todos os demais que colaboraram no desenvolvimento deste trabalho.

Ao instituto de Biociências da USP e ao Royal Ontario Museum.

À Fundação de Amparo à Pesquisa do Estado de São Paulo (FAPESP), ao Conselho Nacional de Desenvolvimento Científico e Tecnológico (CNPq) e ao Natural Sciences and Engineering Research Council of Canada (NSERC).

Aos museus e criadouros que forneceram as amostras para a realização deste trabalho: Luís Fábio Silveira, Museu de Zoologia da USP, São Paulo, SP, Brasil; Alexandre Aleixo, Museu Paraense Emilio Goeldi, Belém, PA, Brasil; Donna Dittmann, Louisiana State University Museum of Natural History, Baton Rouge, Louisiana, USA; Allan Baker, Royal Ontario Museum, Toronto, Ontário, Canadá; Moacyr Carvalho Dias, Criadouro Científico e Cultural Poços de Caldas, Brasil; Vitor Fasano, Criadouro Tropicus, Brasil; Roberto Antonelli; Wagner Tadeu Vieira Santiago, CESP Paraibuna, Brasil; Katya Frank e J.J. Estudillo Lopez, Granja La Sibéria, México; G. Scheres, Crax Foundation; Roberto Azeredo, Fundação Crax, Brasil; e, Fernando G. Gonzales, Fundacion Ara, México. 
Resumo

Capítulo I

Introdução

Capítulo II

Materiais e Métodos

Capítulo III

Filogenia Molecular e Biogeografia das Jacutingas: Pipile

Bonaparte, 1856 é sinônimo de Aburria Reichenbach, 1853.

Capítulo IV

Filogenia Molecular e Biogeografia dos Jacus:

Gênero Penelope - Revisão Taxonômica e Evolutiva

Capítulo V

Conclusões

Anexo I

Artigo publicado (Capítulo III)

Molecular Phylogenetics and Evolution 35: 637-645.

Anexo II

Artigo publicado

Bird Conservation International 13: 115-126.

Anexo III

Artigo publicado

Genome 47: 535-545.

Referências Bibliográficas 


\section{Abstract}

Cracids are large frugivorous Neotropical birds. Comprise 10 genera and 50 species that can be grouped as currasows, chachalacas, guans and Horned Guan. Molecular phylogenetic and biogeographic studies in this family were already performed for intergeneric relationships and among curassows species. Molecular data for intrageneric relationships for guans were not available. Guans comprise 23 species of four genera [Aburria, Chamaepetes, Penelope, and Penelopina] that range from México to Argentina. We estimated the phylogenetic relationships among species of the genus Penelope, including 13 species and about $13 \mathrm{~kb}$ of mitochondrial and nuclear DNA (Bayesian and Maximum Parsimony) and among species of the genus Aburria (plus Pipile), including 5 species and about $2,7 \mathrm{~kb}$ of mitochondrial DNA (Bayesian, Maximum Likelihood and Maximum Parsimony). Results indicate Penelope as monophyletic and Pipile as paraphyletic group. Therefore, we suggest that Pipile should be merged with Aburria, the oldest described genus. For the genus Penelope: Penelope obscura, with three subspecies sampled, appears as paraphyletic group. We suggest that they should be considered as valid species. Molecular dating of divergence time was estimated. The diversification among guans seems to have occurred from Miocene to Pleistocene. Marine transgression, the rise of the Andes, and the subsequent changes in river basins in south America, formation of Amazon Lagoon and habitat specializations seems to be the major factors affecting guan diversification. 


\section{Resumo}

Cracídeos são aves neotropicais frugívoras e de grande porte. Englobam 50 espécies e 10 gêneros que podem ser agrupados em mutuns, jacus e jacutingas, aracuãs e Mutum Cornuto. Filogenias moleculares e estudos biogeográficos dos cracídeos estão disponíveis para as relações intergenéricas da família e entre as espécies de mutuns. Entretanto, não estão disponíveis dados moleculares para o estudo dos jacus e jacutingas. Os jacus e jacutingas englobam 23 espécies em 04 gêneros [Aburria, Chamaepetes, Penelope e Penelopina] com distribuição do México à Argentina. Neste estudo, definimos as relações filogenéticas entre as espécies do gênero Penelope, incluindo 13 espécies e 13 kb de seqüências de DNA mitocondrial e nuclear (análises Bayesiana e de Máxima Parcimônia) e entre as espécies do gênero Aburria (com Pipile), incluindo 5 espécies e 2,7 kb de seqüências de DNA mitocondrial (análises Bayesiana, de Máxima Verossimilhança e de Máxima Parcimônia). Nossos resultados mostraram Penelope como grupo monofilético e Pipile como grupo parafilético. Sugerimos que as espécies de Pipile sejam transferidas para o gênero Aburria, o gênero mais antigo. Em Penelope, as subespécies de Penelope obscura aparecem como grupo parafilético. Sugerimos que sejam consideradas como espécies válidas. No estudo evolutivo de Cracidae, as datações de tempo de divergência indicam que a diversificação dos jacus e jacutingas ocorreu do Mioceno ao Pleistoceno. As transgressões marinhas, o soerguimento dos Andes e suas conseqüências nas bacias dos rios sulamericanos, a formação da Laguna Amazônica e especializações de habitat parecem ser os principais fatores que influenciaram na diversificação dos jacus e jacutingas. 


\section{Introdução}

\section{1) A Família Cracidae}

Os Cracídeos, pertencentes à ordem dos Galliformes, são aves neotropicais de grande porte. Apresentam hábito arborícola, alimentando-se basicamente de folhas e frutos (Delacour \& Amadon, 1973). Habitam, principalmente, florestas tropicais ou florestas em áreas montanhosas e úmidas, sendo importantes na manutenção destes ecossistemas pela dispersão de sementes (Brooks \& Strahl, 2000).

Ocorrendo desde o sul do Texas nos Estados Unidos até o norte da Argentina e Uruguai as espécies apresentam distribuição geográfica bem definida. Espécies congenéricas geralmente apresentam distribuição alopátrica. Contudo, quando as espécies de cracídeos ocorrem em simpatria ocupam microhábitats distintos dentro de uma área geográfica maior (Sick, 1993). Essencialmente, são não-migratórios, entretanto movimentos locais ocorrem em algumas espécies (del Hoyo et al., 1994).

A origem da família é pouco conhecida, havendo duas hipóteses em debate. Vuilleumier (1965) defende a origem norte americana. Esta hipótese é reforçada pela ocorrência de um fóssil de 50 Ma (milhões de anos) em Wyoming (del Hoyo et al., 1994), sendo que nesta época grande parte da América do norte era tropical. Além deste, outros fósseis mais recentes de aproximadamente $30 \mathrm{Ma}$ similares aos aracuãs (gênero Ortalis), foram encontrados na Dakota do Sul (Tordoff \& MacDonald, 1957). Na América do Sul apenas fósseis pleistocênicos de Crax e Penelope foram encontrados em depósitos de cavernas (Vuilleumier, 1965). 
Algumas evidências indicam a origem sul-americana sugerida por Darlington (1957). A descoberta de Ameripodius, um fóssil de galiforme primitivo (Alvarenga, 1995) do Oligoceno superior ou Mioceno inferior da formação de Tremembé no extremo leste do estado de São Paulo, poderia ser uma evidência da origem sul-americana do grupo. Alguns estudos moleculares apontaram Megapodiidae, que ocorre na Austrália, como grupoirmão de Cracidae (Pereira et al., 2002; Sibley et al., 1988) indicando que os ancestrais podem ter-se originado em fragmentos da Gondwana, anteriormente à separação da América do Sul, Antártica e Austrália, como é o caso das aves ratitas (e.g., van Tuinen, et al., 1998). Datações de divergência, com dados moleculares, indicam a origem dos Cracidae entre 64 e 90 Ma (Pereira et al., 2002), coincidente com a separação destes continentes.

A família Cracidae é composta tradicionalmente por 11 gêneros e cerca de 50 espécies, usualmente dividida em quatro grupos: mutuns (Crax, Mitu, Nothocrax e Pauxi); jacus e jacutingas (Aburria, Chamaepetes, Penelopina, Penelope e Pipile); aracuãs (Ortalis); e, Oreophasis (gênero monotípico). Entretanto, revisões taxonômicas internas da família Cracidae (e.g., Vuilleumier, 1965; Vaurie, 1968; Delacour \& Amadon, 1973) apresentam uma grande variação quanto ao status taxonômico de gêneros, espécies e subespécies.

As relações filogenéticas intergenéricas estudadas por Pereira e col. (2002), fundamentado em dados moleculares, forneceram uma nova visão sobre a evolução dos cracídeos, divergindo das classificações tradicionais (e.g., Vaurie, 1968; Delacour \& Amadon, 1973) em diversos pontos. Como 
exemplo, as análises moleculares apresentam Ortalis como grupo-irmão dos mutuns e não dos jacus e jacutingas, o que não era sugerido nas classificações tradicionais, tornando a subfamília Penelopinae parafilética. Outro estudo sobre as relações filogenéticas intergenéricas é o de FrankHoeflich e col. (2007) que analisou um fragmento de gene mitocondrial em conjunto com dados osteológicos, integumentares e comportamentais, gerando resultados em parte concordantes com Pereira e col. (2002). As espécies do grupo dos mutuns também foram estudadas por Pereira e Baker (2004a), que revelaram os gêneros Pauxi e Mitu como não reciprocamente monofiléticos.

Visando ampliar os conhecimentos sobre a sistemática e os padrões evolutivos e biogeográficos dentro dos Cracidae, selecionamos para este projeto as espécies de jacus e jacutingas pertencentes aos gêneros Aburria, Pipile e Penelope. Seguimos a classificação e a nomenclatura de cracídeos adotadas por del Hoyo e col. (1994).

\section{2) Os Jacus e Jacutingas}

Os jacus e jacutingas são aves de porte médio, com até $2,5 \mathrm{~kg}$ (del Hoyo et al., 1994), hábito arborícola, raramente vindo ao chão. Muitas espécies de jacus e jacutingas apresentam garganta nua e uma barbela bem desenvolvida. Os jacus apresentam a barbela vermelha. Nas jacutingas a barbela tem coloração púrpura ou azul, com muitas espécies apresentando ainda a parte inferior da barbela avermelhada.

O grupo é composto tradicionalmente por cinco gêneros: Aburria, Chamaepetes, Penelopina, Penelope e Pipile. Foram propostos diversos 
arranjos para as relações filogenéticas entre os gêneros de jacus e jacutingas, baseando-se principalmente em caracteres morfológicos. Apenas recentemente, em 2002, foi proposta filogenia englobando os gêneros de jacus, jacutingas e outros cracídeos com a utilização de dados moleculares (Pereira et al., 2002), apresentando os jacus e jacutingas como um grupo monofilético.

\section{1) O Gênero Aburria}

O gênero é monotípico. Aburria aburri é encontrada no oeste da Venezuela e norte da Colômbia, leste e oeste do Equador e sul e centro-sul do Peru, ocorrendo em florestas úmidas de montanha em altitudes entre 500 e 2500 m acima do nível do mar (del Hoyo et al., 1994; Ridgely \& Greenfield, 2001).

\section{2) O Gênero Chamaepetes}

O gênero Chamaepetes é composto por duas espécies. Chamaepetes goudotii é encontrado nas florestas tropicais e, em parte, na zona temperada dos Andes na Colômbia, Equador e Peru, enquanto Chamaepetes unicolor ocorre na Costa Rica e Panamá (Delacour \& Amadon, 1973).

\section{3) O Gênero Penelopina}

O gênero Penelopina é monotípico. Penelopina nigra ocorre no Sul do México, Guatemala, El Salvador, Honduras e Nicarágua, em florestas úmidas subtropicais e florestas temperadas entre altitudes de 1000 a 3500 m (Delacour \& Amadon, 1973). 


\section{4) O Gênero Penelope}

A distribuição dos jacus verdadeiros (táxons do gênero Penelope), do México à Argentina, coincide aproximadamente com a das florestas tropicais e florestas úmidas, entretanto algumas espécies ocorrem localmente em matas de galeria (Delacour \& Amadon, 1973). Na América do Sul, três ou quatro espécies são características de florestas de regiões montanhosas, sendo as demais de terras baixas. Na América do Norte observamos a distribuição apenas de Penelope purpuracens chegando ao México. No grupo dos jacus verdadeiros podemos observar, em alguns casos, espécies de mesmo gênero ocorrendo em simpatria, situação incomum na família.

Atualmente, são reconhecidas 15 espécies no gênero Penelope (del Hoyo et al., 1994), havendo várias similares em tamanho, forma corporal e coloração (Delacour \& Amadon, 1973), levando a divergências nas classificações. Várias revisões estudaram a taxonomia dos jacus verdadeiros (e.g., Vuilleumier, 1965; Vaurie, 1964, 1966a, 1966b e 1968; Delacour \& Amadon, 1973), entretanto, o status de alguns táxons ainda não é consenso.

\section{5) O Gênero Pipile}

O gênero Pipile consiste de seis formas, diferenciáveis por caracteres morfológicos, que ocorrem em diferentes regiões geográficas: uma restrita a Trinidad (Pipile pipile) e as demais com ampla distribuição na América do Sul (Pipile cumanensis, Pipile cujubi, Pipile nattereri, Pipile grayi e Pipile jacutinga). Todas as seis formas são bastante similares em aparência e tamanho, mas são essencialmente alopátricas. A definição das espécies é bastante difícil (Vaurie, 1967), sendo que, várias classificações foram 
propostas. Salvatori (1914) sugere a existência de seis espécies, cada uma com ocorrência em uma região geográfica distinta. Entretanto, em 1958 foram coletados seis espécimes intermediários entre cumanensis e grayi, sugerindo a existência de apenas cinco espécies (Vaurie, 1967). Algumas revisões foram feitas por Peters (1934) que dividiu o gênero em três espécies, Hellmayr e Conover (1942) que eliminou grayi e naumburgae e as sinonimizou com nattereri e Vuilleumier (1965) que incluiu todos os táxons do gênero Pipile no gênero Penelope. Em 1967, Vaurie reconhece apenas três espécies válidas em Pipile: Pipile pipile com as subespécies pipile, cumanensis e grayi, Pipile cujubi com as subespécies cujubi e nattereri e Pipile jacutinga. A revisão de Delacour e Amadon (1973), considera as espécies de Pipile pertencentes ao gênero Aburria e divide as seis formas geográficas em duas espécies: Aburria jacutinga com o morfotipo jacutinga e Aburria pipile com os demais cinco morfotipos regionais. No "Handbook of the Birds of the World", del Hoyo e col. (1994), reconhece quatro espécies, assim como Brooks e Strahl (2000): Pipile cujubi, Pipile cumanensis, Pipile jacutinga e Pipile pipile.

\section{3) Sistemática Filogenética, DNA e Biogeografia}

Desde tempos remotos na história da humanidade, já existia uma preocupação de se descrever e classificar a diversidade biológica (revisão em Pereira, 2000). Entretanto, apenas na segunda metade do século $X X$ foi proposto um sistema de classificação biológica baseado na premissa de que os organismos constituem sistemas contínuos e em modificação. A Sistemática Filogenética ou Cladística, proposta por Hennig em 1950, 
embasa suas classificações na história evolutiva dos organismos. Trata das relações filogenéticas tendo como princípio primário o monofiletismo, isto é: a descendência de um ancestral comum e exclusivo e não a simples semelhança, como ocorria em outras escolas. Apenas caracteres apomórficos são utilizados para caracterizar os grupos, por serem os marcadores que permitem indicar onde ocorreram os processos de anacladogênese. Os resultados das análises são apresentados na forma de cladogramas que expressam relações de ancestralidade entre os grupos.

A partir da segunda metade da década de sessenta, quando o trabalho de Hennig foi traduzido do alemão para o inglês, observaram-se grandes avanços conceituais e metodológicos em filogenia. O surgimento de técnicas que facilitaram a análise do DNA, permitiu ampliar os estudos de evolução molecular.

O DNA mitocondrial tem sido empregado em estudos filogenéticos. Primeiramente através de análises de restrição (e.g., Avise \& Nelson, 1989) e atualmente, através do seqüenciamento de DNA (e.g., Hedges, 1994). Em animais, o DNA mitocondrial apresenta-se como uma molécula circular de 15 a $20 \mathrm{~Kb}$ de tamanho (Avise, 1994), contendo 37 genes. Possui herança predominantemente materna não ocorrendo recombinação e nem segregação de alelos. Devido a isso, o DNA mitocondrial representa uma única unidade genealógica não recombinante e multialélica sob a perspectiva filogenética (Avise, 1994). A taxa de evolução do DNA mitocondrial é mais rápida que do genoma nuclear (Brown et al., 1979) e mais variável de gene para gene e entre linhagens evolutivas (Pereira \& Baker, 2006).

Devido a estas características o DNA mitocondrial tem sido utilizado 
em diversos campos, como por exemplo: no estudo de populações de aves da mesma espécie (e.g., Wright \& Wilkinson, 2001); na definição e diferenciação de espécies (e.g., Aleixo, 2002; Bradley \& Baker, 2001; Grau et al., 2003 (anexo 1); Zink \& Blackwell-Rago, 2000); no estudo das relações entre espécies de um mesmo gênero (e.g., Miyaki et al., 1998; Pereira \& Baker, 2004a); na definição das relações entre diferentes gêneros de uma família (e.g., Pereira et al., 2002; Kimura et al., 2004); e, entre outras aplicações, em estudos biogeográficos (e.g., van Tuinen et al., 1998).

Biogeografia é mais um dos termos que, em biologia, podem ter diferentes conceitos e definições, assim como o termo espécie. A biogeografia histórica analisa a origem e a relação entre as biotas. Estuda as distribuições espaciais e temporais dos organismos. Como está intimamente ligada à sistemática, existem escolas com linhas filosóficas distintas. Um dos ramos da biogeografia histórica é a biogeografia filogenética, que, para Hennig, deveria basear-se em um estudo filogenético do grupo estudado.

Estudos biogeográficos com base em dados moleculares (e.g., Aleixo, 2002; Haddrath \& Baker, 2001; Hedges et al., 1996; van Tuinen et al., 1998; Pereira \& Baker, 2004a; Pereira \& Baker, 2004b), tem sido importantes para o conhecimento da evolução das espécies e da maneira como a biodiversidade dos biomas é constituída. 


\section{4) Eventos Paleogeográficos}

No Terciário, a região sul da América do Norte era bem mais úmida do que é hoje, apresentando florestas tropicais até o início do Oligoceno (40 a $23 \mathrm{Ma}$ ), quando começou um período de resfriamento e aumento de precipitação (Salgado-Labouriau, 1994). No Mioceno (23 a 5 Ma) há a formação da maior parte da América Central, uma nova diversificação das angiospermas (Salgado-Labouriau, 1994) e mudanças climáticas no sul da América do Norte. Estes eventos poderiam estar ligados à origem dos Cracidae, se estes diferenciaram-se dos demais Galliformes na América do Norte, uma das hipóteses propostas para a origem da família Cracidae.

Na América do Sul, o soerguimento dos Andes começa no Mioceno, no sentido sul-norte, provocando grandes alterações nas condições climáticas na Amazônia e bacias hidrográficas em todo o continente sulamericano. O soerguimento dos Andes promoveu a inversão da drenagem dos rios amazônicos (Hoorn et al., 1995), provocou mudanças na circulação dos ventos e nos padrões de chuvas no norte do continente (Hooghiemstra \& van der Hammen, 1998), influenciando a evolução da fauna e da flora da região. As conseqüências do soerguimento dos Andes foram sentidas também na região atlântica, causando alterações na distribuição das Matas desta região.

No final do Terciário e durante o Quaternário, outros fatores também provocaram modificações nas florestas tropicais, como a alternância entre períodos glaciais e interglaciais. Estudos recentes com sedimentos marinhos e continentais mostram que houve glaciações desde há 5 Ma no Hemisfério 
Norte e desde 15 Ma no Hemisfério Sul (Salgado-Labouriau, 1994). Os ciclos são resultado de alguns parâmetros orbitais que modificariam a quantidade de energia recebida e forçariam uma mudança no sistema climático (Salgado-Labouriau, 1994).

Os períodos interglaciais caracterizam-se pelo aumento da temperatura da Terra com aumento da pluviosidade, possibilitando a expansão das florestas tropicais. Os períodos glaciais representados pelo resfriamento climático global, com diminuição da pluviosidade, provocariam o avanço das paisagens semi-áridas sobre estas florestas, que se transformariam em refúgios ou ilhas de vegetação florestal (Haffer, 1992; Whitmore, 1990). Como evidência da influência dos ciclos encontramos regiões com fauna e flora características do Cerrado presentes no interior da Floresta Amazônica (Ab'Saber, 1996). Aos ciclos glaciais, também, estão associadas alterações no nível do mar. Marroig e Cerqueira (1997) sugerem que transgressões marinhas, em conjunto com o degelo dos Andes e um aumento da pluviosidade, provocaram a formação de lagunas, por diversas vezes, no interior da Amazônia, sendo a maior formada há 2,5 Ma quando o mar atingiu um nível de 180 metros acima do nível atual (Klammer, 1984).

Estes eventos paleogeográficos influenciaram na evolução da biota sul-americana, conforme apontado em diversos estudos, como por exemplo, no caso dos cracídeos, em Pereira e Baker (2004a) e em Grau e col. (2005). 


\section{5) Cracidae como Objeto de Estudo}

Os cracídeos apresentam distribuição bem definida, são não migratórios e apresentam hábitos sedentários, com distribuição quase restrita a áreas florestadas. Estas características facilitam estudos biogeográficos e a elaboração de hipóteses para a evolução do grupo.

Com base em dados moleculares, estudos sistemáticos e biogeográficos permitiram avançar no conhecimento dos padrões evolutivos em Cracidae e, complementarmente, revelaram-se como ferramentas para auxílio na elaboração de planos de ação conservacionistas, com melhor definição das diferenças taxonômicas e identificação dos grupos mais fragilizados, nesta que é uma das famílias de aves mais ameaçadas de extinção (Brooks \& Strahl, 2000; BirdLife 2000; Collar et al., 1992; Nardelli, 1993). Das 50 espécies válidas, 34 necessitam de atenção conservacionista, sendo pelo menos uma espécie já extinta na natureza, o Mitu mitu, como conseqüência da destruição de seu habitat e da caça excessiva (Brooks \& Strahl, 2000). Dentre os jacus e jacutingas podemos identificar diversas espécies que necessitam, segundo Brooks \& Strahl (2000), de esforços de conservação: com prioridade imediata temos, Penelope albipennis, Penelope perspicax e Pipile pipile; com prioridade muito alta, Penelope barbata e Pipile jacutinga; com prioridade alta, Aburria aburri, Penelope dabbenei, Penelope jacucaca, Penelope ochrogaster, Penelope ortoni, Penelope pileata e Penelopina nigra; e, com prioridade intermediária, Chamaepetes goudotii, Penelope argyrotis, Penelope montagnii, Penelope obscura, Penelope purpuracens, Pipile cujubi. 
Neste trabalho, as relações filogenéticas dos jacus e jacutingas dos gêneros Aburria, Penelope e Pipile são investigadas com base em seqüências de DNA e técnicas de reconstrução filogenética. Também são estimadas datas de divergência entre os táxons e elaboradas hipóteses biogeográficas para a diversificação do grupo.

\section{6) Objetivos do estudo}

Os nossos objetivos, em relação aos gêneros Aburria, Penelope e Pipile, são:

1) Investigar as relações filogenéticas e revisar taxonomia;

2) Reconstruir a história evolutiva baseado em estudos filogenéticos e biogeográficos; e,

3) Disponibilizar informações que possam colaborar para conservação e manejo. 


\section{Materiais e Métodos}

\section{1) Amostragem}

Foram obtidas amostras de sangue, de músculo ou de pele de museu para extração do DNA. As amostras utilizadas encontram-se no acervo do Laboratório de Genética e Evolução Molecular de Aves do Departamento de Genética e Biologia Evolutiva do Instituto de Biociências da Universidade de São Paulo (São Paulo, SP, Brasil), do Museu Paraense Emilio Goeldi (Belém, PA, Brasil), do Louisiana State University Museum of Natural History (Baton Rouge, Louisiana, USA) e do Royal Ontario Museum (Toronto, Ontário, Canadá). As informações sobre as amostras são apresentadas na tabela 1 do capítulo III e na tabela 1 do capítulo IV.

\section{2) Obtenção das Seqüências}

\section{1) Extração de DNA}

A extração de DNA foi realizada em tubos eppendorfs contendo: 300 ul de TNE 1x; 30 ul de Tris $1 \mathrm{M}$ ph 7,5; 8 ul de SDS 25\%; e, 20 ul proteinase $\mathrm{K}$ (25 ng/ml). Uma pequena quantidade de sangue periférico retirado da veia braquial da asa do animal ou de amostra de músculo ou de amostra de pele de museu foi adicionada aos eppendorfs que ficaram em repouso por aproximadamente 18 horas à temperatura de $37^{\circ} \mathrm{C}$. Após a incubação foi adicionado fenol-clorofórmio a essa solução e após centrifugação o sobrenadante foi transferido para outro tubo e o DNA precipitado com etanol absoluto. Uma vez isolado, a qualidade e a concentração do DNA foram verificadas em gel de agarose 0,8\% (Check Gel) ou em espectrofotômetro. 
Após a quantificação do DNA extraído, foram preparadas diluições com concentrações de 5 a 20 ng de DNA por microlitro para utilização nas amplificações.

\section{2) Amplificação do DNA}

As amplificações dos fragmentos de DNA foram realizadas em reações com volume total entre 10 ul a 25 ul. As reações, em sua maioria, foram realizadas em 30 ciclos onde as condições de desnaturação, de hibridação e de extensão foram por 40 segundos a $95^{\circ} \mathrm{C}, 30$ segundos a 50 $60^{\circ} \mathrm{C}$ e 30 segundos a $72^{\circ} \mathrm{C}$, respectivamente. Estes ciclos foram precedidos de um passo inicial de desnaturação por 5 minutos a $95^{\circ} \mathrm{C}$ e sucedidos por uma extensão final de 5 minutos a $72^{\circ} \mathrm{C}$.

A quantidade de 2 ul da reação de PCR foi aplicada em gel de agarose $1 \%$ para averiguar a amplificação dos fragmentos desejados e determinar se

o tamanho dos fragmentos obtidos corresponderam ao tamanho esperado, comparando-se as bandas produzidas com marcador de peso molecular (100 bp ladder, Pharmacia).

\section{3) Seqüenciamento de Produtos de PCR}

O seqüenciamento foi realizado diretamente a partir dos fragmentos amplificados utilizando a técnica de "cycle sequencing" com kit de seqüenciamento "Big Dye Terminator". Inicialmente procedeu-se a reação de seqüenciamento em termociclador. Após, a precipitação da reação foi realizada com etanol absoluto. As amostras obtidas foram carregadas em gel de poliacrilamida para serem lidas pelo seqüenciador automático $A B I 377$ (Perkin Elmer). Algumas seqüências foram obtidas em seqüenciador $A B I$ 
3700 ou ABI 3100 da Applied Biosystems ou 4200 da Li-Cor Biosystems seguindo-se protocolo padrão do fabricante.

\section{4) Preparação do Gel de Acrilamida para o $A B I 377$}

O gel foi preparado com: 10,8 $\mathrm{g}$ de uréia; 0,4 g de resina; $3 \mathrm{ml}$ de acrilamida; $11 \mathrm{ml}$ de água milli-Q; $3 \mathrm{ml}$ de TBE 10x; que foram misturados em agitador magnético até que a uréia dissolvesse. Foi adicionada água Milli-Q até a solução atingir $30 \mathrm{ml}$. A solução foi filtrada e adicionados $21 \mathrm{ul}$ de TEMED e 150 ul de persulfato de amônia e aplicada imediatamente entre as placas de vidro do seqüenciador. Após a polimerização do gel, foram aplicadas as amostras de DNA seqüenciadas pela técnica de "cycle sequencing" e previamente precipitadas.

\section{3) Análises das Seqüências}

\section{1) Correção de Ambigüidades das Seqüências}

Uma vez terminada a leitura das reações de seqüenciamento, o seqüenciador automático gerou arquivos contendo as seqüências e seus respectivos eletroferogramas (representação gráfica do sinal cromatográfico produzido por cada nucleotídeo durante a passagem pelo detector cromatográfico do seqüenciador automático). Para cada amostra, as seqüências da fita leve $L$ e da fita pesada $H$ de cada fragmento foram carregadas no editor Sequence Navigator 1.0.1 (Perkin Elmer) ou no Sequencer 4.7 (Gene Codes Corporation). Esses programas permitem visualizar as seqüências obtidas, bem como analisar os eletroferogramas produzidos. As fitas $\mathrm{H}$ foram revertidas e complementadas para ficarem 
iguais as fitas L. Para resolver os casos onde existiam dúvidas de qual nucleotídeo ocupava uma determinada posição, as fitas $\mathrm{L}$ e $\mathrm{H}$ foram comparadas entre si e com a mesma região gênica já seqüenciada para outros cracídeos.

\section{2) Alinhamento}

Após a correção das seqüências, o alinhamento foi realizado para cada gene individualmente, usando-se o Sequence Navigator, versão 1.0.1 (Perkin Elmer) ou o Sequencher 4.7 (GeneCodes Corporation). Nestes programas, o alinhamento foi conferido para correção de eventuais erros de alinhamento. No caso de erros, a correção foi realizada manualmente. Para a concatenação das seqüências foi utilizado o McClade 4.08 (Madison \& Madison, 2005).

\section{4) Análises Filogenéticas e Evolutivas}

As matrizes geradas após o alinhamento foram utilizadas nas análises filogenéticas e evolutivas.

\section{1) Composição de Bases e Caracterização dos Fragmentos Seqüenciados}

As análises das seqüências quanto a composição de bases, número e taxas de transições e transversões, número e distribuição dos sítios variáveis, mutações sinônimas e não-sinônimas (somente para genes codificantes) e distâncias corrigidas e não-corrigidas foram realizadas utilizando-se os programas MEGA (Kumar et al., 2001) ou PAUP (Swofford, 2001). Antes das reconstruções filogenéticas, a homogeneidade na composição de bases, incluindo-se apenas os sítios variáveis, foi testada utilizando-se o programa 
TREEPUZZLE 5.0 (Strimmer \& von Haeseler, 1996).

\section{2) Análises de Saturação de Substituição}

Para verificar se o número de transições e de transversões atingiu o nível de saturação, isto é, se ocorreu mais do que uma substituição em determinados sítios, foi construído um gráfico onde a coordernada representou os valores das distâncias não corrigidas de cada par de táxons usados e a abscissa os valores das distâncias corrigidas presentes entre cada par de táxons. No caso que não houve saturação, a relação entre estes parâmetros foi linear, isto é, com o aumento da distância corrigida houve um aumento da distância não corrigida. Se tivesse havido substituições múltiplas, o gráfico atingiria um platô, onde um aumento da distância corrigida não corresponderia a um mesmo aumento na distância não corrigida.

\section{3) Máxima Verossimilhança}

As análises de verossimilhança foram realizadas no programa PAUP (Swofford, 2001). Nas análises a árvore foi encontrada utilizando-se o algoritmo de busca heurística ou busca exaustiva. O modelo evolutivo foi escolhido de acordo com o teste de razão de verossimilhança realizado no MODELTEST 3.0 (Posada \& Crandall, 1998) executado em conjunto com o PAUP (Swofford, 2001). 


\section{4) Máxima Parcimônia}

A árvore mais parcimoniosa foi estimada pelo programa PAUP (Swofford, 2001). A busca exaustiva foi realizada em casos onde foi computacionalmente possível encontrar a árvore desta maneira, isto é, estimar o número de passos entre todas as possíveis árvores. Nos casos onde o número de árvores possíveis limitou a busca exaustiva, a procura foi realizada por meio de busca heurística. Este procedimento utilizou menos tempo para encontrar uma árvore, porém a árvore encontrada pode não ter sido a mais parcimoniosa.

\section{5) Análise Bayesiana}

A análise Bayesiana foi realizada no programa MrBayes 3.0 (Ronquist \& Huelsenbeck, 2003). Foi escolhido o modelo de substituição de nucleotídeos encontrado para cada gene no teste de razão de verossimilhança realizado com o software MODELTEST (Posada \& Crandall, 1998) executado em conjunto com o PAUP (Swofford, 2001).

\section{6) Índices de Suporte}

Valores de "bootstrap" (Felsenstein, 1985) foram obtidos, para as análises de Máxima Verossimilhança e Máxima Parcimônia, utilizando-se o PAUP (Swofford, 2001). Probabilidades posteriores foram estimadas na análise Bayesiana utilizando-se MrBayes 3.0 (Ronquist \& Huelsenbeck, 2003). 


\section{7) Datação de Tempo de Divergência entre os Táxons}

Foi utilizado o programa r8s v1.6 (Sanderson, 2003) que permitiu a correção das divergências nas taxas de substituição entre os táxons para se estimar as datações de divergência. $\mathrm{O}$ r8s também permitiu que fossem obtidos os intervalos de confiança para cada datação. As calibrações para as datações foram realizadas seguindo-se Pereira e col. (2002) e Pereira e Baker (2004a).

\section{8) Estudos Biogeográficos}

As reconstruções filogenéticas entre os táxons e as datações de divergência, foram comparadas com a distribuição geográfica atual e com eventos paleogeográficos que pudessem ter influenciado ou estar relacionados com a evolução dos táxons estudados.

Os resultados obtidos foram apresentados e discutidos nos manuscritos dos capítulos III e IV, sob a forma de artigos para publicação. 
Filogenia Molecular e Biogeografia das Jacutingas:

Pipile Bonaparte, 1856 é sinônimo de

Aburria Reichenbach, 1853.

Grau, E.T., Pereira, S.L., Silveira, L.F., Höfling, E., Wajntal, A., 2005. Molecular Phylogenetics and Biogeography of Neotropical piping guans (Aves: Galliformes): Pipile Bonaparte, 1856 is synonym of Aburria Reichenbach, 1853. Molecular Phylogenetics and Evolution 35: 637-645. 


\section{Abstract}

The Cracidae are Neotropical galliform birds with eleven genera currently recognized. To investigate the questioned validity of Pipile Bonaparte, 1856 and the monotypic Aburria Reinchenbach, 1853 as separate genera, we gathered data from 2,727 bp of mitochondrial DNA (cytochrome $b, N D 2$ and control region) and 151 osteological characters. Our phylogenetic analyses of DNA sequences indicated that Aburria aburri is embedded within Pipile. Also, genetic distances between Aburria and any Pipile species are equivalent to the distances estimated for other congeneric cracid species, which genus status is not doubtful. Although the osteological characters do not have phylogenetic signal to solve the phylogenetic relationships at species level, five synapomorphies were found for Aburria and Pipile. Therefore, we suggest that Pipile should be merged with Aburria, which is the oldest described genus. We estimated that speciation in this group occurred in the PlioPleistocene, concordant with other birds, primates and rodents that have similar geographic distribution, and proposed a diversification hypothesis based on the occurrence of sea transgressions and the formation of the Amazon Lagoon. Therefore, we conclude that these paleogeographic events may have contributed to Neotropical taxa diversification to a greater extent than previously suspected. 


\section{Resumo}

Os cracídeos são galiformes neotropicais, com 11 gêneros reconhecidos atualmente. Para investigar a validade de Pipile Bonaparte, 1856 e Aburria Reichenbach, 1853 como gêneros separados, utilizamos 2727 pares de bases $(\mathrm{pb})$ do DNA mitocondrial (citocromo $b, N D 2$ e região controladora) e 151 caracteres osteológicos. As análises filogenéticas indicaram que Aburria aburri está posicionada no interior do clado com as espécies de Pipile. Também, as distâncias genéticas entre Aburria e qualquer das espécies de Pipile são equivalentes às distâncias estimadas entre outras espécies congenéricas de cracídeos, cujo status de gênero não é questionado. Apesar dos caracteres morfológicos não apresentarem sinal filogenético para resolver as relações filogenéticas na categoria taxonômica de espécies, cinco sinapomorfias foram encontradas agrupando Aburria e Pipile. Assim, sugerimos que Pipile seja renomeado para Aburria, que é gênero descrito primeiramente. Estimamos que as especiações no grupo ocorreram no Plio-Pleistoceno, concordante com outras aves, primatas e roedores com distribuição geográfica equivalente e propusemos hipótese de diversificação baseada na ocorrência de transgressões marinhas e na formação da Laguna Amazônica. Concluímos que estes eventos paleogeográficos podem ter contribuído para a diversificação de táxons neotropicais com maior intensidade do que sugerido previamente. 


\section{1) Introdução}

A família Cracidae (Aves, Galliformes) inclui mutuns, jacus, jacutingas e aracuãs, encontrados principalmente na região Neotropical. A maioria das espécies é restrita a áreas de floresta e algumas podem ser utilizadas como bioindicadores da qualidade do hábitat (Brooks \& Strahl, 2000). Devido à perda de hábitat e caça excessiva, muitas espécies e sub-espécies são consideradas ameaçadas e uma considerada extinta na natureza (BirdLife International, 2004; Silveira et al., 2003). Atualmente, 11 gêneros, 50 espécies e mais de 60 subespécies são reconhecidas nesta família, que permanece com problemas taxonômicos, especialmente em categorias taxonômicas de espécies ou subespécies (Brooks \& Strahl, 2000; del Hoyo et al., 1994). Esforços para se entender a história evolutiva dos Cracidae tem sido realizados. Como exemplo, a relação filogenética de grupos-irmão entre Cracidae e Phasianidae (latu sensu) é hoje bem estabelecida por dados moleculares e morfológicos (Dimcheff et al., 2002; Dyke et al., 2003; Silveira, 2003) e relações filogenéticas entre os gêneros de cracídeos foi proposta recentemente, usando-se seqüências nucleares e mitocondriais (Pereira et al., 2002) e caracteres osteológicos (Silveira, 2003). Apesar de incongruências entre a hipótese molecular e a osteológica, todos os gêneros parecem ser monofiléticos (Silveira, 2003) e o foco em categorias taxonômicas inferiores aparece como importante linha de pesquisa.

Aburria e Pipile são gêneros que merecem um aprofundamento no estudo da validade do seu status taxonômico como gêneros separados. As espécies em Pipile representam um grupo taxonômico morfologicamente bem definido. Desconsiderando-se a proposta de Vuilleumier (1965), que agrupou 
estes gêneros com Penelope, a maioria dos sistematas (e.g., del Hoyo et al., 1994; Sick, 1993; Strahl \& Schmitz, 1997; Vaurie, 1968) preferem manter estes gêneros distintos dos demais cracídeos. Outra exceção notável é encontrada em Delacour e Amadon (1973) que baseados em caracteres de plumagem e partes nuas, sinonimizaram Pipile em Aburria. Seqüências de DNA mitocondrial e nuclear indicam relação filogenética muito próxima entre Aburria e Pipile e nenhuma evidência para agrupá-las com Penelope (Pereira et al., 2002) e dados morfológicos também confirmam a hipótese de Delacour e Amadon (Silveira, 2003). O tempo de divergência estimado para Aburria e Pipile, baseado em seqüências mitocondriais e nucleares foi de $3.8 \mathrm{Ma}$, bem abaixo do encontrado entre os gêneros de mutuns de 8 a 10 Ma ou entre outros gêneros de jacus e jacutingas de 10 a 18 Ma (Pereira et al., 2002). Este tempo de divergência também está entre os valores encontrados entre as espécies de Crax e entre as espécies de Mitu, baseadas em seqüências mitocondriais (Pereira \& Baker, 2004 ${ }^{\mathrm{a}}$ ).

O gênero Aburria, é considerado monotípico. Aburria aburri ocorre no oeste da Venezuela e norte da Colômbia, leste e oeste do Equador e sul do Peru, primariamente em florestas úmidas de montanha em altitudes de 500 a 2500 metros acima do nível do mar (del Hoyo et al., 1994; Ridgely \& Greenfield, 2001). Já as seis formas de Pipile (sensu del Hoyo et al., 1994) são encontradas, principalmente, em florestas a leste dos Andes por toda a América do Sul (e Trinidad), exceto Chile e Uruguai (Figura 1). 


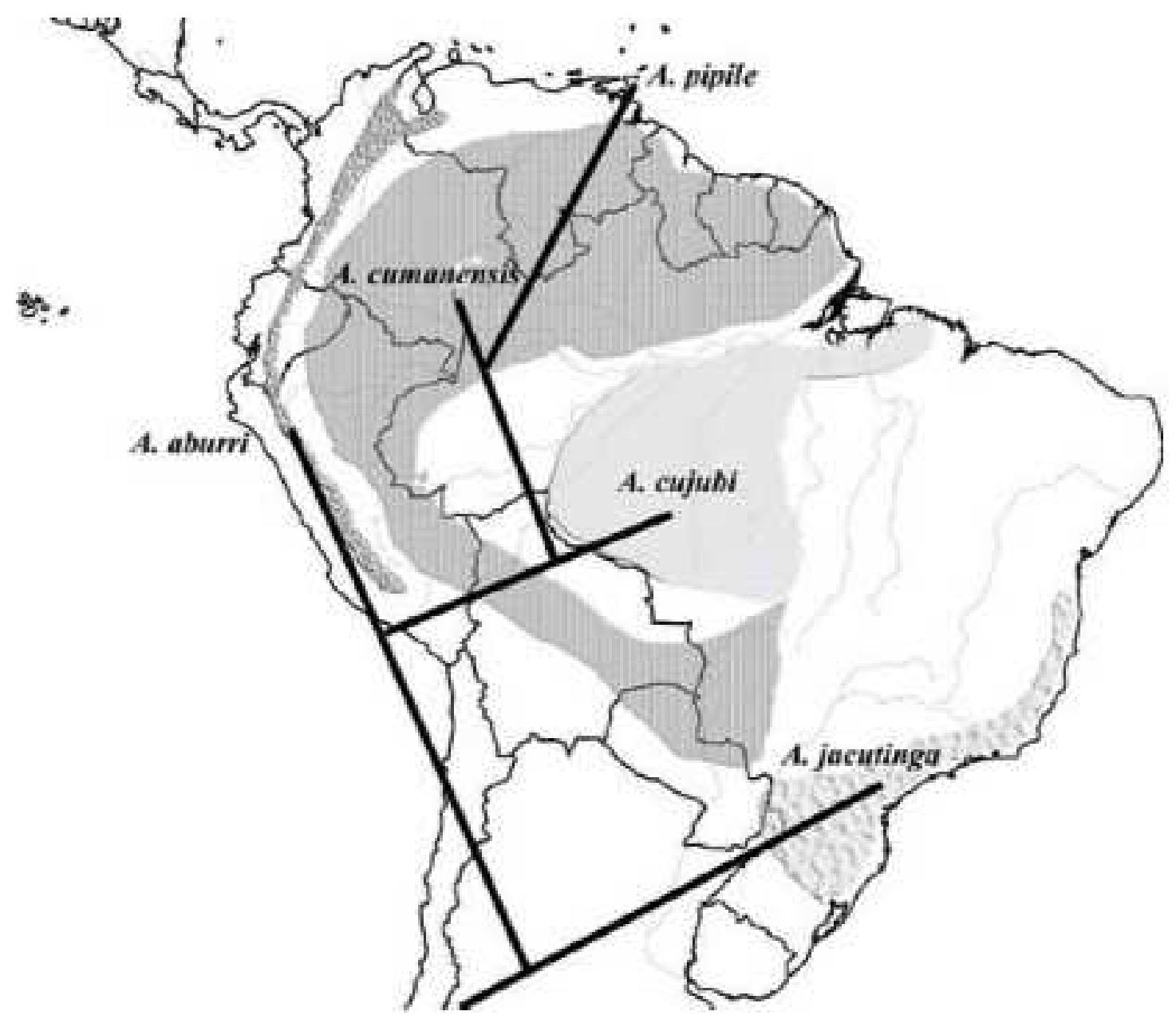

Figura 1 - Distribuição das espécies de Aburria. Distribuição modificada de Delacour e Amadon (1973) e relações filogenéticas estimadas neste trabalho, baseadas em seqüências de DNA mitocondrial.

A taxonomia das espécies de Pipile é controversa e problemática, existindo um permanente desacordo entre autores em relação ao número de espécies, que varia de duas (Delacour \& Amadon, 1973; Sick, 1993; Vuilleumier, 1965) a quatro (del Hoyo et al., 1994; Strahl \& Schmitz, 1997). Também não há consenso em relação à validade e ao número de subespécies. Está claro que temos um longo caminho para entender melhor a diversidade de Pipile. Neste manuscrito seguimos del Hoyo e col. (1994) 
que reconhece quatro espécies de Pipile: Pipile cujubi, Pipile cumanensis, Pipile jacutinga e Pipile pipile.

Entre as espécies de Pipile, somente $P$. jacutinga e $P$. pipile são monotípicas. $P$. pipile apresenta distribuição restrita a Trinidad, enquanto $P$. jacutinga é encontrada em florestas do leste e sul do Brasil, nordeste da Argentina e sudeste do Paraguai. P. cumanensis tem duas subespécies reconhecidas: Pipile cumanensis cumanensis - largamente distribuída na Guiana Francesa, Guiana, Suriname, Venezuela, noroeste do Brasil e nas terras baixas do centro e leste da Colômbia - e Pipile cumanensis grayi - com uma distribuição mais limitada no sudeste do Peru, norte e centro da Colômbia, sudoeste do Brasil e nordeste do Paraguai. Esta espécie é substituída na Amazônia brasileira ao sul do rio Amazonas por P. cujubi, também com duas subespécies reconhecidas: Pipile cujubi cujubi encontrada do baixo rio Madeira ao norte do Pará - e Pipile cujubi nattereri encontrada em florestas no oeste do Brasil (del Hoyo et al., 1994).

Neste trabalho, investigamos as relações filogenéticas entre os táxons de Aburria e Pipile, baseados em seqüências de DNA mitocondrial e caracteres morfológicos, para verificar o status destes gêneros como distintos. Também estimamos os tempos de divergência entre os táxons e propusemos hipótese biogeográfica para a sua evolução do grupo. 


\section{2) Materiais e Métodos}

\section{1) Dados Moleculares}

\subsection{1) Amostragem}

Aproximadamente $0,1 \mathrm{ml}$ de sangue foi coletado de aves de sete espécies de cracídeos (Tabela 1) e mantido em etanol absoluto à temperatura ambiente. As aves amostradas são mantidas em cativeiro por zoológicos ou criadores particulares na América Latina. As amostras de sangue estão depositadas no Laboratório de Evolução Molecular de Aves do Instituto de Biociências da Universidade de São Paulo.

Tabela 1 - Seqüências utilizadas com respectivo voucher e número de acesso ao GenBank.

\begin{tabular}{|c|c|c|c|c|c|c|}
\hline Espécie & Voucher & Aviário & Origem & $R C$ & ND2 & cyt b \\
\hline Aburria aburri & $\begin{array}{l}\text { C172 } \\
\text { C173 }\end{array}$ & Criadouro Tropicus & Cativeiro & AF165430 & $\underset{*}{\operatorname{AY} 140740}$ & $\underset{*}{\mathrm{AF} 165466}$ \\
\hline Pipile cujubi cujubi & C156 & $\begin{array}{l}\text { Coletado por R. } \\
\text { Antonelli }\end{array}$ & $\begin{array}{c}\text { Jacareacanga } \\
\text {, Pará }\end{array}$ & AY145314 & $\begin{array}{l}\text { AY367098 } \\
\text { AY367092 }\end{array}$ & AY367104 \\
\hline $\begin{array}{l}\text { Pipile cumanensis } \\
\text { cumanensis }\end{array}$ & C164 & $\begin{array}{c}\text { Criadouro } \\
\text { Conservacionista } \\
\text { e Cultural Poços } \\
\text { de Caldas }\end{array}$ & $\begin{array}{l}\text { Boa Vista, } \\
\text { Roraima }\end{array}$ & AY145319 & $\begin{array}{l}\text { AY367099 } \\
\text { AY367093 }\end{array}$ & AY367105 \\
\hline Pipile jacutinga & C100 & CESP-Paraibuna & Cativeiro & AF165431 & $\underset{*}{\mathrm{AY} 140744}$ & $\underset{*}{\mathrm{AF} 165476}$ \\
\hline Pipile pipile & C264 & Granja La Siberia & Trinidad & AY145320 & $\begin{array}{l}\text { AY367100 } \\
\text { AY367094 }\end{array}$ & AY367106 \\
\hline Penelope obscura & $\begin{array}{l}\text { C28 } \\
\text { C150 }\end{array}$ & CESP-Paraibuna & $\begin{array}{l}\text { Paraibuna, } \\
\text { São Paulo }\end{array}$ & AF165432 & $\underset{*}{\mathrm{AY} 140742}$ & $\underset{*}{\mathrm{AF} 165474}$ \\
\hline $\begin{array}{l}\text { Penelope } \\
\text { superciliaris }\end{array}$ & C084 & CESP-Paraibuna & $\begin{array}{l}\text { Paraibuna, } \\
\text { São Paulo }\end{array}$ & AY145313 & $\begin{array}{l}\text { AY367096 } \\
\text { AY367090 }\end{array}$ & AY367102 \\
\hline
\end{tabular}

* seqüências publicadas anteriormente (Pereira et al., 2002). 


\subsection{2) Amplificação de DNA, Seqüenciamento e Alinhamento}

Algumas seqüências utilizadas do citocromo $b$ (cyt $b$ ) e da subunidade 2 do NADH desidrogenase (ND2) foram obtidas por Pereira et al. (2002) e estão indicadas na Tabela 1. Para cyt $b, N D 2$ e região controladora $(R C)$ as seqüências obtidas neste estudo foram amplificadas, seqüenciadas e alinhadas conforme descrito em Grau e col. (2003). Os primers utilizados para amplificação por PCR são descritos em Grau e col. (2003) e Pereira e Baker (2004a).

\subsection{3) Distâncias e Saturação}

Distância de Tamura-Nei, assumindo taxas de substituição de DNA com distribuição gama $(T N+G)$, foi escolhido como melhor modelo de substituição de DNA para as seqüências concatenadas e para o ND2, de acordo com o teste de razão de verossimilhança implementado no MODELTEST 3.0 (Posada \& Crandall, 1998). Para a RC e o cyt $b$, o melhor modelo escolhido foi Hasegawa-Kishino-Yano, também, assumindo distribuição gama para variação das taxas entre os sítios $(H K Y+G)$. Para cada gene e para os genes concatenados estimamos as distâncias corrigidas e não-corrigidas (distância " $p$ ") entre todas as sete espécies estudadas, usando MEGA 2.0 (Kumar et al., 2001). Plotamos distâncias corrigidas contra distâncias " $p$ " para checar se houve saturação de substituições neste grupo, o que poderia influenciar negativamente a reconstrução filogenética. 


\subsection{4) Análises Filogenéticas}

Reconstruções filogenéticas foram realizadas com Pipile cujubi, Pipile cumanensis, Pipile jacutinga, Pipile pipile e Aburria aburri como grupo interno e Penelope obscura e Penelope superciliaris como grupos externos. Antes das reconstruções filogenéticas, a homogeneidade na composição de bases, incluindo-se apenas os sítios variáveis, foi testada utilizando-se o programa TREEPUZZLE 5.0 (Strimmer \& von Haeseler, 1996). O PAUP 4.0 b10 (Swofford, 2001) foi utilizado nas reconstruções filogenéticas de máxima verossimilhança $(\mathrm{ML})$ e máxima parcimônia $(\mathrm{MP})$. A árvore de MP foi obtida por busca exaustiva. A árvore de $\mathrm{ML}$ foi obtida por busca exaustiva sob o modelo de evolução de DNA selecionado pela análise dos dados com o programa MODELTEST 3.0 (Posada \& Crandall, 1998). O suporte dos ramos foi estimado por "bootstrap" de 100 réplicas com 10 adições aleatórias de seqüências para ambas as análises em MP e ML. Análise Bayesiana (BA) com amostragem pelo algoritmo da cadeia de "Markov Chain Monte Carlo" (MCMC) foi implementada no MrBayes 3.0 (Ronquist \& Huelsenbeck, 2003) com verossimilhança particionada (Lee \& Hugall, 2003). O modelo de substituição escolhido para cada partição gênica da análise de $M L$ foi também imposto na análise Bayesiana. Implementamos três corridas independentes por 3 milhões de gerações cada, com três "cadeias quentes" e uma "cadeia fria" e um "burn-in time" determinado pelo tempo de convergência dos índices de verossimilhança. $O$ burn-in time determina 0 número de gerações que são descartados previamente ao algoritmo ter atingindo convergência. Uma árvore foi amostrada a cada mil gerações. 


\subsection{5) Datação de Divergência}

Os tamanhos dos ramos da árvore de ML foram re-estimados forçando-se um relógio molecular, utilizando o PAUP 4.0 b10 (Swofford, 2001). A diferença entre as verossimilhanças da árvore de $M L$ sem assumir taxa constante de substituição (relógio molecular) e da árvore de ML com relógio, multiplicada por dois, foi comparada com uma distribuição de quiquadrado $\left(X^{2}\right)$. Com o Programa r8s 1.6 (Sanderson, 2003) foram estimadas as datações de divergência e intervalos de confiança. A abordagem escolhida foi bootstrap semiparamétrico penalizado (Sanderson, 2002) que permite variação das taxas evolutivas entre as linhagens, mas uma penalidade é aplicada para minimizar variações de taxas entre um nó e seus descendentes, através de um parâmetro de suavização (do inglês "smoothing parameter"). Quanto menor o parâmetro de suavização, maior a variação de taxas observadas nos dados. Um teste de validação cruzada gerenciado pelos dados foi aplicado para escolher o melhor valor para o parâmetro de suavização (Sanderson, 2002). Este procedimento retira linhagens da árvore, estima um parâmetro de suavização para as linhagens restantes e repetidamente tenta prever o parâmetro de suavização para a linhagem retirada até o melhor parâmetro ser encontrado (Sanderson, 2002). Assumimos que o grupo-externo (Penelope) divergiu há 10,5 Ma (intervalo de confiança de 95\%: 8,8-12,3 Ma) do grupo-interno de acordo com estimativas obtidas por Pereira e col. (2002) que utilizou um grande conjunto de dados, incluindo seqüências nucleares e mitocondriais. Infelizmente, pontos de calibração não-moleculares, como, por exemplo, eventos geológicos utilizados por Pereira e Baker (2004a), não estão disponíveis para checarmos 
a independência de nossas estimativas. Entretanto, estamos confiantes de que utilizamos uma boa calibração, pois os tempos de divergência e intervalos de confiança estimados são equivalentes aos encontrados para os mutuns (Pereira \& Baker, 2004a). As datações nos mutuns foram similares quando obtidas por calibração molecular ou geológica, o que indica que as calibrações de Pereira e col. (2002) podem ser apropriadas para calibrações moleculares secundárias, quando pontos de calibração não estão disponíveis.

\section{2) Dados Morfológicos}

Os estudos morfológicos foram realizados por Luís Fábio Silveira com o objetivo de complementar os resultados obtidos com os dados moleculares.

\subsection{1) Amostragem}

Silveira utilizou 28 esqueletos abrangendo todas as espécies de Pipile e A. aburri e 17 esqueletos de Penelope (Penelope obscura e Penelope superciliaris). Estes dados foram obtidos para um estudo mais amplo da família Cracidae (Silveira, 2003; Frank-Hoeflich et al., 2007). Nosso objetivo foi coletar evidências independentes para validar Aburri e Pipile como gêneros separados e checar a utilidade destes caracteres para inferência de filogenia na categoria de espécies em conjunto com dados moleculares obtidos neste estudo.

Os materiais estudados estão depositados em museus, conforme detalhado no artigo publicado disponível no anexo I. 


\section{3) Resultados}

\section{1) Dados Moleculares}

\subsection{1) Amplificação de DNA e Seqüenciamento}

Estamos confiantes que as seqüências são de origem mitocondrial pois: (1) seqüências de Aburria aburri foram obtidas por amplificação de grandes fragmentos de 3Kb (Pereira et al., 2004), (2) somente produtos únicos de PCR foram amplificados e seqüenciados e (3) as seqüências das espécies de Pipile e Penelope não tem características típicas de pseudogenes e foram similares aquelas obtidas para Aburria aburri. $\mathrm{O}$ genoma nuclear da galinha e outros eucariotos seqüenciados até o momento, não parecem apresentar grande quantidade de pseudogenes mitocondriais maiores do que $1 \mathrm{~kb}$ inseridos no genoma nuclear, quando comparados com genomas humano e de plantas (Pereira \& Baker, 2004b; Richly \& Leister, 2004). Sendo esta uma característica do genoma das aves, pseudogenes mitocondriais raramente serão amplificados. Além disso, todas as seqüências obtidas têm similaridade com seqüências correspondentes de outros cracídeos depositadas no Genbank, a predição da seqüência de aminoácidos para o cyt $b$ e o ND2 foi conforme esperado, e os blocos conservados da $R C$, encontrados em outros cracídeos, também foram identificados em todas as espécies de Aburria e Pipile (Pereira et al., 2004). O conjunto de dados concatenado consiste em 2727 pb (699 pb do cyt b, 895 pb do ND2 e 1133 pb da $R C$ completa). Números de acesso do GenBank são dados na tabela 1. 


\subsection{2) Distâncias e Saturação}

Distâncias " $p$ " e $T N+G$ foram estimadas para todos os pares de espécies estudadas (Tabela 2). As seqüências comparadas neste estudo não apresentam nenhuma evidência de saturação de substituição do DNA (gráfico não apresentado). Comparamos espécies congenéricas para checar a magnitude das distâncias par-a-par dentro do gênero. Distâncias $T N+G$ variaram entre $0,7 \%$ e 2,9\% com média de 2,2\% para o grupo Pipile-Aburria. Estas estimativas estão no intervalo para espécies aceitas do gênero Penelope (4,4\%; tabela 2) e fragmentos correspondentes do cyt b e ND2 de Crax e Mitu (1,3\% - 3,0\% estimados por Grau et al., 2003).

Tabela 2 - Distâncias $p$ não corrigidas e distâncias $T N+G$, acima e abaixo da diagonal, respectivamente.

\begin{tabular}{|l|l|l|l|l|l|l|l|}
\hline & $\begin{array}{l}\text { A. } \\
\text { aburri }\end{array}$ & $\begin{array}{l}P . \\
\text { cujubi }\end{array}$ & $\begin{array}{l}\text { P. } \\
\text { cumanensis }\end{array}$ & $\begin{array}{l}P . \\
\text { jacutinga }\end{array}$ & P. pipile & $\begin{array}{l}P . \\
\text { obscura }\end{array}$ & $\begin{array}{l}\text { P. } \\
\text { superciliaris }\end{array}$ \\
\hline A. aburri & - & 0,024 & 0,025 & 0,026 & 0,024 & 0,044 & 0,042 \\
\hline P. cujubi & 0,027 & - & 0,012 & 0,023 & 0,012 & 0,043 & 0,045 \\
\hline P. cumanensis & 0,028 & 0,013 & - & 0,022 & 0,007 & 0,044 & 0,045 \\
\hline P. jacutinga & 0,029 & 0,025 & 0,025 & - & 0.022 & 0,043 & 0,041 \\
\hline P. pipile & 0,027 & 0,013 & 0,007 & 0,024 & - & 0,046 & 0,045 \\
\hline P. obscura & 0,053 & 0,053 & 0,054 & 0,052 & 0,056 & - & 0,037 \\
\hline P. superciliaris & 0,050 & 0,055 & 0,054 & 0,049 & 0,055 & 0,044 & - \\
\hline
\end{tabular}

\subsection{3) Análises Filogenéticas}

A composição de bases entre as espécies é homogênea $(P$ de 0,87 a 0,97 no grupo-interno e $P=0,69$ para o grupo-externo). As árvores estimadas por ML, MP e BA resultaram na mesma topologia sugerindo que $P$. jacutinga é grupo-irmão do clado contendo Aburria aburri e as outras pipiles (Figura 1). 
Os índices de suporte foram altos em todas as análises, exceto para as relações entre Aburria aburri e demais Pipile, em exclusão à Pipile jacutinga (figura 2). BA recuperou apenas três topologias alternativas: (1) uma correspondendo às topologias de ML/MP/BA com probabilidade posterior de 0,76; e (2) uma árvore em que Aburria é irmã de todas as espécies de Pipile com probabilidade posterior de 0,23; e (3) uma árvore onde Aburria e Pipile jacutinga são espécies irmãs em exclusão às demais espécies de Pipile, com probabilidade posterior de 0,01. Para melhor avaliar as diferenças entre as três topologias recuperadas por BA, foi realizado o "approximately unbiased (AU) test" de Shimodaira (2002) implementado no programa CONSEL $0.1 \mathrm{f}$ (Shimodaira \& Hasegawa, 2001). Os valores $p$ para as árvores 1, 2 e 3 foram 0,710, 0,322 e 0,009, respectivamente. A probabilidade posterior estimada neste programa foi de 0,984 para nossa árvore de ML/MP/BA, 0,016 para Pipile sendo um grupo monofilético e praticamente zero para a árvore em que Pipile jacutinga e Aburria aburri são um clado irmão às outras espécies de Pipile.

\subsection{4) Datação de Divergência}

Nossos resultados indicam que há variação da taxa de substituição de DNA entre os táxons suficiente para rejeitarmos a hipótese do relógio molecular (Ln sem relógio molecular: 5157,22691; Ln com relógio molecular: 5710,82762; diferença: 553,6007; $X^{2}=11,07$ para nível de significância de 0,05 com 5 graus de liberdade). Sendo assim, utilizamos um método que relaxa a hipótese do relógio molecular para estimar os tempos de divergência. O procedimento escolhido foi a verossimilhaça semiparamétrica 
penalizada (Sanderson, 2002), com parâmetro de suavização ajustado para 0,16 , indicando uma substancial variação nas taxas de substituição entre as seqüências de DNA utilizadas. A ancestralidade comum do grupo AburriaPipile data do Plioceno e as divergências mais recentes entre espécies datam do Pleistoceno (Figura 2). Tempos de divergência e intervalos de confiança são apresentados na figura 2 .

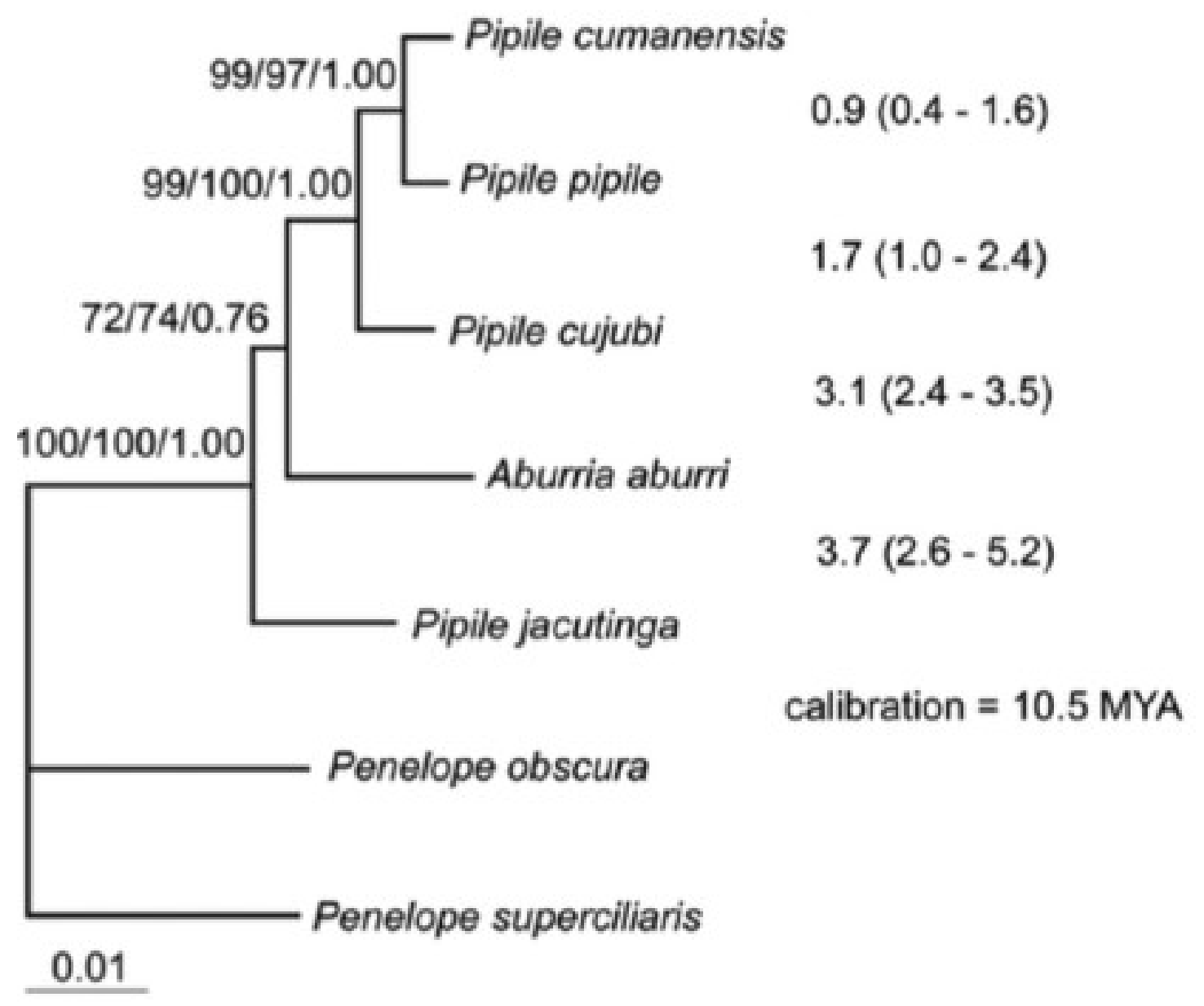

Figura 2 - Topologia obtida por BA com análise combinada das seqüências do cyt $b, N D 2 \mathrm{e}$ $R C$. Valores de "bootstrap" para ML e MP e probabilidades posteriores para BA, respectivamente, para cada nó, são apresentadas à esquerda da árvore. Estimativas de tempo de divergência (intervalos de confiança) baseados em verossimilhança com penalidade são apresentadas à direita de cada nó da árvore. 


\section{2) Dados Morfológicos}

\subsection{1) Osteologia}

Apesar dos dados morfológicos não apresentarem variação para estabelecer as relações filogenéticas de $A$. aburri e as outras quatro espécies de Pipile, cinco sinapomorfias suportam a nossa hipótese de que Aburria e Pipile devem ser considerados apenas um gênero: presença, no crânio, de um processo mediocaudal na região do duto nasolacrimal, de uma crista desenvolvida na porção caudal da tuba auditiva e, nos palatinos, de uma fossa coanal estreita. Na ulna, todas as espécies apresentam uma impressio brachialis bem desenvolvida.

\section{4) Discussão}

Nossos dados moleculares e morfológicos forneceram informações complementares sobre o status taxonômico de Pipile e Aburria. Os dados morfológicos revelaram a presença de cinco sinapomorfias definindo Aburria e Pipile como um grupo distinto dentre os cracídeos, rejeitando a hipótese de inclusão no gênero Penelope, conforme sugerido por Vuilleumier (1965). Estes caracteres morfológicos foram utilizados para a inferência das relações filogenéticas entre os gêneros de Cracidae (Silveira, 2003), e não forneceram resolução para as relações filogenéticas entre as espécies do grupo AburriaPipile. Já foi comprovado que dados osteológicos não são informativos para categorias taxonômicas abaixo de gêneros neste grupo. As seqüências de DNA indicam que Aburria aburri tem um ancestral comum mais recente com (Pipile cujubi, (Pipile cumanensis, Pipile pipile)), excluindo-se Pipile 
jacutinga. $\mathrm{O}$ baixo índice de suporte obtido nas análises filogenéticas para a relação irmã entre Aburria aburri com as demais espécies de Pipile pode refletir eventos de diversificação quase simultâneos. Isso evitaria que substituições de DNA sejam acumuladas suficientemente para apoiar esta associação. Entretanto, o teste $\mathrm{AU}$ e as probabilidades posteriores para as árvores amostradas indicam que a árvore na qual Aburria aburri é posicionada entre as pipiles é estatisticamente a mais provável.

Uma abordagem complementar às análises filogenéticas é a comparação das distâncias genéticas obtidas entre as espécies do grupo Aburria-Pipile com as obtidas para outros grupos de Cracidae com mesmo nível taxonômico. Abordagens similares foram utilizadas para se checar 0 status taxonômico de gêneros e espécies (e.g., Aleixo, 2002; Grau et al., 2003; Zink \& Blackwell-Rago, 2000). Apesar de um padrão não ter sido encontrado entre os diferentes grupos no mesmo nível taxonômico, dados moleculares podem ser importantes ferramentas nestes estudos para táxons intimamente relacionados. A porcentagem de divergência de seqüência entre Aburia aburria e as espécies de Pipile aproxima-se das encontradas entre espécies, com status taxonômico bem definido, de Penelope (tabela 2) e de Crax e Mitu (Grau et al., 2003). Seqüências de DNA para RC, cyt b e ND2 divergiram em 1,3-3,0\% entre espécies congenéricas de cracídeos com status taxonômico não questionado. Assim recomendamos que Aburria e Pipile sejam agrupadas em um gênero, como proposto há duas décadas por Delacour e Amadon (1973) baseando-se em plumagem e caracteres das áreas nuas. 
Seguindo a regra de prioridade cronológica (artigo 23) do Código Internacional de Nomenclatura Zoológica (1999, p. 24) o gênero Pipile Bonaparte, 1856 deve ser considerado sinônimo de Aburria Reichenbach, 1853 e todos os táxons de Pipile devem ser transferidos para o gênero Aburria, em concordância com Delacour e Amadon (1973) e Silveira (2003). Então, seguindo a taxonomia adotada por del Hoyo e col. (1994), o gênero Aburria Reichenbach, 1853 inclui as seguintes espécies: Aburria aburri Lesson, 1828; Aburria cujubi Pelzeln, 1858; Aburria cumanensis Jacquin, 1784; Aburria jacutinga Spix, 1825; e, Aburria pipile Jacquin, 1784. A partir deste ponto utilizamos esta nomenclatura, aceita pelo Comitê Brasileiro de Registros Ornitológicos (CRBO).

\section{1) Biogeografia e Tempo de Divergência}

Estimamos que a diversificação intragenérica no clado Aburria ocorreu entre 0,4 e 5,2 Ma, baseando-se nos intervalos de confiança. Estas datas, que correspondem ao Plioceno e Pleistoceno, são posteriores à formação dos principais traços topográficos da América do Sul que têm sido evocados como agentes vicariantes na diversificação das aves, incluindo cracídeos (Nores, 2004; Pereira \& Baker, 2004a; Pereira et al., 2002). Eventos geológicos, como soerguimento norte da Cordilheira dos Andes, formação do Planalto Brasileiro e das Guianas e formação do sistema atual de drenagem dos rios, foram estabelecidos há pelos menos 8 Ma (Clapperton, 1993; Lundberg et al., 1998). Entretanto, sua influência na formação da América do Sul atual se estendeu pelos períodos geológicos seguintes e podem, também, ter influenciado a diversificação da flora e fauna, incluindo as 
espécies de Aburria. Propomos uma hipótese biogeográfica para a especiação de Aburria baseando-se em eventos geológicos e geográficos conhecidos da história da América do Sul que foram conseqüências destas mudanças mais antigas, como também, outros eventos independentes de influência global.

Os principais eventos paleogeográficos do Plio-Pleistoceno estão relacionados aos ciclos de Milankovitch, resultando em períodos glaciais e interglaciais (Haffer, 1974; Haffer \& Prance, 2001; Marroig \& Cerqueira, 1997; Nores, 1999). Neste contexto, duas principais hipóteses foram propostas para explicar a riqueza de espécies encontrada na região neotropical. Uma delas, a hipótese dos refúgios, declara que a Floresta Neotropical tornou-se fragmentada durante os períodos glaciais secos e expandiu-se durante as condições climáticas úmidas interglaciais. Isto isolaria populações em fragmentos de florestas remanescentes, chamados refúgios, e promoveria a diferenciação entre elas e conseqüentemente levaria a especiações alopátricas (Haffer, 1974; Haffer \& Prance, 2001). Um mecanismo alternativo de fragmentação de hábitat e diversificação de espécies tem sido proposto com base na evidência das transgressões marinhas (Nores, 1999) e da formação da Laguna Amazônica durante os períodos interglaciais (Marroig \& Cerqueira, 1997). A existência da Laguna Amazônica foi sugerida anteriormente por vários autores (e.g., Guerra, 1956; Haffer, 1974; Irion, 1984; Paula Couto, 1956; Sioli, 1957).

Os períodos interglaciais quentes do Plio-Pleistoceno foram responsáveis por elevações do nível do mar que podem de atingido $180 \mathrm{~m}$ acima do nível atual, por volta de 2,5 Ma (Klammer, 1984). Na América do 
Sul as transgressões marinhas afetaram três áreas principais (Lundberg et al., 1998): (1) as terras baixas da Argentina, Uruguai, Paraguai e sul e centro do Brasil afetando a bacia dos rios Prata e Paraná, (2) Venezuela central, Colômbia e norte do Peru na bacia atual do rio Orinoco e (3) a bacia baixa do rio Amazonas no norte da América do Sul. Também, nas últimas duas áreas, a formação simultânea de uma laguna de água fresca, a Laguna Amazônica, pode ter afetado os ecossistemas na maior parte da Floresta Amazônica, conforme a água invadia todas as terras abaixo do nível do mar. A laguna foi resultado de um aumento da pluviosidade e do derretimento das geleiras andinas. O total de água descarregada é considerado suficiente para evitar a transgressão marinha no delta do Amazonas (Marroig \& Cerqueira, 1997). A distribuição atual das espécies de Aburria, juntamente com as nossas estimativas de tempos de divergência, sugerem que populações ancestrais destas aves tornaram-se isoladas e especiaram nas áreas elevadas da Floresta Atlântica na região leste da América do Sul ( $A$. jacutinga), na encosta dos Andes (A. aburri) e nos planaltos Brasileiro (A. cujubi) e das Guianas ( $A$. cumanensis), como conseqüência da invasão de água doce e salgada nas terras baixas. Esta hipótese é consistente com a hipótese biogeográfica proposta para os mutuns (Pereira \& Baker, 2004a), já que representantes de dois gêneros de mutuns e $A$. jacutinga separaram-se das suas espécies irmãs amazônicas aproximadamente no mesmo tempo. A separação entre $A$. cujubi de $A$. cumanensis e $A$. pipile foi entre 2,4 e 1,0 Ma, mesmo tempo de divergência estimado entre espécies de mutuns distribuídas nas mesmas áreas (Pereira \& Baker, 2004a) e corresponde para o tempo estimado (2,5 Ma) para a transgressão marinha máxima de $180 \mathrm{~m}$ acima do 
atual nível do mar (Klammer, 1984).

Também propomos que $A$. cumanensis, durante as épocas de regressão das águas, ocupou as terras baixas e que os vários períodos glaciais/interglaciais levaram à formação de duas subespécies $A$. c. cumanensis e A. c. gray. Situação semelhante é também proposta para $A$. cujubi, com a população ancestral vivendo no Planalto Brasileiro, onde provavelmente ocupava matas de galeria, já que parte considerável deste planalto foi historicamente ocupada pelo cerrado e pela caatinga, ambos pobres em cobertura arbórea. A. cujubi é representada atualmente por $A$. c. cujubi e A. c. nattereri ocorrendo preferencialmente ao longo de matas de galeria. Mais ainda, a presença de $A$. cumanensis gray e A. cujubi nattereri no Pantanal, em Mato grosso, indica que estas espécies expandiram sua distribuição já que esta é uma região de confluência entre vários biomas. Entretanto, A. c. nattereri ocorre em áreas de florestas mais altas e A. c. gray ocorre no cerradão/mata de transição (Olmos, 1998).

A diversificação recente entre $A$. cumanensis e $A$. pipile (restrita a Trinidad) foi estima entre 0,4 e 1,6 Ma. Esta datação é inconsistente com a idade de Trinidad, estimada em 11.000 anos (Ffrench et al., 1991). Entretanto, como Trinidad é uma ilha de origem continental a 10-15 km da Venezuela e rodeada pela plataforma continental a menos de 200 abaixo do nível do mar, a dispersão dos ancestrais de $A$. pipile a partir do continente é uma hipótese plausível. Durante os períodos glaciais as regressões do nível do mar do Pleistoceno chegou a $180 \mathrm{~m}$ abaixo do atual nível do mar (Salgado-Labouriau, 1994), o que faria Trinidad contígua com o continente ao redor. 
A fisiografia presente de Trinidad é muito peculiar: a maior parte da sua área é composta por terras baixas e pequenas montanhas. Entretanto, no norte, o prolongamento da cordilheira costeira da Venezuela, onde $A$. pipile ainda pode ser encontrada, existem altos picos com mais 1000 metros e encostas inclinadas sem nenhum platô acima de 500 metros. No centro da ilha existem montanhas baixas, todas com menos de 300 metros com flancos cuja altura raramente atinge 200 metros (Ffrench et al., 1991). Durante as grandes transgressões marinhas do passado a maior parte destas áreas ficou submersa.

Datas similares de divergência foram estimadas para espécies congenéricas de mutuns (Pereira \& Baker, 2004a), macacos (Collins \& Dubach, 2000; Cortés-Ortiz et al., 2003) e ratos Vésper (Salazar-Bravo et al., 2001). Estes estudos mostraram a separação entre os táxons atlânticos e suas espécies irmãs ocorrendo nas regiões da Amazônia ou Pantanal/Chaco no Plioceno. Transgressões marinhas, juntamente com a formação da Laguna Amazônica e a formação das bases atuais dos rios devido ao soerguimento dos Andes, têm sido considerados possíveis eventos vicariantes na diversificação destes grupos. Estes eventos paleogeográficos podem ter contribuído para a diversificação dos táxons Neotropicais com maior intensidade do que suspeitado anteriormente, revelando um padrão comum de vicariância para organismos com distribuição geográfica similar no Neotrópico. 
Filogenia Molecular e Biogeografia dos Jacus:

Gênero Penelope - Revisão Taxonômica e Evolutiva 


\section{Abstract}

We have put efforts to understand the evolutionary history of Cracidae, which includes about 50 species of Neotropical currassows, chachalacas, guans and the "Horned Guan" distributed in 10 genera. Molecular phylogenetic and biogeographic studies have already been performed for all 14 species of curassows and all 5 species of guans in the genus Aburria. Here, we present the results of phylogenetic analysis based on 13,310 base pairs of nuclear and mitochondrial DNA sequences of 13 out of 15 species of the guans in the genus Penelope. Our analyses using Bayesian and Maximum Parsimony methods recovered a well-supported phylogeny for the group, mostly showing an initial split among Penelope with cis- and trans-Andean distribution. Penelope obscura appears to be a paraphyletic group and some taxonomic modifications are suggested. Molecular dating of divergence time was estimated using a penalized likelihood approach that relaxes the molecular clock. The diversification among guans seems to have occurred from the Miocene to the Pliocene. Marine transgressions, the rising of the Andes, and subsequent changes in river basins in South America and habitat specializations seems to be the major factors affecting the diversification of Penelope. The spatial and temporal pattern revealed for the evolution of this group is similar to that found for other cracids birds. 


\section{Resumo}

Esforços têm sido realizados para compreender a história evolutiva da família Cracidae, que engloba 50 espécies de mutuns, aracuãs, jacus e jacutingas e "Mutum Cornudo", distribuídas em 10 gêneros. Estudos da filogenia molecular e da biogeografia das 14 espécies de mutuns e das cinco espécies de jacutingas foram realizados. Neste trabalho, apresentamos os resultados das análises filogenéticas de 13.310 pares de bases de seqüências de DNA nuclear e mitocondrial de 13 das 15 espécies de jacus do gênero Penelope. Análises Bayesiana e de Máxima Parcimônia resultaram em uma topologia bem resolvida, apresentando uma separação inicial cis- e trans-andina entre os táxons de Penelope. Penelope obscura parece ser um grupo parafilético e algumas mudanças taxonômicas são sugeridas. Datações moleculares de tempo de divergência usando máxima verossimilhança penalizada para relaxar o relógio molecular foram obtidas. A diversificação entre os táxons de Penelope ocorreu do Mioceno ao Plioceno. Transgressões marinhas, o soerguimento dos Andes e suas conseqüências nas bacias de rios sul americanos e especilizações de habitat parecem ser os principais fatores afetando a diversificação de Penelope. O padrão especial e temporal de evolução do grupo é similar ao encontrado em outros Cracidae. 


\section{1) Introdução}

Os jacus verdadeiros, gênero Penelope (Cracidae: Galliformes), são aves de porte médio, com coloração escura, podendo atingir 2,5 kg (del Hoyo et al., 1994). Apresentam hábito arborícola, raramente vindo ao chão, e alimentação baseada na ingestão de folhas e frutos, ocasionalmente ingerem insetos e pequenos vertebrados. São essencialmente não-migratórios. Ocorrem em florestas tropicais e florestas de montanha e algumas espécies localmente em matas de galeria (Delacour \& Amadon, 1973). Com ampla distribuição na América do Sul, três ou quatro espécies são características de florestas de montanha, sendo as demais primariamente de terras baixas. $\mathrm{Na}$ América Central e do Norte, observamos apenas Penelope purpuracens, com distribuição estendendo-se até o México. Os jacus verdadeiros podem ocorrer em simpatria o que não é comum em cracídeos (del Hoyo et al., 1994). Nestes casos, as espécies ocupam microhábitats distintos e ainda não é claro se espécies em simpatria dividem um ancestral comum mais recente ou se elas representam linhagens evolutivas distintas.

O gênero Penelope engloba $30 \%$ das espécies de Cracidae. Atualmente, são reconhecidas 15 espécies de jacus verdadeiros, segundo a classificação de del Hoyo e col. (1994), adotada como padrão neste trabalho. O número de espécies válidas não é consenso (Blake, 1977; Brooks \& Strahl, 2000; Delacour \& Amadon, 1973; Vaurie, 1964, 1966a, 1966b e 1968; Vuilleumier, 1965), o que dificulta um melhor entendimento da evolução do grupo. Por exemplo, Blake (1977) considera P. perspicax como uma subespécie de P. jacquacu, enquanto Brooks e Strahl (2000), Delacour e Amadon (1973) e outros autores classificam-na como espécie válida; Vaurie 
(1968) e Blake (1977) classificam $P$. barbata como subespécie de $P$. argyrotis enquanto Brooks e Strahl (2000) e Delacour e Amadon (1973) classificam $P$. barbata como espécie.

Recentemente, foi publicado um estudo filogenético englobando uma grande quantidade de espécies abrangendo todos os gêneros da família Cracidae, baseado em um fragmento de $661 \mathrm{pb}$ do citocromo $b$ e em caracteres osteológicos, integumentares e comportamentais (Frank-Hoeflich et al., 2007). Apenas seis espécies de Penelope foram incluídas nas análises. Os resultados indicaram Penelope como um gênero monofilético. Entretanto, uma análise mais detalhada das relações filogenéticas intragenéricas não foi realizada até o momento.

Estudos filogenéticos e biogeográficos baseados em dados moleculares tem sido informativos para o entendimento da evolução da família Cracidae (e.g., Pereira et al., 2002; Pereira \& Baker, 2004a; Grau et al., 2005). A falta de uma hipótese das relações filogenéticas entre os jacus verdadeiros impede a avaliação do impacto de eventos de vicariância na diversificação do grupo. Também, impede que avaliemos se espécies ocorrendo em simpatria apresentam um ancestral comum tão recente quanto espécies que divergiram devido a um evento vicariante. A diversificação de outros grupos de cracídeos tem sido correlacionada, principalmente, a eventos vicariantes, associados aos hábitos sedentários e essencialmente não-migratórios dos Cracidae. A elaboração de hipóteses biogeográficas da evolução da família tem ressaltado a influência do soerguimento dos Andes, oscilações do nível do mar, formação da Laguna Amazônica, entre outros fatores, na diversificação do grupo (e.g., Pereira \& Baker, 2004a; Grau et al., 
2005). A origem do gênero Penelope foi estimada em 10,5 Ma por Pereira e col. (2002) com base em dados moleculares.

No presente trabalho, com base em seqüências de DNA, calculamos as distâncias genéticas, inferimos as relações filogenéticas e estimados os tempos de divergência entre 17 táxons do gênero Penelope, com o objetivo de entender a sistemática e elaborar hipóteses biogeográficas para diversificação do grupo.

\section{2) Materiais e Métodos}

\section{1) Amostragem}

Foram obtidas amostras de 25 táxons (Tabela 1), incluindo 17 gruposinternos (representando 13 das 15 espécies Penelope e seis subespécies) e oito grupos-externos (Aburria aburri, Aburria jacutinga, Chamaepetes goudotii, Penelopina Nigra, Crax alberti, Crax daubentoni, Crax rubra e Ortalis canicollis). Não foi possível obter amostras de Penelope perspicax e Penelope ortoni. Estas duas espécies apresentam distribuição restrita, respectivamente, uma na Colômbia e outra na Colômbia e Equador. As amostras estão depositadas nas coleções de origem (Tabela 1). 
Tabela 1 - Amostragem.

\begin{tabular}{|c|c|c|c|c|}
\hline Espécie & $\begin{array}{l}\text { Voucher } \\
\text { LGEMA }\end{array}$ & $\begin{array}{l}\text { Voucher } \\
\text { Origem }\end{array}$ & Localidade & \begin{tabular}{|l} 
Aviário \\
Museu
\end{tabular} \\
\hline Penelope albipennis & C302 & - & Cativeiro & FCI \\
\hline Penelope argirotys & C303 & - & Cativeiro & FCI \\
\hline Penelope barbata & - & B5 & A confirmar & ROM \\
\hline Penelope dabbenei & - & 38304 & Santa Cruz Department - Bolívia & LSU \\
\hline Penelope jacquacu & $\mathrm{C} 266$ & Pendente & Estação Ecológica Mogica Nava - Rondônia & MZUSP \\
\hline Penelope jacucaca & C299 & - & Cativeiro & ССРC \\
\hline \multirow{2}{*}{ Penelope marail } & C316 & MPEG56256 & AC, Rio Branco, Caracaraí, 08/2002 & MPEG \\
\hline & C319 & MPEG41567 & AM, Rio Uatamã, UHE de Balbina & MPEG \\
\hline Penelope montagnii & C304 & - & Cativeiro & FCI \\
\hline Penelope obscura bridgesi & - & 6603 & Santa Cruz Department - Bolívia & LSU \\
\hline Penelope obscura bronzina & $\mathrm{C} 150$ & U13618 & Cativeiro & CESP \\
\hline Penelope obscura obscura & $\mathrm{C} 270$ & - & Lagoa Vermelha - Rio Grande do Sul & - \\
\hline Penelope ochrogaster & C197 & 293 & Cativeiro & СCPC \\
\hline \multirow{2}{*}{ Penelope pileata } & C300 & - & Cativeiro & CCPC \\
\hline & C311 & MPEG57296 & A confirmar & MPEG \\
\hline Penelope purpuracens & C196 & - & Cativeiro & FCI \\
\hline Penelope superciliaris jacupemba & $\mathrm{C} 140$ & - & Cativeiro & CESP \\
\hline Penelope superciliaris ochromitra & C267 & Pendente & Serra das Confusões & MZUSP \\
\hline \multirow{2}{*}{ Penelope superciliaris superciliaris } & C307 & MPEG57300 & A confirmar & MPEG \\
\hline & C309 & MPEG57299 & A confirmar & MPEG \\
\hline Aburria aburri & C172 & AAM & Cativeiro & CT \\
\hline \multirow{2}{*}{ Aburria jacutinga } & C100 & 005 & Cativeiro & CESP \\
\hline & C165 & - & Cativeiro & CCPC \\
\hline Chamaepetes goudotii & C189 & - & Cativeiro & FA \\
\hline Penelopina Nigra & C192 & - & Cativeiro & FA \\
\hline Crax alberti & $\mathrm{C} 168$ & CAM & Cativeiro & CT \\
\hline Crax daubentoni & C195 & 148 & Cativeiro & $\mathrm{CCPC}$ \\
\hline Crax rubra & $\mathrm{C} 170$ & CRM & Cativeiro & CT \\
\hline \multirow{2}{*}{ Ortalis canicollis } & C167 & - & Cativeiro & СCPC \\
\hline & $\mathrm{C} 178$ & - & Cativeiro & FC \\
\hline
\end{tabular}

CCPC - Criadouro Conservacionista Poços de Caldas; MZUSP - Museu de Zoologia da USP; FCI Fundação Crax Internacional; FC - Fundação Crax; MPEG - Museu Paraense Emílio Goeldi; ROM Royal Ontario Museum; LSU - Louisiana State University; CT - Criadouro Tropicus;e, FA - Fundacion Ara. 


\section{2) Amplificação do DNA e Seqüenciamento}

Após a extração do DNA, o protocolo descrito por Hagelberg e col. (1994) foi utilizado para as amplificações. Amplificamos e seqüenciamos fragmentos do DNA mitocondrial correspondendo aos genes ATPase 6/8, COI, tRNA Asp - COII, COIII, Cyt b, ND1 - tRNA Ile - tRNA GIn, ND2, ND4, ND5, ND6 - tRNA Pro, 16S rDNA, 12S rDNA e Região Controladora $(R C)$; e, fragmentos do DNA nuclear correspondendo ao intron 5 do beta fibrinogênio (FIB5) e "recombination activating gene 2" (RAG2). O seqüenciamento foi realizado em seqüenciadores $A B \mid 377$ e $A B \mid 3100$ da Applied Biosystems e 4200 da Li-Cor Biosciences de acordo com o protocolo padrão do fabricante e com a utilização dos mesmos primers usados nas amplificações. Os primers utilizados para amplificação por PCR são descritos em Grau et al. (2003) e Pereira e Baker (2004a).

\section{3) Alinhamento das Seqüências e Composição de Bases}

Para todas as seqüências foram comparadas as fitas $\mathrm{L}$ e $\mathrm{H}$ para correção de ambigüidades geradas durante o seqüenciamento. As seqüências corrigidas foram alinhadas manualmente no McClade 4.08 (Madison \& Madison, 2005). Previamente às análises filogenéticas, a homogeneidade da composição de bases foi testada no TREEPUZZLE 5.0 (Strimmer \& von Haeseler, 1996) para cada fragmento, incluindo apenas os sítios variáveis, já que os sítios constantes poderiam interferir na análise (Foster \& Hickey, 1999). 


\section{4) Distâncias e Saturação}

Utilizamos o PAUP 4.0 b10 (Swofford, 2001) para calcular, entre todos os táxons, as distâncias par-a-par não-corrigidas e as distâncias corrigidas com o modelo de substituição de DNA sugerido pelos testes de razão de verossimilhança realizados no MODELTEST 3.0 (Posada \& Crandall, 1998). Foram selecionados os modelos para cada região seqüenciada, para o conjunto de seqüências mitocondriais, para o conjunto de seqüências nucleares e para todas as seqüências concatenadas. As distâncias nãocorrigidas foram plotadas contra as distâncias corrigidas para verificar se existia saturação de substituição de nucleotídeos.

\section{5) Análises Filogenéticas}

As reconstruções filogenéticas foram realizadas através de análise Bayesiana (BA) com amostragem pelo algoritmo da cadeia de "Markov Chain Monte Carlo" (MCMC) no MrBayes 3.0 (Ronquist \& Huelsenbeck, 2003) com verossimilhança particionada (Lee \& Hugall, 2003). Para cada partição gênica foi definido no MrBayes 3.0 (Ronquist \& Huelsenbeck, 2003) o modelo de substituição selecionado pela análise dos dados com 0 programa MODELTEST 3.0 (Posada \& Crandall, 1998). Implementamos duas corridas independentes por 5 milhões de gerações cada, com três "cadeias quentes" e uma "cadeia fria" e um "burn-in time" determinado pelo tempo de convergência dos índices de verossimilhança. Uma árvore foi amostrada a cada mil gerações. Análise de Máxima Parcimônia (MP) com busca heurística foi realizada no PAUP 4.0 b10 (Swofford, 2001). O suporte dos ramos foi estimado por 100 réplicas de "bootstrap", cada uma com 10 ciclos de adições 
aleatórias de seqüências.

\section{6) Estimativa do Tempo de Divergência entre os Táxons}

Utilizando o Programa r8s 1.6 (Sanderson, 2003) foram estimadas as datações de divergência e os intervalos de confiança, com base na árvore da análise Bayesiana. A abordagem escolhida foi bootstrap semiparamétrico penalizado (Sanderson, 2002) que permite variação das taxas evolutivas entre as linhagens, mas uma penalidade é aplicada para minimizar variações de taxas entre um nó e seus descendentes, através de um parâmetro de suavização (do inglês "smoothing parameter"). Quanto menor o parâmetro de suavização, maior a variação de taxas observadas nos dados. Um teste de validação cruzada gerenciado pelos dados foi aplicado para escolher o melhor valor para o parâmetro de suavização (Sanderson, 2002). Assumimos como pontos de calibração que Crax rubra divergiu de (Crax alberti; Crax daubentoni) entre 5,4 Ma e 8,2 Ma e que Crax alberti divergiu de Crax daubentoni entre 5,5 Ma e 8,2 Ma, conforme sugerido por eventos geológicos e independentemente confirmado por datações moleculares (Pereira \& Baker, 2004a). 


\section{3) Resultados}

3.1) Seqüências e Composição de Bases:

A matriz de alinhamento final concatenada apresentou $13.310 \mathrm{pb}$ sendo 11.771 pb do DNA mitocondrial (11.771 pb) e 1539 pb do DNA nuclear (conforme Tabela 2). Seqüenciados 1.398 pb (COIII com 772 pb e $12 S$ com 626 pb) para Penelope obscura bridgesi, devido a problemas de amplificação.

Cada amplificação por PCR apresentou um único produto de tamanho esperado. O quadro de leitura para os genes codificantes e os blocos conservados da região controladora foram identificados conforme esperado para genes mitocondriais funcionais e os fragmentos mitocondriais são similares a outras seqüências funcionais de aves correspondentes no GenBank.

A composição de bases para o conjunto das seqüências de origem mitocondrial $(A=28,1 \% ; C=40,2 \% ; G=9,8 \% ; T=21,9 \%)$ é típica para seqüências mitocondriais de aves. Para o conjunto dos genes nucleares a composição de bases foi: $A=35,1 \% ; C=10,7 \% ; G=26,9 \%$; e, $T=27,4 \%$. No teste de homogeneidade da composição de bases, apresentaram $p<0,05$ apenas Crax rubra para o ND4 e Chamaepetes goudotii $(\mathrm{P}=0,02)$ para um dos fragmentos do ND2. 
Tabela 2 - Apresenta as regiões e tamanhos dos fragmentos seqüenciados. São identificados os fragmentos seqüenciados para cada espécie.

\begin{tabular}{|c|c|c|c|c|c|c|c|c|c|c|c|c|c|c|c|c|c|}
\hline Gene & $\begin{array}{c}\text { ATPase } \\
6 / 8\end{array}$ & $\mathrm{col}$ & \begin{tabular}{|} 
tRNA Asp \\
- COII
\end{tabular} & cOIII & Cyt b & $\left|\begin{array}{c}\text { ND1- } \\
\text { tRNA Ille- } \\
\text { tRNA GIn }\end{array}\right|$ & \multicolumn{2}{|c|}{ ND2 } & \multirow{2}{*}{$\begin{array}{l}\text { ND4 } \\
1016 \\
\end{array}$} & \multirow{2}{*}{$\begin{array}{r}\text { ND5 } \\
819 \\
\end{array}$} & \multirow{2}{*}{\begin{tabular}{|c|}
$\begin{array}{c}\text { ND6. } \\
\text { tRNA Pro }\end{array}$ \\
604 \\
\end{tabular}} & \multirow{2}{*}{\begin{tabular}{|c|}
$16 S$ rDNA \\
1042 \\
\end{tabular}} & \multirow{2}{*}{\begin{tabular}{|c|}
$12 S$ rDNA \\
698 \\
\end{tabular}} & \multicolumn{2}{|c|}{$C R$} & \multirow{2}{*}{$\begin{array}{c}\text { FIB5 } \\
613 \\
\end{array}$} & \multirow{2}{*}{$\begin{array}{c}R A G 2 \\
926\end{array}$} \\
\hline Tamanho do Fragmento $[\mathrm{pb}]$ & 839 & 1335 & 754 & 782 & 699 & 1118 & 441 & 454 & & & & & & & 170 & & \\
\hline $\begin{array}{c}\text { Táxon } \\
\end{array}$ & \multicolumn{17}{|c|}{ Voucher ou Número de Acesso no Genbank } \\
\hline Penelope albipennis & $\mathrm{C} 302$ & C302 & C302 & $\mathrm{C} 302$ & C302 & C302 & $\mathrm{C} 302$ & $\mathrm{C} 302$ & $\mathrm{C} 302$ & $\mathrm{C} 302$ & $\mathrm{C} 302$ & $\mathrm{C} 302$ & C302 & C302 & $\mathrm{C} 302$ & $\mathrm{C} 302$ & C302 \\
\hline Penelope argyrotis & C303 & C303 & C303 & C303 & C303 & C303 & C303 & C303 & C303 & C303 & - & C303 & C303 & C303 & C303 & $\mathrm{C} 303$ & C303 \\
\hline Penelope barbata & ROM - -85 & ROM - B5 & ROM - B5 & ROM - -85 & ROM - B5 & ROM - B5 & ROM - -85 & ROM - B5 & ROM- B5 & ROM - B5 & - & ROM - -85 & ROM - -85 & ROM - 85 & ROM - B5 & - & ROM - -85 \\
\hline Penelope dabbenei & 38304 & - & 38304 & 38304 & 38304 & 38304 & 38304 & 38304 & - & 38304 & 38304 & 38304 & 38304 & 38304 & 38304 & - & - \\
\hline Penelope jacquacu & $\mathrm{C} 266$ & C266 & $\mathrm{C} 266$ & $\mathrm{C} 266$ & $\mathrm{C} 266$ & $\mathrm{C} 266$ & $\mathrm{C} 266$ & C266 & $\mathrm{C} 266$ & $\mathrm{C} 266$ & $\mathrm{C} 266$ & $\mathrm{C} 266$ & $\mathrm{C} 266$ & $\mathrm{C} 266$ & $\mathrm{C} 266$ & $\mathrm{C} 266$ & $\mathrm{C} 266$ \\
\hline Penelope jacucaca & C299 & C299 & C299 & C299 & C299 & C299 & C299 & C299 & C299 & C299 & C299 & C299 & C299 & C299 & C299 & C299 & C299 \\
\hline Penelope marail & C316 & c316/c319 & $\mathrm{c} 316$ & C316 & c316/c319 & $\mathrm{c} 316$ & C316/C319 & c316/c319 & C316 & - & $\mathrm{c} 316$ & $\mathrm{C} 316$ & C316 & C316 & C316/C319 & - & C316/C319 \\
\hline Penelope montagnii & C304 & C304 & C304 & C304 & C304 & C304 & C304 & C304 & C304 & C304 & $\mathrm{C} 304$ & C304 & C304 & $\mathrm{C} 304$ & C304 & C304 & C304 \\
\hline Penelope obscura bridgesi & - & 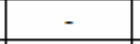 & - & LSU 6603 & - & - & - & - & - & - & - & - & LSU 6603 & - & - & - & - \\
\hline Penelope obscura bronzina & AY143688 & AF165498 & AF165510 & AF165486 & AF165474 & C150 & AY140742 & AY140742 & AY141957 & AY140756 & $\mathrm{C} 150$ & AF165462 & AF165450 & genbank & genbak & $\mathrm{C} 150$ & AY140784 \\
\hline Penelope obscura obscura & C270 & C270 & $\mathrm{C} 270$ & $\mathrm{C} 270$ & $\mathrm{C} 270$ & $\mathrm{C} 270$ & C270 & $\mathrm{C} 270$ & C270 & $\mathrm{C} 270$ & $\mathrm{C} 270$ & C270 & C270 & $\mathrm{C} 270$ & - & $\mathrm{C} 270$ & C270 \\
\hline Penelope ochrogaster & C197 & 97 & 87 & 97 & AY367101 & 97 & AY367095 & AY367089 & 97 & 97 & 197 & C197 & C197 & genbank & genbak & $\begin{array}{c}\mathrm{C} 197 \\
\end{array}$ & C197 \\
\hline Penelope pileats & C311 & C311 & 11 & C311 & C300 & C311 & C300 & C300 & C311 & C311 & C311 & c311 & C311 & $\mathrm{C} 300$ & C311 & C311 & C311 \\
\hline Penelope purpuracens & 96 & 6 & 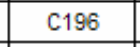 & C196 & AY367103 & C196 & AY367097 & AY367091 & C196 & C196 & C196 & C196 & C196 & genbank & genbank & 196 & C196 \\
\hline Penelope superciliaris ochromitra & 67 & 8 & $\mathrm{C} 267$ & 87 & C267 & 67 & $\mathrm{C} 267$ & $\mathrm{C} 267$ & & $\mathrm{C} 267$ & C267 & C267 & C267 & C267 & 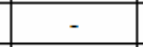 & $\begin{array}{c}\mathrm{C} 267 \\
\end{array}$ & $\mathrm{C} 268$ \\
\hline Penelope superciliaris superciliaris & C307 & C307 & 07 & C307 & C307 & C307 & C307 & C307 & C307 & C307 & C307 & C307 & C307 & - & - & $\begin{array}{cc}\mathrm{C} 307 \\
\end{array}$ & C309 \\
\hline Penelope supercilliaris jacupemba & C140 & C140 & C140 & C140 & AY367102 & C140 & AY367096 & AY367090 & - & C140 & - & C140 & C140 & genbank & genbank & C140 & C140 \\
\hline Aburria jacutinga & AY143690 & AF165500 & AF165512 & AF165488 & AF165476 & 65 & AY140744 & AY140744 & AY141959 & AY140758 & 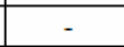 & AF165464 & AF165452 & genbank & genbank & $\mathrm{C} 100$ & AY140786 \\
\hline Aburria aburri & AY143680 & AF165490 & AF165502 & AF165480 & AF165466 & C172 & AY140740 & AY140740 & AY141940 & AY140754 & - & AF165454 & AF165442 & genbank & genbank & C172 & AY140782 \\
\hline Chamaepetes goudoti & AY143681 & AF165491 & AF165503 & AF165481 & AF165467 & C189 & AY140741 & AY140741 & AY141941 & AY140755 & - & AF165455 & AF165443 & genbank & genbank & C189 & AY140783 \\
\hline Penelopina nigra & AY143689 & AF165499 & AF165511 & AF165487 & AF165475 & 192 & AY140743 & AY140743 & AY141958 & AY140757 & - & AF165463 & AF165451 & genbank & genbank & C192 & AY140785 \\
\hline Crax alberti & AY141900, & AY141910 & C168 & C168 & AY141920 & C168 & AY141930 & AY141930 & AY141942 & - & - & C168 & C168 & genbank & genbank & - & C168 \\
\hline Crax daubentoni & AY141902 & AY141912 & C195 & C195 & AY141922 & C195 & AY141932 & AY141932 & AY141945 & - & - & C195 & C195 & genbank & genbank & - & C195 \\
\hline Crax rubre & AY141905, & AY141915 & $61 / 1$ & $61 / 1$ & AY141925 & C171 & AY141935 & AY141935 & AY141948 & - & - & C171 & C171 & genbank & genbank & - & C170 \\
\hline Ortallis canicollis & AY143686 & AF165496 & AF165508 & AF165485 & AF165472 & C178 & AY140746 & AY140746 & AY141954 & AY140760 & - & AF165460 & AF165448 & genbank & genbank & C167 & AY140788 \\
\hline
\end{tabular}




\section{2) Distâncias Genéticas e Saturação}

Para o cálculo das distâncias corrigidas foi escolhido o modelo de substituição de DNA "GTR+/+G" para ATP, COI, COIII, ND1-ILE-GLN, ND5, $12 S, 16 S, C R$, conjunto de todos as seqüências mitocondriais e conjunto de todos os fragmentos seqüenciados; "GTR+l" para ND2 (fragmento na região inicial do ND2); "GTR+G" para ND4 e ND2 (fragmento na região final do $N D 2)$; "HKY+l" para RAG2 e conjunto das seqüências nucleares; " $H K Y+G$ " para ASP-COII, CYTB e ND6-PRO; e, "F81+G" para FIB5. Não foi detectada evidência de saturação de substituições (gráficos não apresentados).

As distâncias estimadas entre os táxons de Penelope, com base na matriz com todos os fragmentos seqüenciados, são apresentadas na tabela 3. As distâncias corrigidas variaram entre $0,3 \%$ e $6,6 \%$, com média de 4,2\%+1,2\% e as distâncias não-corrigidas variaram entre $0,3 \%$ e $4,8 \%$, com média de $3,4 \% \pm 0,9 \%$. Considerando apenas as comparações entre subespécies consideradas válidas de uma mesma espécie as distâncias corrigidas variaram entre $1 \%$ e $3,8 \%$, com média de $2,0 \% \pm 1,1 \%$, e as distâncias nãocorrigidas variaram entre $0,9 \%$ a $3,2 \%$, com média de $1,8 \% \pm 0,9 \%$. 
Tabela 3 - Distâncias percentuais entre os táxons de Penelope calculadas com base nos $13.310 \mathrm{pb}$ concatenados. Na diagonal superior distâncias " $p$ " não-corrigidas e na inferior distâncias corrigidas com o modelo $G T R+/+G(I=0,569 ; G=0,7584)$.

\begin{tabular}{|c|c|c|c|c|c|c|c|c|c|c|c|c|c|c|c|c|c|}
\hline & 1 & 2 & 3 & 4 & 5 & 6 & 7 & 8 & 9 & 10 & 11 & 12 & 13 & 14 & 15 & 16 & 17 \\
\hline 1 - P. pileata & - & 0,4 & 0,3 & 1,8 & 1,7 & 3,6 & 1,9 & 4,0 & 3,6 & 3,9 & 3,8 & 3,7 & 4,1 & 3,9 & 3,7 & 3,8 & 3,6 \\
\hline 2 - P. jacucaca & 0,4 & - & 0,4 & 1,8 & 1,9 & 3,6 & 2,0 & 4,1 & 3,7 & 4,0 & 3,9 & 3,7 & 4,1 & 4,0 & 3,8 & 3,8 & 3,7 \\
\hline 3 - P. ochrogaster & 0,3 & 0,4 & - & 1,7 & 1,8 & 3,6 & 1,9 & 4,0 & 3,6 & 4,0 & 3,9 & 3,7 & 4,1 & 4,0 & 3,7 & 3,8 & 3,7 \\
\hline 4 - P. o. bronzina & 1,9 & 1,9 & 1,9 & - & 3,2 & 3,7 & 2,1 & 4,0 & 3,7 & 3,9 & 4,0 & 3,7 & 4,1 & 4,1 & 3,8 & 3,8 & 3,6 \\
\hline 5 - P. o. bridgesi & 1,9 & 2,2 & 2,0 & 3,8 & - & 4,2 & 2,3 & 4,8 & 4,3 & 4,5 & 4,2 & 3,9 & 3,9 & 4,1 & 4,6 & 4,5 & 4,0 \\
\hline $6-P$. argirotys & 4,4 & 4,4 & 4,4 & 4,5 & 5,6 & - & 3,7 & 3,6 & 3,4 & 3,6 & 3,2 & 3,3 & 3,8 & 3,6 & 3,4 & 3,6 & 3,4 \\
\hline 7 - P. o. obscura & 2,1 & 2,2 & 2,2 & 2,4 & 2,6 & 4,6 & - & 3,9 & 3,5 & 3,9 & 3,9 & 3,5 & 3,8 & 3,9 & 3,7 & 3,7 & 3,7 \\
\hline 8 - P. s. ochromitra & 5,1 & 5,2 & 5,0 & 5,0 & 6,6 & 4,5 & 4,9 & - & 1,1 & 1,1 & 3,0 & 3,7 & 4,2 & 3,8 & 3,6 & 3,7 & 3,5 \\
\hline 9 - P. s. jacupemba & 4,4 & 4,7 & 4,5 & 4,6 & 5,9 & 4,2 & 4,4 & 1,1 & - & 0,9 & 3,0 & 3,5 & 4,1 & 3,6 & 3,2 & 3,5 & 3,3 \\
\hline 10 -P.s. superciliaris & 5,0 & 5,1 & 5,0 & 5,0 & 6,0 & 4,5 & 5,0 & 1,1 & 1,0 & - & 3,1 & 3,6 & 4,3 & 3,7 & 3,5 & 3,7 & 3,6 \\
\hline 11 - P. marail & 4,9 & 4,9 & 4,9 & 5,1 & 5,5 & 3,9 & 4,9 & 3,6 & 3,6 & 3,7 & - & 3,4 & 3,9 & 3,5 & 3,6 & 3,6 & 3,6 \\
\hline 12 - P. jacquacu & 4,6 & 4,6 & 4,6 & 4,7 & 4,8 & 4,1 & 4,4 & 4,6 & 4,4 & 4,5 & 4,2 & - & 0,8 & 2,4 & 3,5 & 3,6 & 3,4 \\
\hline 13 - P. dabbenei & 5,2 & 5,3 & 5,2 & 5,3 & 5,0 & 4,9 & 4,8 & 5,5 & 5,3 & 5,6 & 4,9 & 0,9 & - & 2,9 & 4,0 & 4,1 & 4,0 \\
\hline 14 - P. albipennis & 4,9 & 5,0 & 5,1 & 5,3 & 5,1 & 4,4 & 4,9 & 4,8 & 4,4 & 4,6 & 4,3 & 2,8 & 3,4 & - & 3,6 & 3,7 & 3,6 \\
\hline 15 - P. montagnii & 4,6 & 4,7 & 4,6 & 4,8 & 6,0 & 4,2 & 4,6 & 4,4 & 3,8 & 4,3 & 4,5 & 4,3 & 5,0 & 4,4 & - & 2,1 & 2,1 \\
\hline 16 - P. barbata & 4,7 & 4,8 & 4,8 & 4,7 & 6,3 & 4,5 & 4,7 & 4,6 & 4,4 & 4,6 & 4,4 & 4,5 & 5,2 & 4,5 & 2,3 & - & 2,1 \\
\hline 17 - P. purpuracens & 4,5 & 4,6 & 4,6 & 4,5 & 5,2 & 4,1 & 4,6 & 4,3 & 4,0 & 4,4 & 4,5 & 4,2 & 5,0 & 4,4 & 2,3 & 2,4 & - \\
\hline
\end{tabular}




\section{3) Análises Filogenéticas}

O mesmo modelo de substituição, utilizado para o cálculo das distâncias para cada fragmento, foi utilizado na análise Bayesiana para inferir as relações filogenéticas entre os táxons de Penelope. A topologia consenso obtida na análise Bayesiana (Figura 1) sugere uma radiação basal com a formação de cinco clados. As três subespécies de Penelope superciliaris formam um grupo monofilético. As três subespécies de Penelope obscura, no entanto, formam um grupo parafilético.

A topologia bayesiana apresentou altas probabilidades posteriores em geral. Encontramos baixos índices de suporte em dois nós na base da árvore filogenética de Penelope e entre as relações filogenéticas das subespécies de Penelope obscura. Para verificarmos se os baixos índices de suporte destes nós poderiam estar associados a informações divergentes entre os genes, implementamos análise Bayesiana para cada gene (árvores não apresentadas). As topologias obtidas apresentaram politomias nas relações filogenéticas basais de Penelope, indicando falta de sinal filogenético nestes nós. Os baixos índices de suporte na base da árvore podem estar associados a eventos de especiação ocorridos em curto período de tempo. O posicionamento de Penelope argyrotis, sustentado por baixos índices de suporte, variou consideravelmente nas árvores gênicas. Nas análises filogenéticas por fragmento, as subespécies de Penelope obscura permaneceram como um grupo parafilético e as de Penelope superciliaris como um grupo monofilético. 
A análise de Máxima Parcimônia apresentou resultados semelhantes aos da análise Bayesiana (Figura 1), divergindo apenas no posicionamento das subespécies de Penelope obscura. No geral, os índices de suporte foram altos e as cinco linhagens permaneceram monofiléticas (figura 1).

\section{4) Datação do Tempo de Divergência}

As estimativas de tempos de divergência, obtidas com parâmetro de suavização de 0,05 , são apresentadas na Figura 1 . Os táxons do gênero Penelope diversificam-se entre 0,4 Ma e 7,3 Ma. Podemos observar uma rápida radiação basal há aproximadamente 7 Ma com a formação de cinco linhagens que nomeamos como: Linhagem Andina, Linhagem Oeste Amazônica, Linhagem Leste Amazônica, Linhagem Norte Amazônica e Linhagem Atlântica. 

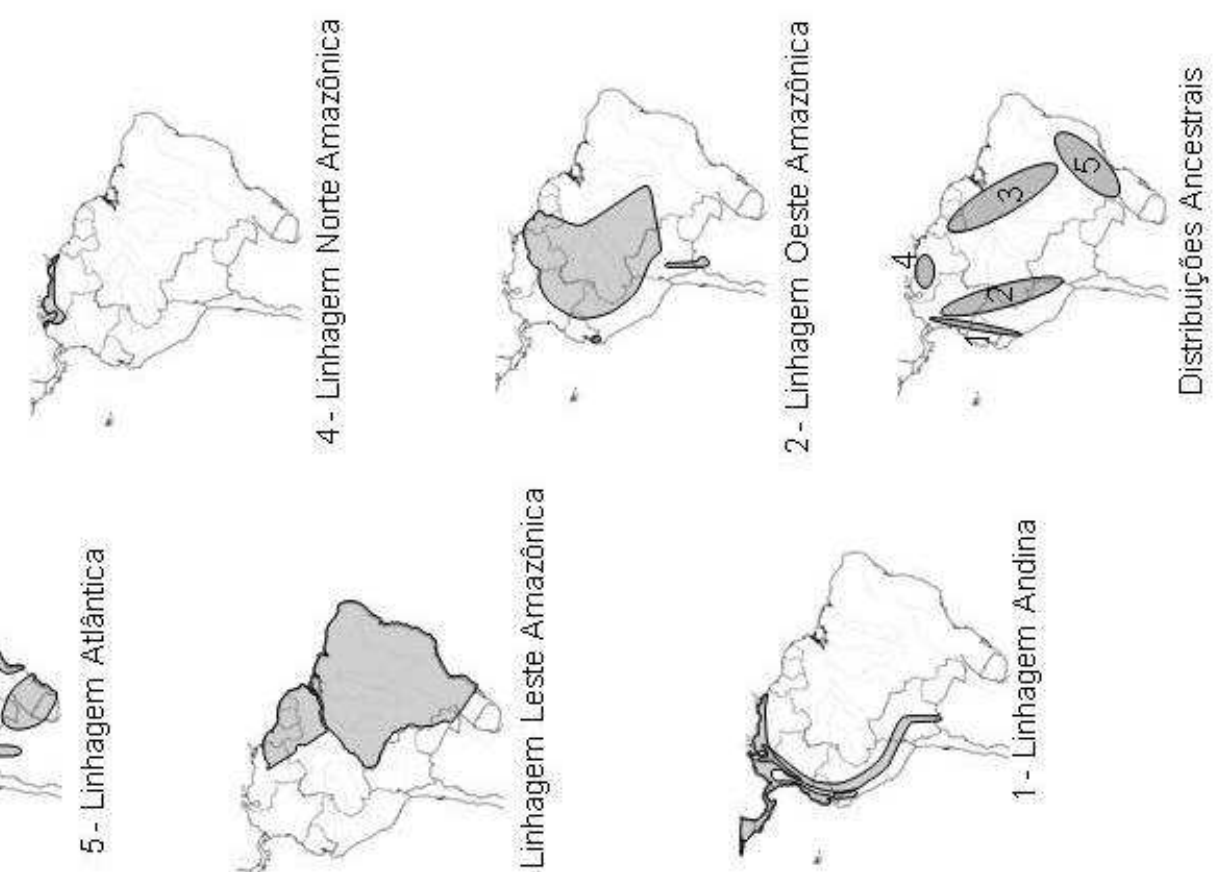

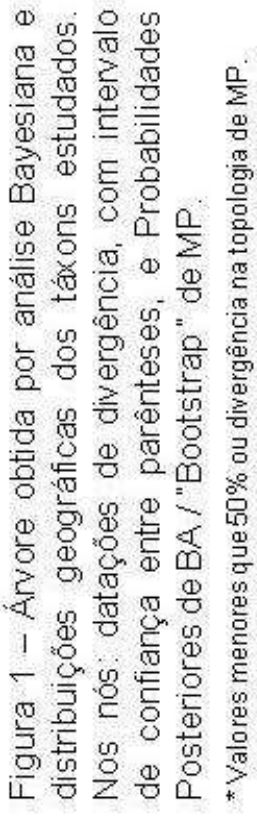

Grupos-Externos
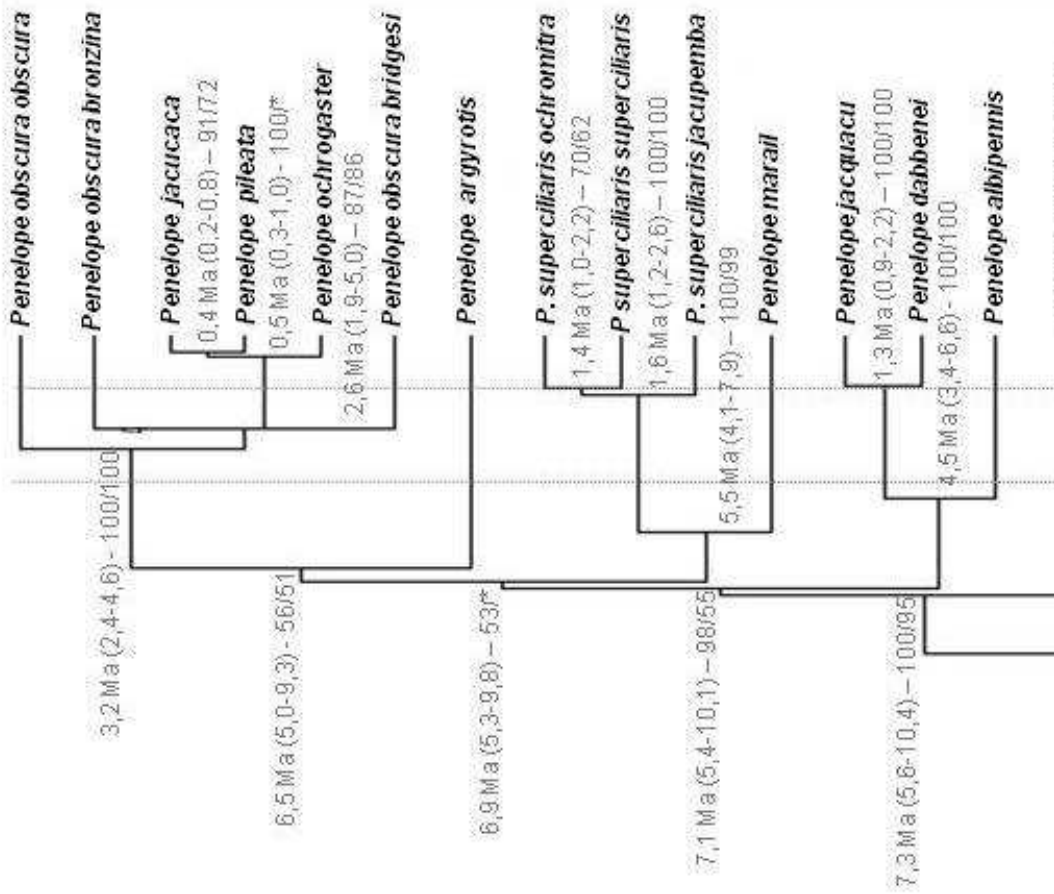

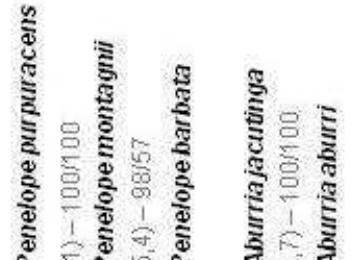

密

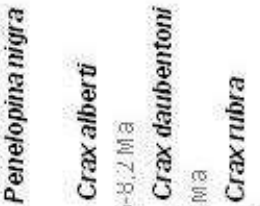

0
0
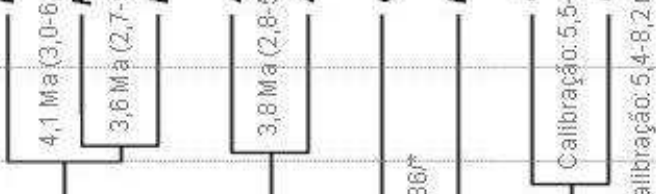

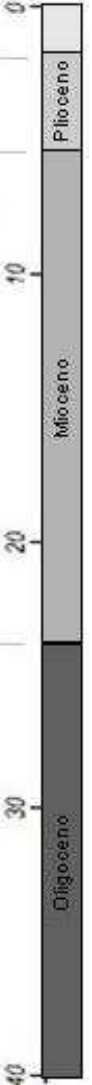




\section{4) Discussão}

\section{1) Implicações Sistemáticas e Taxonômicas}

A sistemática de Penelope foi abordada em diversos trabalhos (Blake, 1977; Brooks \& Strahl, 2000; Delacour \& Amadon, 1973; del Hoyo et al., 1994; Pereira et al., 2002; Silveira et al., 2007; Vaurie, 1964, 1966a, 1966b; Vuilleumier, 1965) e alguns pontos de divergência continuam em aberto, principalmente em relação à definição de espécies válidas. Analisamos uma grande quantidade de seqüências de genes mitocondriais e nucleares de 17 táxons de Penelope, através de reconstruções filogenéticas, distâncias genéticas e datações de divergência, para averiguar a monofilia do gênero e o status taxonômico de 13 das suas 15 espécies. Incluímos seis subespécies para um melhor entendimento das relações filogenéticas e para servirem como referência complementar na avaliação de status taxonômico.

A análise das distâncias genéticas, complementarmente às reconstruções filogenéticas, tem se mostrado como ferramenta útil para o estudo de status taxonômico de gêneros e espécies (e.g., Aleixo, 2002; Grau et al., 2003; Grau et al., 2005; Zink \& Blackwell-Rago, 2000). Conforme esperado, não há uma distância mínima ou datação de divergência mínima padrão que permita definir unequivocamente o status taxonômico de gêneros, espécies ou subespécies. Diversos fatores como tempo de geração, tamanho populacional, fluxo gênico, pressões seletivas, entre outros, interferem no processo de especiação. Assim, por exemplo, populações ancestrais com tamanho pequeno e separadas de outras populações por barreiras, físicas ou não, que eliminem totalmente o fluxo gênico especiariam em tempo mais 
curto do que nos casos de especiações envolvendo grandes populações.

A hipótese de monofilia de Penelope e da sua distinção em relação aos demais gêneros de Cracidae foi apoiada por Blake (1977), Brooks e Strahl (2000), Delacour e Amadon (1973), del Hoyo e col. (1994), Pereira e col. (2002), Frank-Hoelich e col. (2007) e Vaurie (1964, 1966a, 1966b). Vuilleumier (1965) agrupou Penelope e Aburria como congenéricos. As reconstruções filogenéticas apresentaram Penelope como monofilético e como grupo-irmão de Aburria (incluindo Pipile), em ambos os casos, com probabilidades posteriores de $100 \%$ na análise Bayesiana. Estudos osteológicos de Silveira (2003) apontam que as espécies pertencentes a Penelope podem ser diagnosticadas através da presença da articulação do processo supra-orbital do lacrimal com a porção dorsolateral do processo maxilopalatino e por possuírem um longo processo orbital lacrimal, que quase toca a barra jugal. As distâncias genéticas intergenéricas estimadas entre espécies de Penelope e Aburria (média de $5,7 \pm 0,3 \%$ ) foram maiores do que as encontradas nas comparações intragenéricas (Penelope: média de 4,2£1,2 - Aburria: 2,3\%) e as datações de divergência entre os gêneros Penelope e Aburria são equivalentes às datações encontradas entre outros gêneros irmãos em Cracidae (Pereira et al., 2002; Pereira \& Baker, 2004a). Nossos resultados reforçam a monofilia e apóiam Penelope como distinto de Aburria, sugerimos que o status atual do gênero seja mantido.

Revisões taxonômicas intragenéricas foram propostas para o gênero Penelope por Vaurie (1964, 1966a, 1966b), Vuilleumier (1965) e Delacour e Amadon (1973) e consideraram diferentes quantidades de espécies válidas. A uniformidade de coloração e de forma entre diferentes táxons de Penelope 
dificulta a delimitação das espécies e subespécies (Delacour \& Amadon, 1973). No Handbook of the Birds of the World, del Hoyo e col. (1994) fazem uma compilação das classificações e sugerem Penelope com 15 espécies, classificação adotada neste trabalho.

As análises filogenéticas, em geral, apresentaram altos índices de suporte para as relações entre as 13 espécies do gênero Penelope estudadas. As distâncias corrigidas encontradas entre estas diferentes espécies, consideradas como válidas por del Hoyo e col. (1994), variaram entre $0,3 \%$ e $6,6 \%$ e entre as subespécies de uma mesma espécie variaram entre $1,0 \%$ e 3,8\%. Neste caso, há distâncias estimadas entre subespécies de uma mesma espécie maiores do que distâncias estimadas entre espécies consideradas válidas e houve parafiletismo no caso das subespécies de Penelope obscura. Em outros cracídeos encontramos distâncias genéticas entre espécies válidas de um mesmo gênero variando entre 0,7\% e 2,9\% em Aburria (incluindo Pipile), estimados com base em fragmentos do cyt $b, N D 2$ e região controladora, (Grau et al., 2005) e entre 1.3\% - 3.0\%, em Crax e Mitu estimados com base em fragmentos do cyt b e ND2 (Grau et al., 2003). Em Cracidae, as distâncias genéticas intraespecíficas, detectadas a partir da análise de genes mitocondriais, foram próximas a zero (Grau et al, 2003).

Dentre os táxons analisados, discutimos a seguir o status taxonômico de Penelope obscura, dos jacus vermelhos (Penelope ochrogaster, Penelope pileata e Penelope jacucaca), de Penelope superciliaris, de Penelope dabbenei e de Penelope jacquacu e, desde já, consideramos as demais espécies como válidas, seguindo-se del Hoyo e col. (1994).

As reconstruções filogenéticas apresentam as subespécies de 
Penelope obscura, como um grupo parafilético. Encontramos distâncias genéticas de 2,6\% entre Penelope obscura obscura e Penelope obscura bridgesi, de 2,5\% entre Penelope obscura obscura e Penelope obscura bronzina e de 3,8\% entre Penelope obscura bridgesi e Penelope obscura bronzina. Estas distâncias são equivalentes às encontradas entre táxons com status de espécie não questionado em Penelope (Tabela 2), Aburria (Grau et al., 2005) e Crax (Grau et al., 2003). Também, são maiores do que as distâncias médias $(2,0 \% \pm 0,2 \%$ para distâncias corrigidas) encontradas quando comparamos par-a-par estas subespécies de Penelope obscura com espécies de jacus vermelhos (Penelope ochrogaster, Penelope pileata e Penelope jacucaca). Nossos resultados sugerem que as subespécies de Penelope obscura, que apresentam distribuição disjunta, são espécies distintas e deveriam ser renomeadas de acordo com o princípio da prioridade cronológica (artigo 23) do código de internacional de nomenclatura zoológica como: Penelope obscura Temminck, 1815, Penelope bridgesi Gray, 1860 e Penelope bronzina Hellmayr, 1914.

Os Jacus vermelhos (Penelope ochrogaster, Penelope pileata e Penelope jacucaca), que formam um grupo monofilético, apresentaram as menores distâncias entre espécies consideradas válidas (entre 0,3\% e 0,4\%). As três espécies são grupos taxonômicos bastante próximos, provavelmente, subespécies de uma mesma espécie. O status taxonômico destas espécies tem sido debatido: Vuilleumier (1965), as considera como subespécies de uma mesma espécie, enquanto Vaurie (1966) e Delacour e Amadon (1973) as classificam como espécies distintas. Os três táxons apresentam distribuição disjunta, ocorrendo em florestas e em matas de galeria de 
biomas distintos (cerrado, caatinga e Floresta Amazônica). Sugerimos, com base em nossos resultados, que o status taxonômico destas espécies seja reavaliado.

Penelope superciliaris apresenta ampla distribuição geográfica ao sul do rio Amazonas até o norte da Argentina e morfotipos regionais podem ser identificados, sendo classificados como subespécies. Vaurie (1966) e Delacour e Amadon (1973) sugerem a existência de três subespécies: Penelope superciliaris superciliaris, Penelope superciliaris jacupemba e Penelope superciliaris major. A subespécie Penelope superciliaris ochromitra é sinonimizada por Vaurie (1966) com Penelope superciliaris jacupemba. Analisamos amostras de três subespécies de Penelope superciliaris. Encontramos Penelope superciliaris ochromitra como grupo-irmão de Penelope superciliaris superciliaris e não de Penelope superciliaris jacupemba, divergindo de Vaurie (1966). As distâncias genéticas calculadas entre as subespécies variaram entre $1,0 \%$ e $1,1 \%$. Nossos resultados indicam que o status de subespécie deve ser mantido para estes táxons e que a subespécie Penelope superciliaris ochromitra não deveria ser sinonimizada com Penelope superciliaris jacupemba.

Observamos distância de $0,9 \%$ entre Penelope jacquacu e Penelope dabbenei. Distâncias inferiores às encontradas entre as subespécies de Penelope superciliaris $(1,0 \%-1,1 \%)$ e superiores às encontradas entre as espécies de jacus vermelhos (0,3-0,4\%). Penelope jacquacu apresenta ampla distribuição geográfica no oeste da região amazônica ocorrendo na zona climática tropical e, localmente, na zona subtropical. Penelope dabbenei ocorre nas regiões tropicais ou subtropicais úmidas de altitude, entre 2000- 
2500 metros acima do nível do mar, na encosta leste dos Andes, com distribuição restrita a sul da distribuição de Penelope jacquacu. Sugerimos que esta classificação seja mantida levando-se em conta as diferenças de hábitat entre as espécies e o endemismo de Penelope dabbenei, enquanto não houver uma avaliação mais cuidadosa sobre este assunto.

Nossos resultados sugerem que o status taxonômico da maioria das espécies consideradas válidas por del Hoyo e col. (1994) e incluídas neste trabalho deve ser mantido e que as subespécies de Penelope obscura devem ser consideradas como espécies válidas.

\section{2) Biogeografia e Tempos de Divergência}

Os Jacus, e os cracídeos em geral, habitam áreas florestadas, e portanto, sua história evolutiva está intimamente ligada à presença de florestas e são sujeitos aos mesmos fatores que causam modificações na estrutura destas. As alterações climáticas, transgressões marinhas e o soerguimento de cadeias de montanhas, podem interferir na continuidade dos ambientes florestais e constituir barreiras ao fluxo gênico, sendo portanto responsáveis pela diferenciação de diferentes linhagens e conseqüentemente pela especiação.

Com base na árvore consenso da análise Bayesiana estimamos os tempos de divergência entre os táxons e propusemos hipótese biogeográfica para a evolução de Penelope. A diversificação intragenérica de Penelope foi estimada entre 7,3 e 0,3 Ma. Há uma radiação basal há 7 Ma (intervalo de confiança 95\%: 5,0 a 10,4 Ma) que leva à formação de cinco linhagens (Figura 1), que identificamos como: 1) Linhagem Andina; 2) Linhagem Oeste 
Amazônica; 3) Linhagem Leste Amazônica; 4) Linhagem Norte Amazônica; e, 5) Linhagem Atlântica. Altas probabilidades posteriores sustentam a monofilia de cada uma das linhagens (100\%), com mais de uma espécie, e a monofilia de um clado, grupo-irmão da Linhagem Andina, agrupando as demais quatro linhagens (98\%). As relações filogenéticas entre estas quatro linhagens foram suportadas por baixas probabilidades posteriores. Nossos resultados sugerem eventos de especiação ocorridos em curto período de tempo na formação destas linhagens, a rápida diversificação dificulta a fixação de mutações com sinal filogenético suficiente para a reconstrução das relações filogenéticas por dados moleculares.

A linhagem andina (Figura 2) como grupo-irmão do clado englobando as demais linhagens evidencia um padrão de vicariância cis-tras-andino, seguido de diversificação das demais linhagens na região a leste dos Andes.

No Mioceno tardio (10 Ma - $8 \mathrm{Ma}$ ) o soerguimento dos Andes causa grandes modificações nos sistemas de drenagem das bacias sul-americanas, culminando na inversão da drenagem da bacia amazônica do Oceano Pacífico e Mar do Caribe para o Oceano Atlântico (Lundberg, 1998). A inversão da drenagem da Bacia Amazônica, concomitantemente à ocorrência de transgressões marinhas, causa o alagamento das terras baixas a oeste da Amazônia com a formação de grandes lagos (Lundberg, 1998). A intensa ocorrência de transgressões marinhas, neste período, também provoca o alagamento das bacias do Rio Paraná, do Prata e do Orinoco e terras baixas da região leste Amazônica (Lundberg, 1998). Outra influência do soerguimento dos Andes é o bloqueio dos ventos úmidos recebidos do pacífico levando à aridificação da região central da América do Sul 
(Hooghiemstra \& van der Hammen, 1998). Dados palinológicos não indicam a presença de vegetação de áreas abertas antes do Mioceno tardio nesta região (Hoorn, 1994). Também, um aumento da elevação das montanhas na costa sudeste do Brasil (Almeida, 1976; Riccomini et al., 1989; Safford, 1999) reforça as barreiras e o isolamento das áreas florestadas da região atlântica. Estes eventos, em conjunto ou isoladamente, provocariam modificações nas florestas tropicais e as regiões mais altas, nas encostas dos Andes, no Planalto das Guianas, no Planalto Brasileiro e no "Merida Andes" (Norte da Venezuela), permaneceriam mais disponíveis para ocupação. Neste cenário, sugerimos a diferenciação das linhagens nas seguintes áreas: a oeste dos Andes a Linhagem Andina, nas encostas a leste dos Andes a Linhagem Oeste Amazônica, no "Merida Andes" a Linhagem Norte Amazônica, na região central do Planalto Brasileiro e no Planalto das Guianas a Linhagem Leste Amazônica e na Floresta Atlântica no leste do Planalto Brasileiro a Linhagem Atlântica, conforme Figura 2.

A diversificação dos táxons dentro de cada linhagem também parece ter sido influenciada pelas transgressões marinhas e pelo soerguimento dos Andes e suas conseqüências.

A Linhagem Andina é composta por três espécies (Figura 3). Penelope purpuracens com distribuição em terras baixas, desde o México até a América do Sul (Delacour \& Amadon, 1973), primariamente a oeste dos Andes. Penelope montagnii que ocorre essencialmente na zona temperada à leste dos Andes, podendo atingir até 12 mil pés. Quase certamente ocorre em altitudes maiores do que qualquer outra espécie de Cracidae (Delacour e 


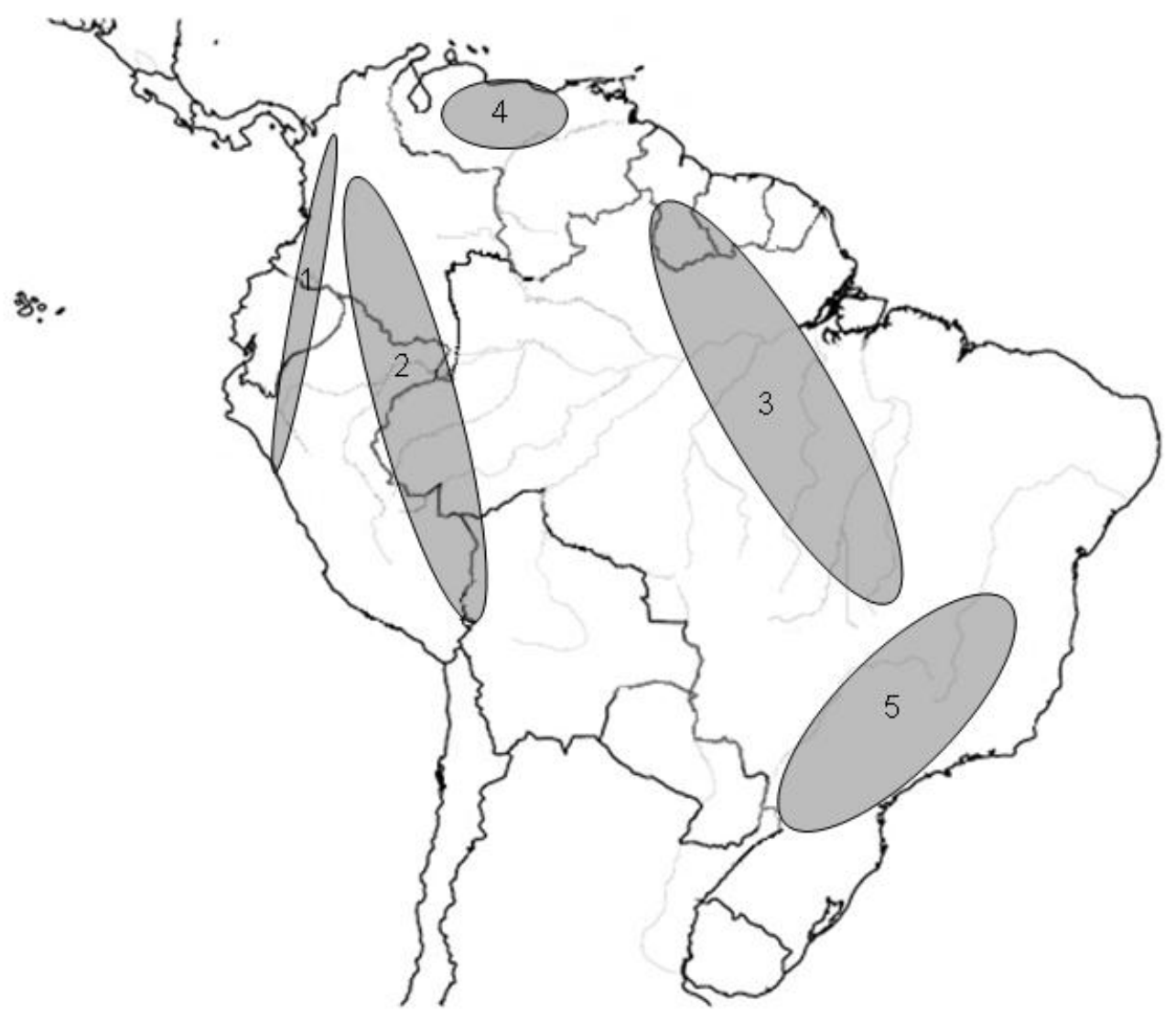

Figura 2 - Sugestão de regiões de distribuição das linhagens ancestrais de Penelope: Andina (1); Oeste Amazônica (2); Leste Amazônica (3); Norte Amazônica (4); e, Atlântica (5). Mapa e distribuições modificados de Delacour e Amadon (1973).

Amadon, 1973). Ao sul da sua distribuição atinge o extremo norte da Argentina. Penelope barbata que também ocorre na zona temperada e, no sul de sua distribuição, talvez, na zona subtropical de altitude. Distribui-se a oeste dos Andes do sul do Equador ao noroeste do Peru. Delacour e Amadon (1973) sugerem que as distribuições de Penelope barbata e Penelope montagnii não se sobrepõem em nenhum ponto e Koepckes (in Delacour \& Amadon, 1973) sugere que Penelope barbata seria uma forma equivalente de Penelope montagnii a oeste dos Andes. A diferenciação de Penelope purpuracens do clado Penelope montagnii e Penelope barbata foi estimada em 4,1 Ma $(3,0-6,1)$ e a diferenciação entre Penelope montagnii e Penelope 
barbata estimada 3,6 Ma (2,7-5,4). Ambas datações são concordantes com um padrão vicariante devido ao soerguimento final do segmento norte dos Andes (Pereira \& Baker, 2004a). No caso de Penelope montagnii e Penelope barbata também pode ter sido influenciada pelas oscilações climáticas. $O$ local em que há maior proximidade entre as distribuições de Penelope montagnii e Penelope barbata é na região na divisa entre o Equador e o Peru que apresenta pontos com menor altitude nos Andes que poderiam permitir a migração da população ancestral de Penelope montagnii para o leste do Andes durante os períodos com clima mais quente, os períodos interglaciais, e ocasionaria o isolamento nos períodos mais frios, períodos glaciais.

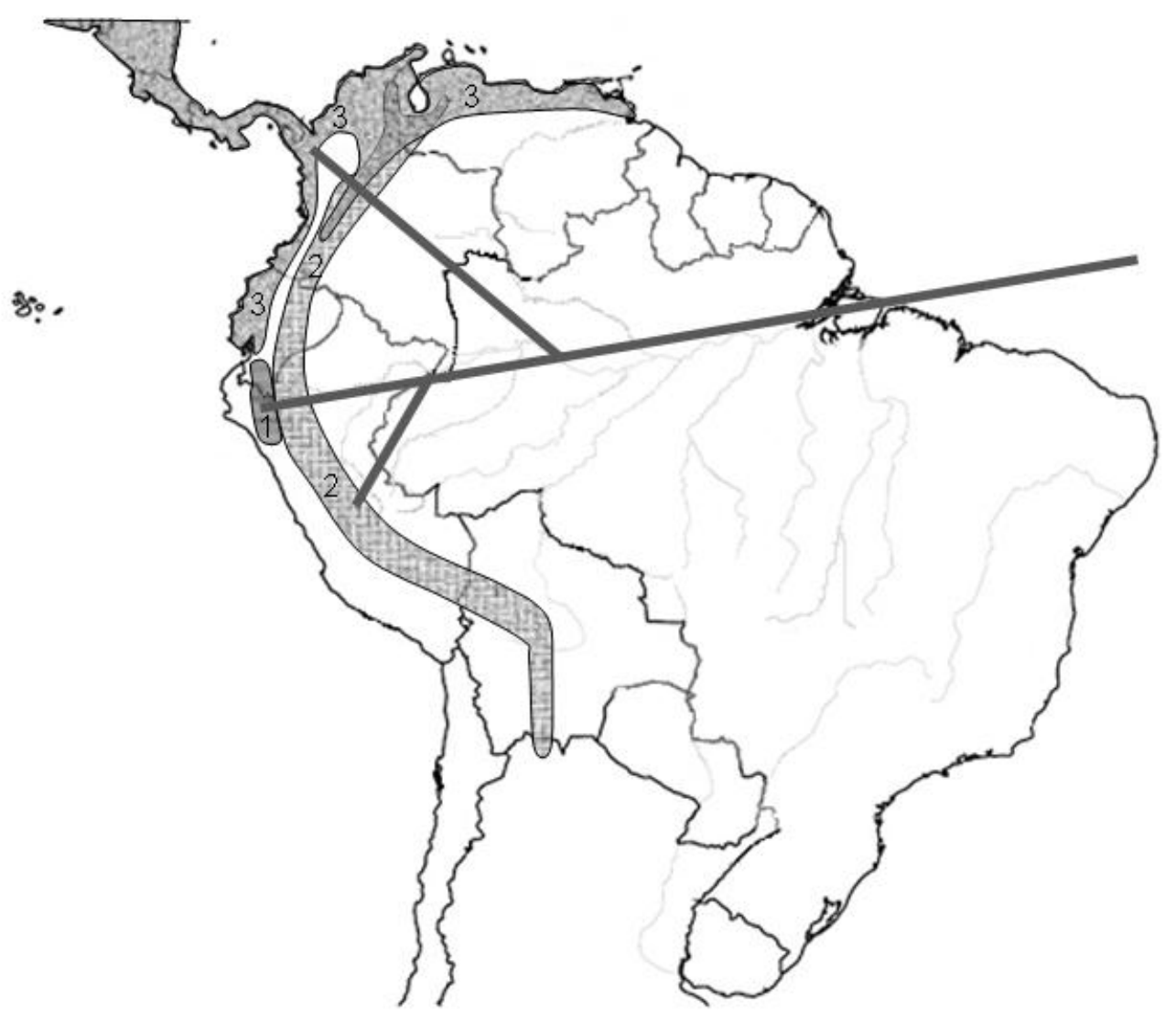

Figura 3 - Distribuição das espécies da Linhagem Andina: Penelope barbata (1); Penelope montagnii (2); e, Penelope purpuracens (3). Mapa e distribuições modificados de Delacour e Amadon (1973). 
A Linhagem Oeste Amazônica (Figura 4) é composta por três espécies. Penelope jacquacu apresenta ampla distribuição geográfica na região oeste da Amazônia, ocorrendo na zona climática tropical e, localmente, na zona subtropical. Penelope dabbenei ocorre entre 2000-2500 metros acima do nível do mar, na encosta leste dos Andes, do sul da Bolívia ao extremo noroeste da Argentina, ao sul da distribuição de Penelope jacquacu. Penelope albipennis ocorre na região costeira do noroeste do Peru, a oeste dos Andes, com distribuição bastante restrita. A separação de Penelope albipennis do clado contendo Penelope jacquacu e Penelope dabbenei foi estimada em 4,5 Ma $(3,4-6,6)$ podendo estar associada ao soerguimento final dos Andes e aos efeitos das oscilações climáticas. O local em que há maior proximidade entre as distribuições de Penelope jacquacu e Penelope albipennis é na região na divisa entre o Equador e o Peru, este padrão pode ser equivalentemente ao que influenciou a separação entre Penelope barbata e Penelope montagnii, já que o evento ocorreu no mesmo período e região, entretanto em sentido contrário, com migração da população ancestral para o oeste dos Andes. Para Penelope jacquacu e Penelope dabbenei o tempo de divergência foi estimado em 1,3 Ma $(0,9-2,2)$. Nesta época, houve transgressão marinha com o nível do mar atingindo 100 metros acima do nível atual (Haq et al., 1985; Nores, 1999) com alagamento das terras baixas das Bacias do Prata, do Paraná e Amazônica. Nesta condição a distribuição de Penelope jacquacu ficaria restrita à encosta dos Andes. As variações do nível do mar e posterior especialização de habitat por Penelope dabbenei, que ocorre em altitudes acima de 2000 metros, poderiam provocar o isolamento das populações da forma ancestral e diferenciação das espécies. 


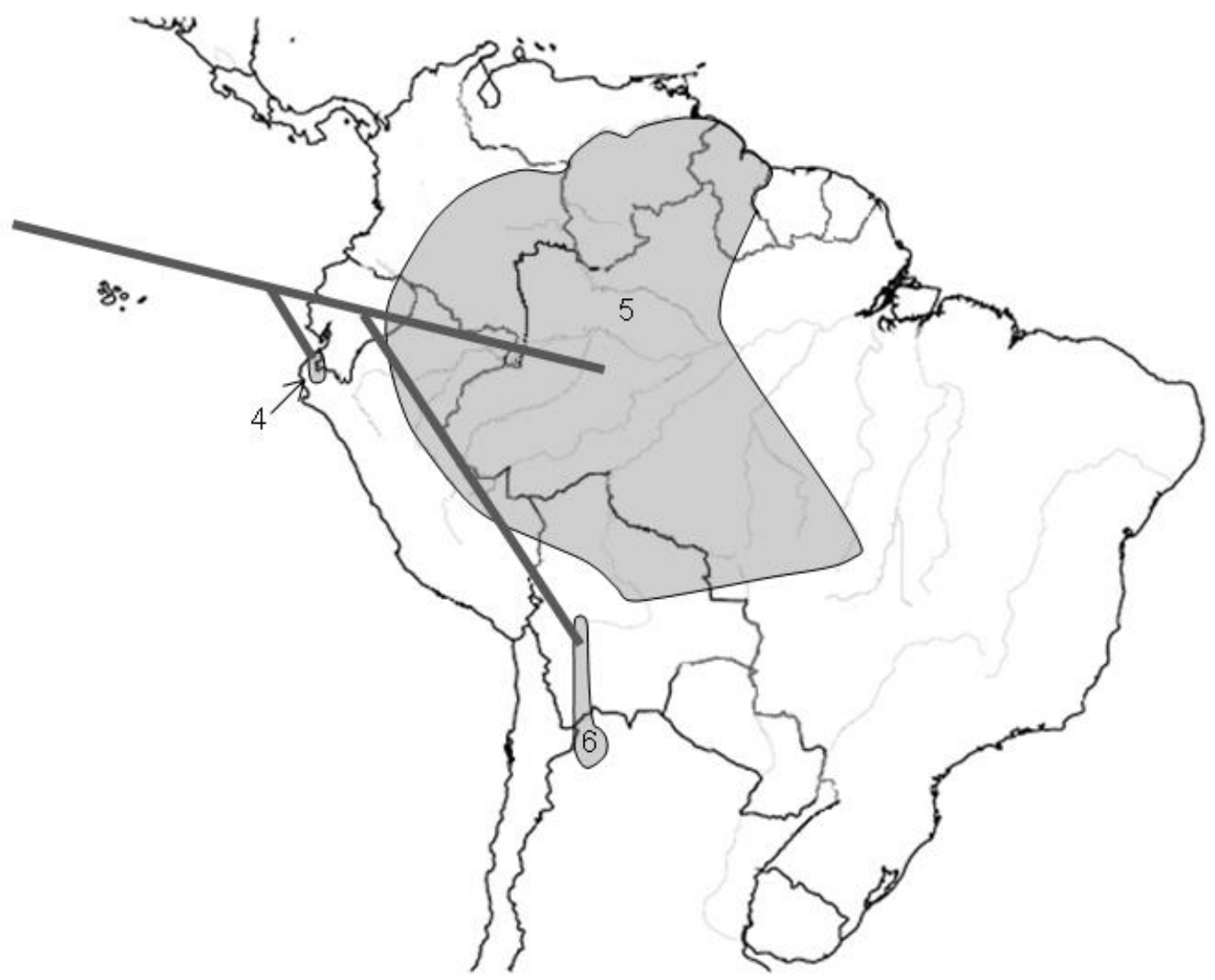

Figura 4 - Distribuição das espécies da Linhagem Oeste Amazônica: Penelope albipennis (4); Penelope jacquacu (5); e, Penelope dabbenei (6). Mapa e distribuições modificados de Delacour e Amadon (1973).

Na Figura 5 observamos a Linhagem Leste Amazônica formada por duas espécies. Penelope marail ocorre ao norte do rio Amazonas e Penelope superciliaris ao sul. A divergência entre os táxons foi estimada em 5,5 Ma (4,1-6,6). Há aproximadamente 8 Ma estava estabelecido o padrão de drenagem do rio Amazonas com descarga no atlântico, (Lundberg et al., 1998) depois do rompimento da barreira formada pelo arco de Purus que ligava o Planalto Brasileiro ao Planalto das Guianas. Entretanto, a inversão da drenagem parece não ter sido suficiente para que ocorresse diferenciação suficiente para formação de duas espécies: Penelope superciliaris e 
Penelope marail. Uma transgressão marinha há $5 \mathrm{Ma}$ provocou o um aumento do nível do mar 100 metros acima do nível atual e durou por 0,8 Ma (Haq et al., 1987), com o alagamento das terras baixas da região amazônica e aumentando o tamanho da barreira entre as espécies, podendo ter influenciado nesta especiação. Entre as subespécies de Penelope superciliaris encontramos datações de divergência entre 1,4 Ma e 1,6 Ma, a diferenciação das subespécies pode estar associada às oscilações climáticas e seus efeitos na América do Sul, com episódios de retração de florestas e isolamento de refúgios durante o Pleistoceno (Haffer, 1974; Haffer \& Prance, 2001) ou apenas representar um gradiente de adaptação às condições ambientais.

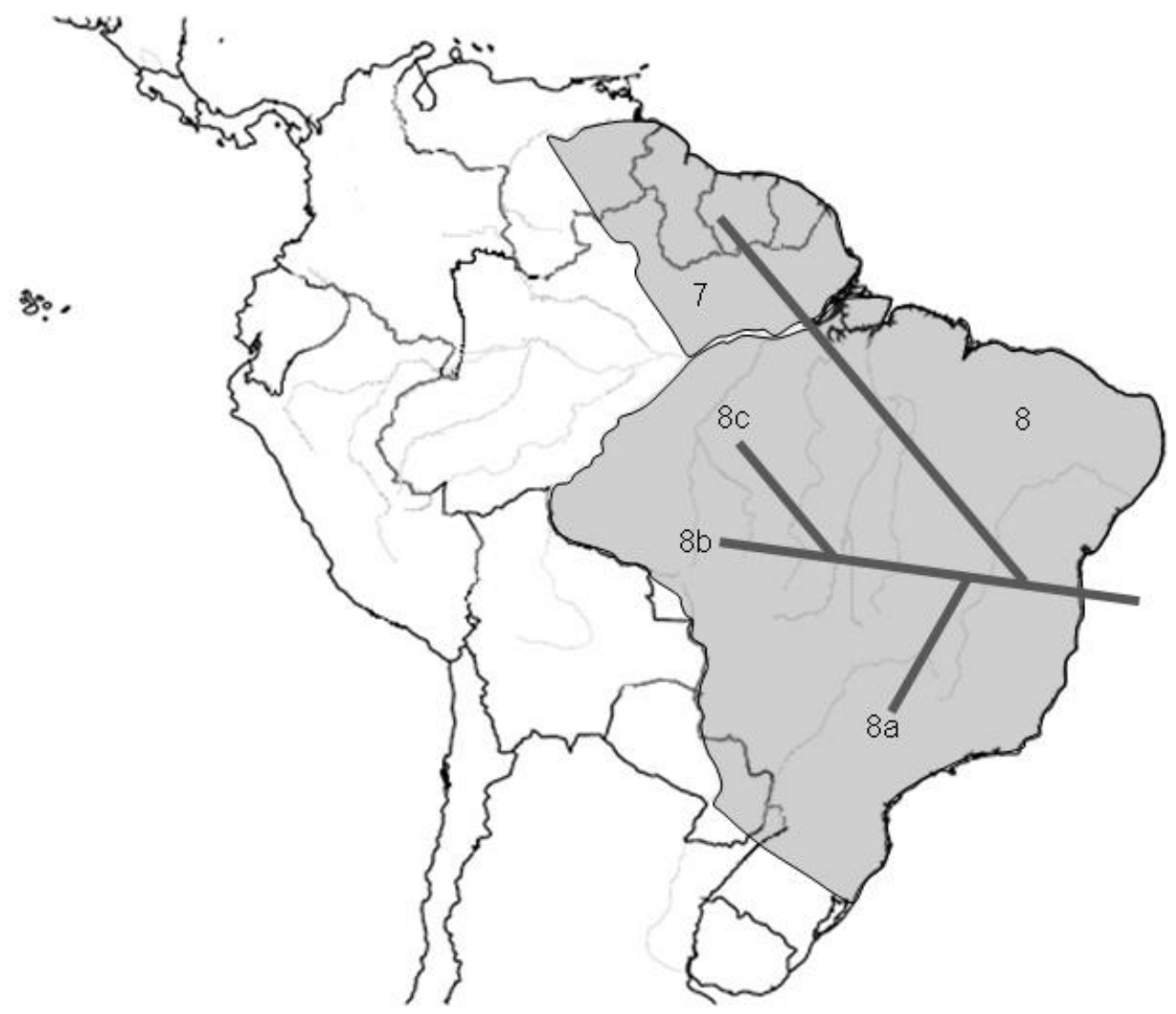

Figura 5 - Distribuição das espécies da Linhagem Leste Amazônica: Penelope marail (7); e, Penelope superciliaris (8) com subespécies bronzina (8a), ochromitra (8b) e superciliaris (8c). Mapa e distribuições modificados de Delacour e Amadon (1973). 
A Linhagem Norte Amazônica (Figura 6) é composta apenas por Penelope argyrotis, com distribuição na região norte da Amazônia em altitudes entre 900 e 2400 metros.

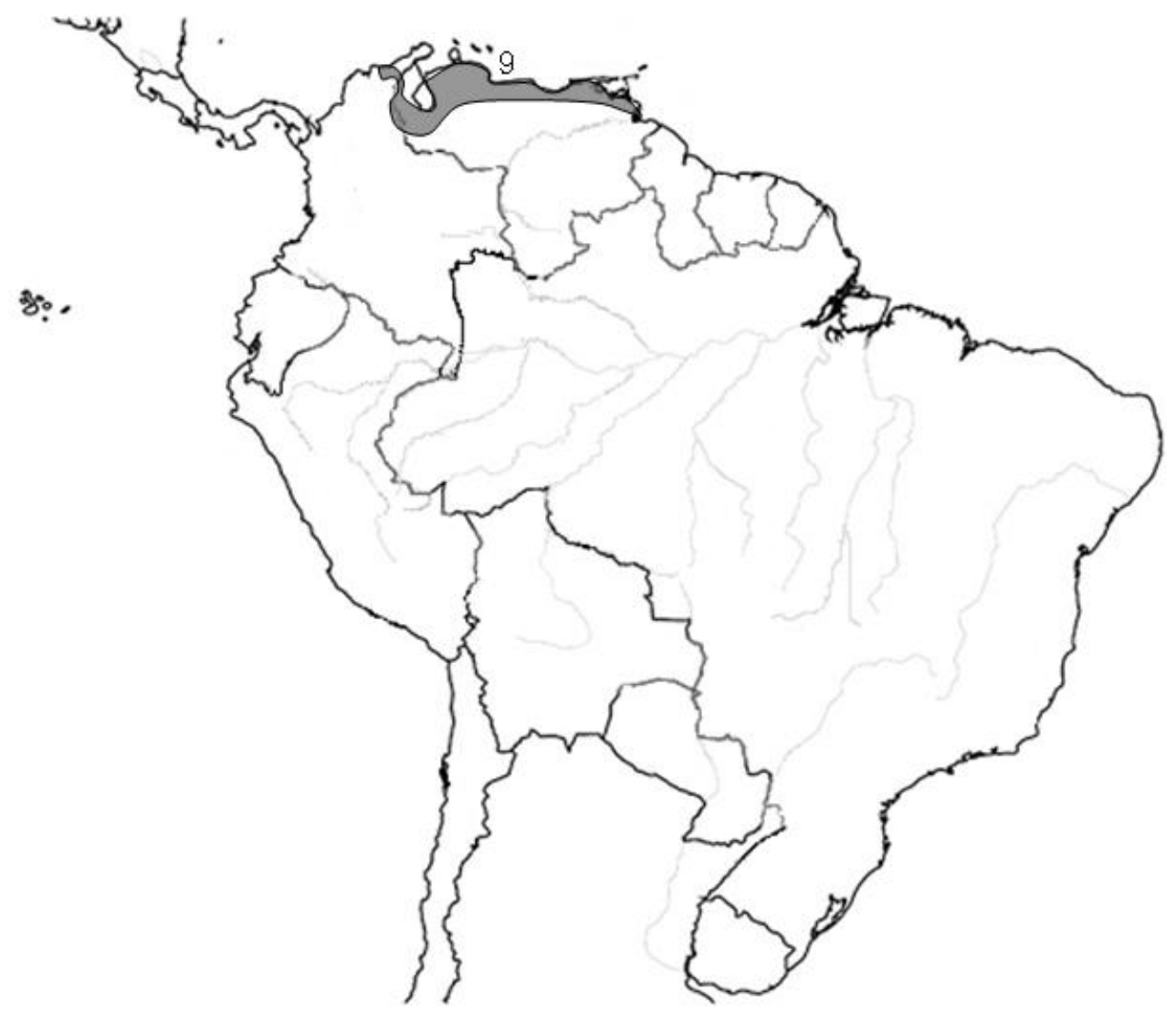

Figura 6 - Distribuição das espécies da Linhagem Norte Amazônica: Penelope argyrotis (9). Mapa e distribuição modificados de Delacour e Amadon (1973).

A Linhagem Atlântica (Figura 7) é composta por seis táxons. Foi estimada em, aproximadamente, 3 Ma a diversificação que promoveu a formação de quatro clados (Penelope obscura, Penelope bridgesi, Penelope jacupemba e jacus vermelhos). Vaurie (1968) sugere que uma modificação secundária na distribuição entre Penelope bridgesi e Penelope obscura, decorrente do aumento da aridez do Chaco, isolou a forma ancestral em duas populações. Alternativamente o isolamento poderia ter sido influenciado pelo alagamento das bacias do Prata e do Paraná durante transgressões 
marinhas, já que há 2,5 Ma o nível do mar atingiu 180 metros acima do nível atual (Klammer, 1984). A diversificação dos jacus vermelhos foi estimada em, aproximadamente, 0,5 Ma podendo ter sido influenciada pelas expansões e retrações da Mata Atlântica e da Floresta Amazônica decorrentes das oscilações climáticas dos períodos glaciais-interglaciais, com as populações ampliando a distribuição em períodos interglaciais e reduzindo a distribuição e fragmentando nos períodos glaciais. Penelope jacucaca como grupo-irmão de Penelope pileata revela uma possível invasão de um táxon da Mata Atlântica na Amazônica em concordância com o corredor norte proposto por Por (1992) em Costa (2003).

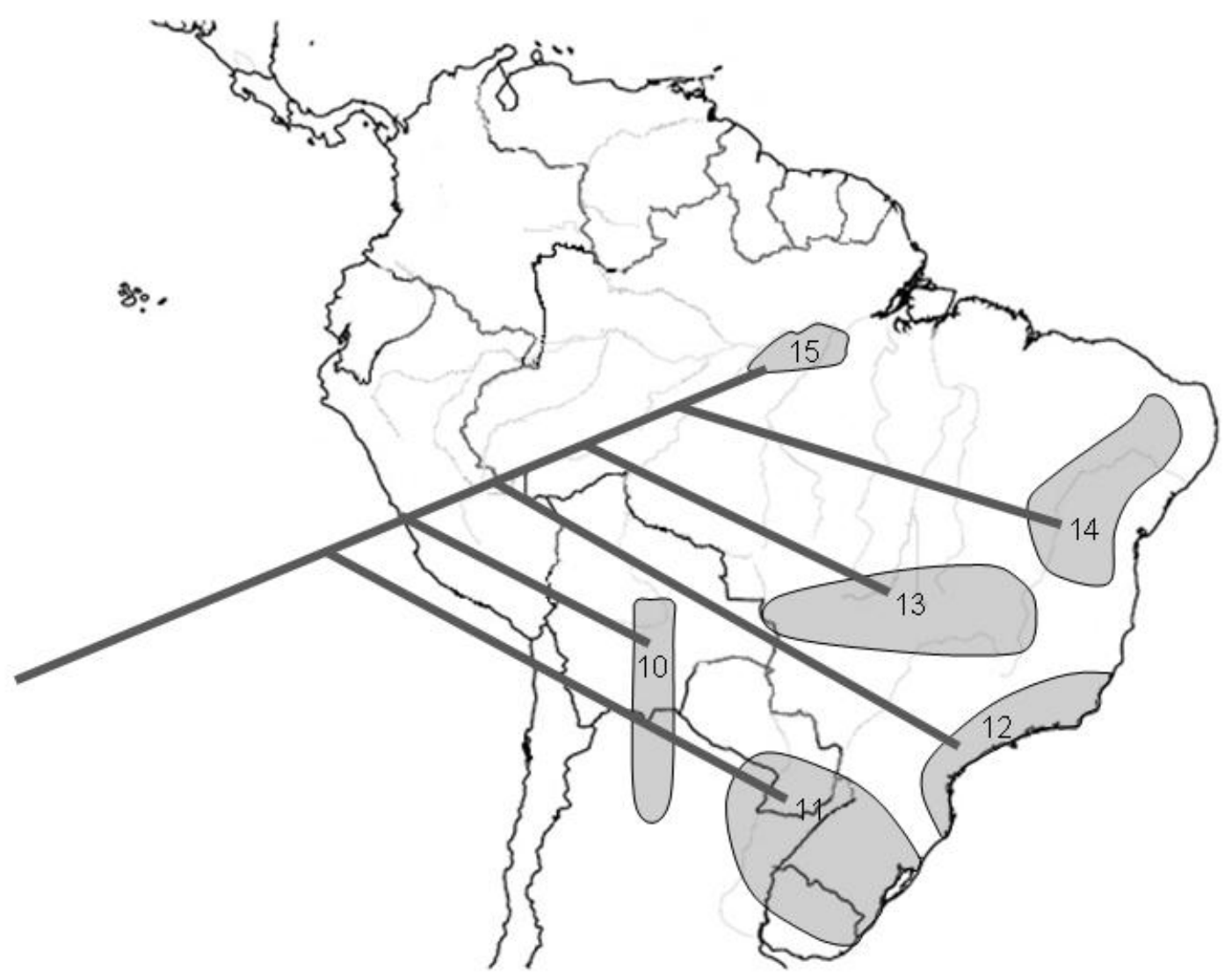

Figura 7 - Distribuição das espécies da Linhagem Atlântica: Penelope bridgesi (10); Penelope obscura (11); Penelope bronzina (12); Penelope ochrogaster (13); Penelope pileata (14); e, Penelope jacucaca (15). Mapa e distribuições modificados de Delacour e Amadon (1973). 
Delacour e Amadon (1978) sugerem que os jacus verdadeiros podem ocorrer em simpatria, situação que não é comum em cracídeos, e que nestes casos ocupariam microhábitats distintos dentro de uma mesma distribuição. $\mathrm{Na}$ figura 8 são apresentadas as distribuições das espécies estudadas, seguindo Delacour e Amadon (1973), e os possíveis pontos de ocorrência de simpatria. Em "A" a espécies ocorrem em altitudes e tipos de habitat diferentes e parece não haver ocorrência de simpatria. Nos demais casos, de $\mathrm{B}$ a H, há sobreposição das distribuições da Linhagem Leste Amazônica com várias outras espécies. Nossos resultados sugerem que as espécies que ocorrem em simpatria não são espécies-irmãs e apresenta vários gruposirmãos com distribuição lado-a-lado separados por barreira geográfica, como por exemplo: Penelope marail e Penelope superciliaris, separadas pelo rio amazonas; e, (Penelope jacquacu+Penelope dabbenei) e Penelope albipennis, separadas pelos Andes o mesmo ocorrendo entre Penelope barbata e Penelope montagnii. As espécies que em ocorrem altas altitudes não formaram um grupo monofilético, normalmente estão relacionadas a espécies de terras baixas. 


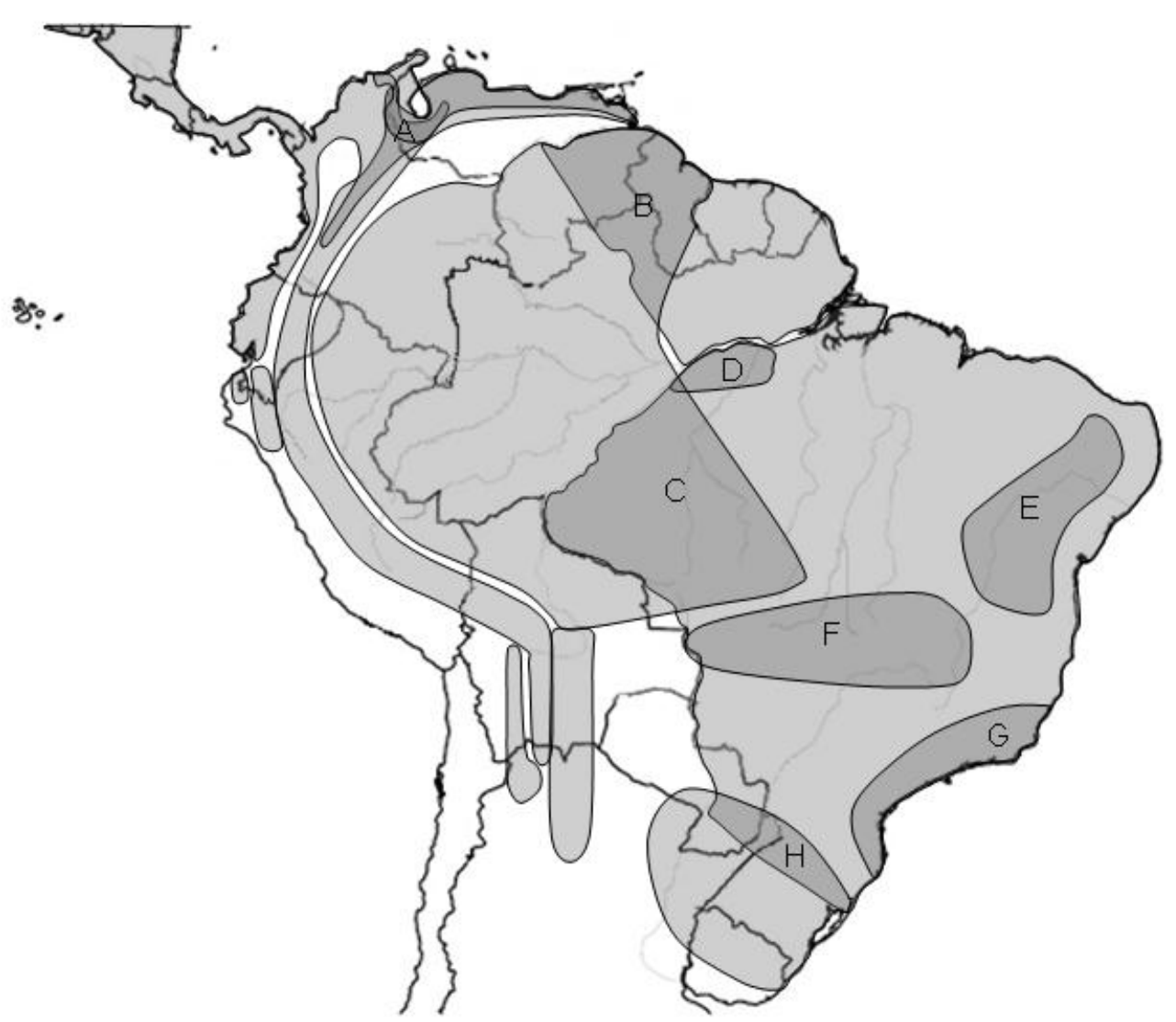

Figura 8 - Distribuição das espécies estudadas. Simpatria de Penelope argyrotis, Penelope purpuracens e Penelope montagnii (A); simpatria de Penelope Marail com Penelope jacquacu (B); e, simpatria de Penelope superciliaris com Penelope jacquacu (C), com Penelope jacucaca (D), com Penelope pileata (E), com Penelope ochrogaster (F), com Penelope jacupemba (G) e com Penelope obscura (H). Mapa e distribuições modificados de Delacour e Amadon (1973).

Nossos dados sugerem que a diversificação entre os Jacus teve início no final do Mioceno e se estendeu ao longo do Plioceno e do Pleistoceno. As poucas linhagens cuja separação ocorreu mais recentemente, durante o Quaternário, possivelmente ainda não acumularam diferenças significantes e nossa tendência é de que sejam melhor estudados para verificar se devem ser consideradas como espécies ou subespécies. Foi possível constatar, em diversos casos, que alguns táxons estavam mais proximamente relacionados a táxons que ocupavam o lado oposto de uma suposta barreira do que a táxons que ocupavam o mesmo lado. Padrões vicariantes de diversificação 
em Penelope parecem ser comuns. A influência das transgressões marinhas e do soerguimento dos Andes e suas conseqüências, incluindo as subseqüentes mudanças nos rios da América do Sul, e especializações de hábitat parecem ter afetado a diversificação de Penelope. O padrão espacial e temporal de evolução é semelhante ao encontrado para outros cracídeos. Este padrão foi encontrado em outros grupos de aves (e.g Ribas et al., 2007; Moyle, 2005), em macacos (Collins \& Dubach, 2001; Cortes-Ortiz et al., 2003) e em roedores (Galewski et al., 2005; Salazar-Bravo et al., 2001). 


\section{Conclusões}

\section{1) Filogenia: Revisão Taxonômica dos Jacus e Jacutingas}

Revisamos as relações filogenéticas e o status de táxons dos gêneros Aburria, Penelope e Pipile, englobando aproximadamente $40 \%$ das espécies de Cracidae.

1.1) Os estudos filogenéticos das espécies de Aburria e Pipile, indicam que Pipile é um gênero parafilético (Figura 3). Assim, sugerimos que as espécies de Pipile Bonaparte, 1856 sejam transferidas para o gênero Aburria Reichenbach, 1853, seguindo-se a regra de prioridade cronológica do Código Internacional de Nomenclatura Zoológica, reconstituindo a monofilia intragenérica.

1.2) Os estudos filogenéticos de Penelope, indicam que o gênero é monofilético e distinto dos demais gêneros de Cracidae (Figura 1). Sugerimos que o status taxonômico de algumas espécies estudadas seja reavaliado e que as subespécies de Penelope obscura sejam consideradas espécies válidas, renomeadas para: Penelope obscura Temminck, 1815, Penelope bridgesi Gray, 1860 e Penelope bronzina Hellmayr, 1914.

1.3) São necessários estudos para níveis taxonômicos subespecíficos para se entender os limites que permitiriam estabelecer com maior clareza o status taxonômico das espécies e subespécies com status questionado. 


\section{2) Biogeografia: Nova Hipótese Evolutiva para Jacus e Jacutingas}

2.1) As datações de divergência indicam que as especiações ocorreram no Plio-Pleistoceno entre as espécies de Aburria (Figura 2) e do final do Mioceno ao Pleistoceno entre as espécies de Penelope (Figura 1). Estas datações de divergência de jacutingas e jacus são concordantes com as de mutuns e outras aves, primatas e roedores com distribuição geográfica equivalente.

2.2) Nossos resultados sugerem que a diversificação de jacus e jacutingas sofreu influência das transgressões marinhas, do soerguimento dos Andes e suas conseqüências, incluindo as mudanças nos rios da América do Sul, da formação da Laguna Amazônica e de especializações de hábitat.

2.3) Espécies com distribuição simpátrica não são espécies-irmãs. Vários grupos-irmão com distribuição lado-a-lado separados por barreira geográfica foram encontrados, evidenciando a influência de eventos vicariantes na diversificação do grupo. Espécies que ocorrem em grandes atitudes não formaram um grupo monofilético.

\section{3) Planos de Ação Conservacionista para Espécies mais Ameaçadas}

3.1) Nossos resultados permitem um melhor entendimento das relações filogenéticas entre os táxons de jacus e jacutingas e a avaliação de status taxonômico, importantes informações para definição de prioridades de conservação e elaboração de planos de manejo.

3.2) Também foi possível identificar fatores que influenciaram nas especiações e avaliar a influência de eventos vicariantes, agregando mais conhecimentos sobre o modo de evolução no grupo o que pode colaborar na proteção de espécies mais fragilizadas por ação antrópica. 

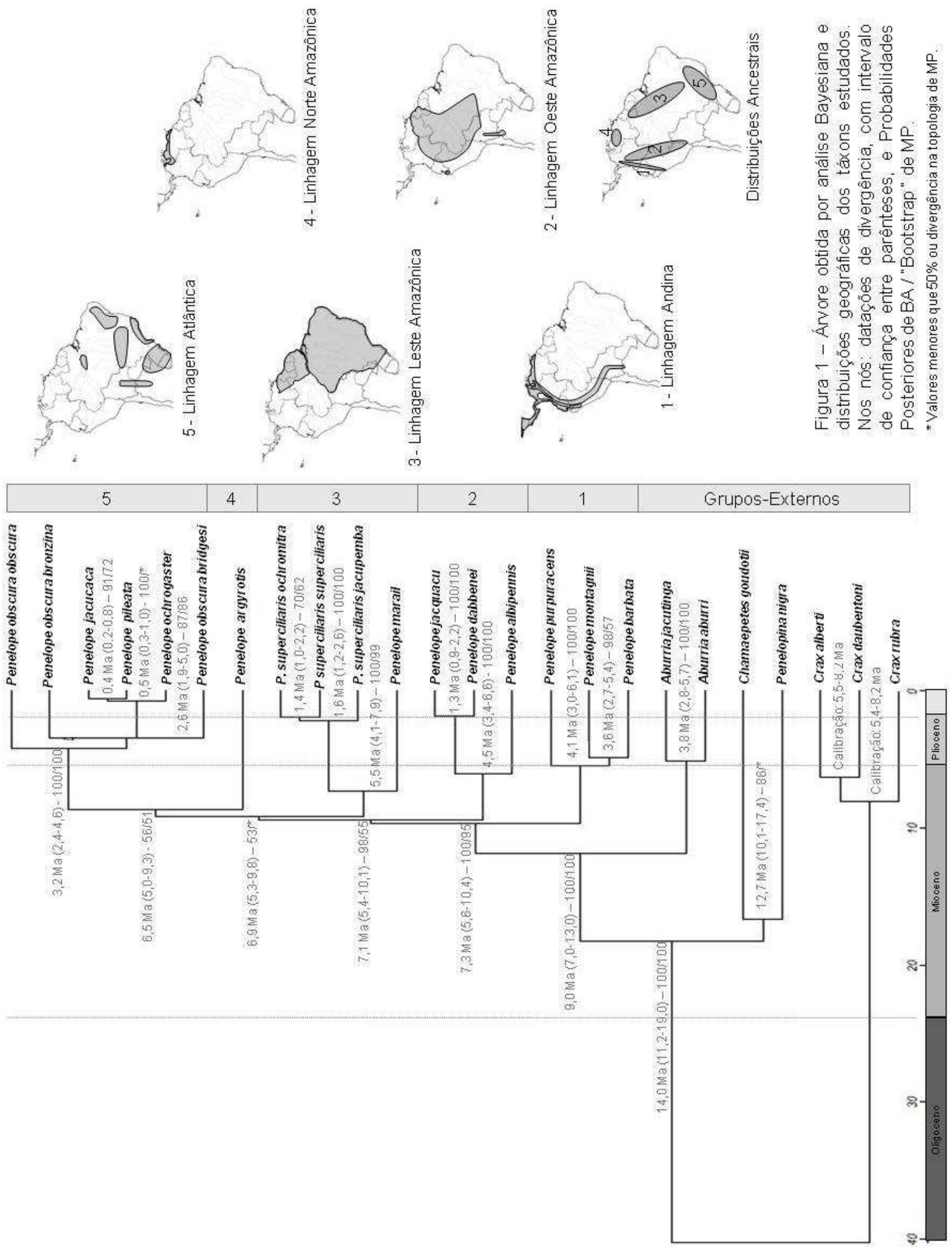


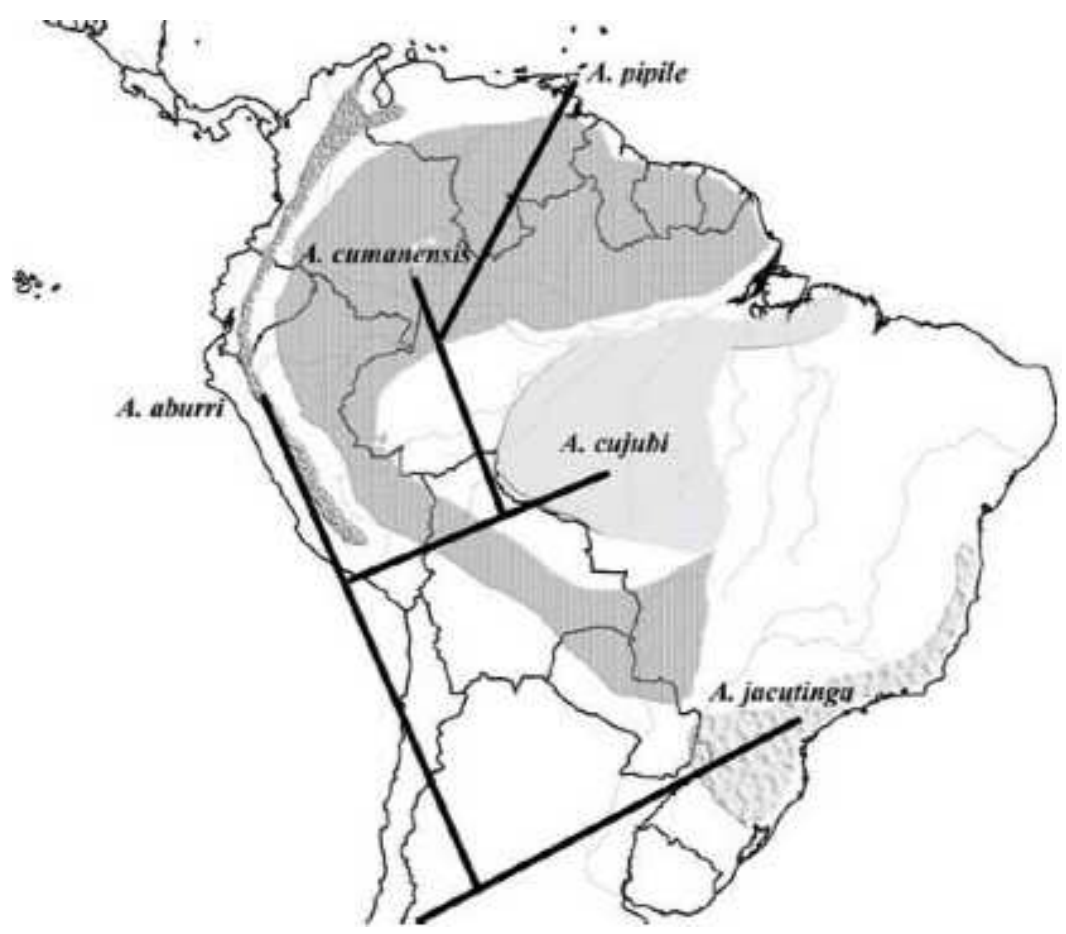

Figura 2 - Distribuição das espécies de Aburria. Distribuição modificada de Delacour e Amadon (1973) e relações filogenéticas estimadas neste trabalho, baseadas em seqüências de DNA mitocondrial.

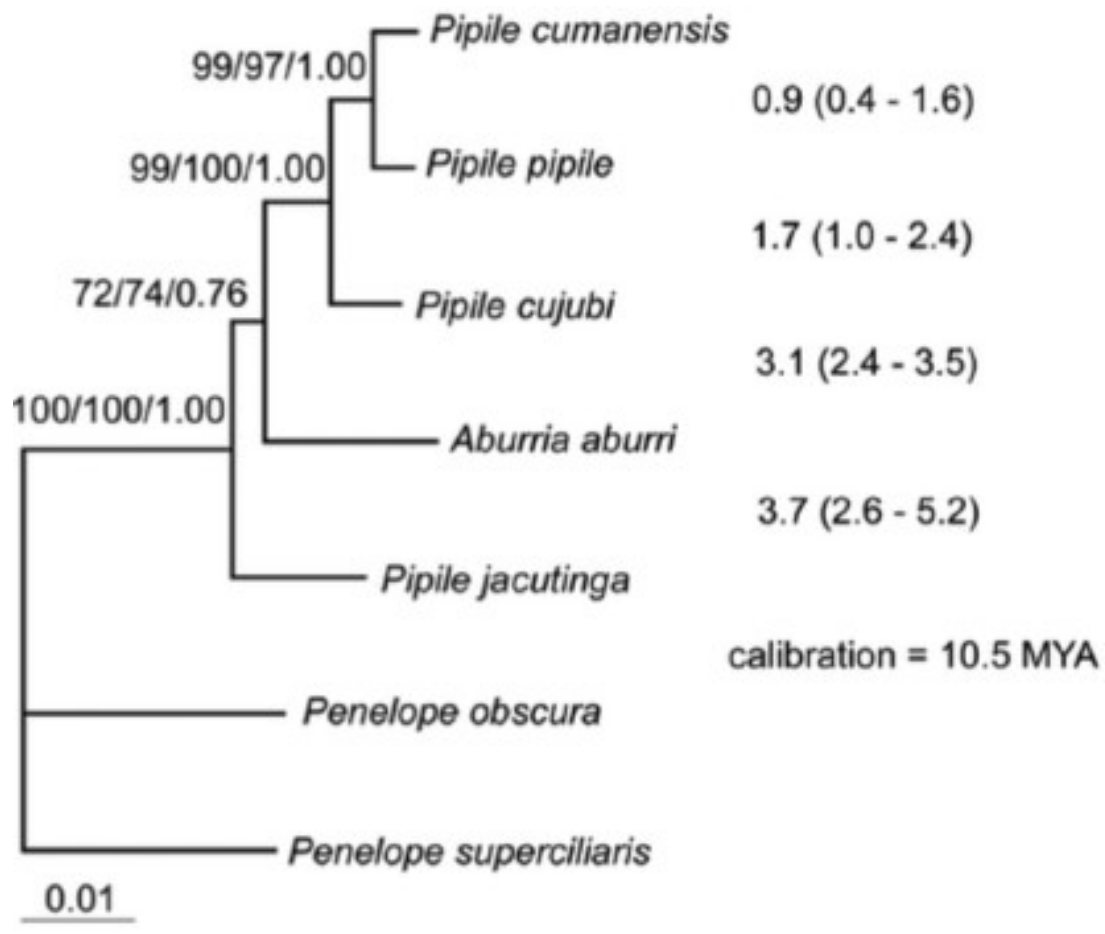

Figura 3 - Topologia obtida por BA com análise combinada das seqüências do cyt $b, \mathrm{ND} 2 \mathrm{e}$ RC. Valores de "bootstrap" para ML e MP e probabilidades posteriores para BA, respectivamente, para cada nó, são apresentadas à esquerda da árvore. Estimativas de tempo de divergência (intervalos de confiança) baseados em verossimilhança com penalidade são apresentadas à direita de cada nó da árvore. 


\section{ANEXO I - Artigo publicado (Capítulo III)}

Grau, E.T., Pereira, L.P., Silveira, L.F., Höfling, E., Wajntal, A., 2005. Molecular Phylogenetics and Biogeography of Neotropical piping guans (Aves: Galliformes): Pipile Bonaparte, 1856 is synonym of Aburria Reichenbach, 1853. Molecular Phylogenetics and Evolution 35, 637-645. 


\title{
Molecular phylogenetics and biogeography of Neotropical piping guans (Aves: Galliformes): Pipile Bonaparte, 1856 is synonym of Aburria Reichenbach, 1853
}

\author{
Erwin T. Grau ${ }^{\mathrm{a}}$, Sérgio Luiz Pereira ${ }^{\mathrm{a}, \mathrm{b}, *}$, Luís Fábio Silveira ${ }^{\mathrm{c}, \mathrm{d}}$, Elizabeth Höfling ${ }^{\mathrm{c}}$, \\ Anita Wajntal $^{\mathrm{a}}$ \\ ${ }^{a}$ Departamento de Biologia, Universidade de São Paulo, Caixa Postal 11461, CEP 05422-970, São Paulo, Brazil \\ ${ }^{\mathrm{b}}$ Department of Natural History, Royal Ontario Museum, 100 Queen's Park, Toronto, Canada M5S 2C6 \\ ${ }^{\mathrm{c}}$ Departamento de Zoologia, Universidade de São Paulo, Caixa Postal 11461, CEP 05422-970, São Paulo, Brazil \\ ${ }^{\mathrm{d}}$ Museu de Zoologia da Universidade de São Paulo, Caixa Postal 42494, CEP 04218-970, São Paulo, Brazil
}

Received 23 July 2004; revised 1 December 2004

Available online 25 January 2005

\begin{abstract}
The Cracidae are Neotropical galliform birds with 11 genera currently recognized. To investigate the questioned validity of Pipile Bonaparte, 1856 and the monotypic Aburria Reichenbach, 1853 as separate genera, we gathered data from 2727 bp of mitochondrial DNA (cytochrome $b$, ND2 and control region) and 151 osteological characters. Our phylogenetic analyses of DNA sequences indicated that Aburria aburri is embedded within Pipile. Also, genetic distances between Aburria and any Pipile species are equivalent to the distances estimated for other congeneric cracid species, which genus status is not doubtful. Although the osteological characters do not have phylogenetic signal to solve the phylogenetic relationships at species level, five synapomorphies were found for Aburria and Pipile. Therefore, we suggest that Pipile should be merged with Aburria, which is the oldest described genus. We estimated that speciation in this group occurred in the Plio-Pleistocene, concordant with other birds, primates and rodents that have similar geographic distribution, and proposed a diversification hypothesis based on the occurrence of sea transgressions and the formation of the Amazon Lagoon. Therefore, we conclude that these palaeogeographic events may have contributed to Neotropical taxa diversification to a greater extent than previously suspected.
\end{abstract}

(C) 2004 Elsevier Inc. All rights reserved.

Keywords: Aburria; Pipile; Phylogenetic analysis; mtDNA; Osteological characters; Biogeography

\section{Introduction}

The family Cracidae (Aves, Galliformes) includes curassows, guans, and chachalacas, found mainly in the Neotropical region. Most species are restricted to forested areas, and some can be used as bioindicators of habitat quality (Brooks and Strahl, 2000). Due to loss of habitat and extensive hunting, many species and subspe-

\footnotetext{
* Corresponding author. Fax: +1 4165865553.

E-mail address: sergio.pereira@utoronto.ca (S.L. Pereira).
}

cies are threatened, and one is considered extinct in the wild (BirdLife International, 2004; Silveira et al., 2003). Currently, 11 genera, 50 species, and over 60 subspecies are recognized in this family that still has taxonomic problems, especially at and below species level (Brooks and Strahl, 2000; del Hoyo et al., 1994). Efforts to understand their evolutionary history are underway. For example, the sister relationship of Cracidae to Phasianidae (latu sensu) is now well corroborated by molecular and morphological data (Dimcheff et al., 2002; Dyke et al., 2003; Silveira, 2003) and phylogenetic relationships at the genus level have been proposed recently using nuclear 
and mitochondrial DNA sequences (Pereira et al., 2002) and osteological characters (Silveira, 2003). Although there is incongruence between the molecular and osteological hypotheses, all genera seem to be monophyletic (Silveira, 2003), and a new focus at lower taxonomic categories raise as an important line of research.

The piping guans (Aburria and Pipile) are a group that deserves further study to check the validity of their current status as separate genera. All Pipile species represent a morphologically well-defined group. Despite Vuilleumier's (1965) proposal, which merged this genus in Penelope, most authors (e.g., del Hoyo et al., 1994; Sick, 1993; Strahl and Schmitz, 1997; Vaurie, 1968) prefer to keep this genus as distinct amongst the Cracidae. Another notable exception is found in Delacour and Amadon (1973) which, based on characters of plumage and bare parts, merged Pipile into Aburria. Nuclear and mitochondrial DNA sequences indicate a very close relationship between Pipile and Aburria and no evidence to merge them with Penelope (Pereira et al., 2002), and osteological data corroborate the suggestion of Delacour and Amadon (Silveira, 2003). The divergence time estimated for Aburria and Pipile based on nuclear and mitochondrial DNA sequence data was around 3.8 MYA (million years ago), well below the range of 8-10 MYA among genera of curassows or 10-18 MYA among other genera of guans (Pereira et al., 2002). Also, this divergence time is within the range estimated for species of curassows within Crax and within Mitu based on mitochondrial DNA sequences (Pereira and Baker, 2004a).
The genus Aburria, as currently accepted, is monotypic (Aburria aburri). This species is found in W Venezuela and $\mathrm{N}$ Colombia, E and $\mathrm{W}$ Ecuador and S and SC Peru, occurring primarily in wet mountain forests, in altitudes from 500 to $2500 \mathrm{~m}$ above sea-level (del Hoyo et al., 1994; Ridgely and Greenfield, 2001). Contrastingly, all six currently accepted forms of Pipile (sensu del Hoyo et al., 1994) are mostly found in forests east of the Andes all over South America (and Trinidad) except in Chile and Uruguay (Fig. 1).

The taxonomy of the species of Pipile has been controversial and problematic, and there is a persistent disagreement among authors regarding the number of species, which varies from two (Delacour and Amadon, 1973; Sick, 1993; Vuilleumier, 1965) to four (del Hoyo et al., 1994; Strahl and Schmitz, 1997). There is also a disagreement regarding the existence and the number of subspecies. It is clear that we have a long way to go to have a better understanding of the diversity of the Amazonian piping guans, but in this paper we followed del Hoyo et al. (1994) who recognized four species of Pipile: Pipile cujubi, Pipile cumanensis, Pipile jacutinga, and Pipile pipile.

Amongst the species of Pipile considered here, only $P$. jacuting $a$ and $P$. pipile are monotypic. $P$. pipile (Trinidad Piping-guan) is restricted to Trinidad, while $P$. jacutinga (Black-fronted Piping-guan) is found in the forests of E and S Brazil, NE Argentina, and SE Paraguay. The Blue-throated Piping-guan ( $P$. cumanensis) has two subspecies recognized: Pipile cumanensis

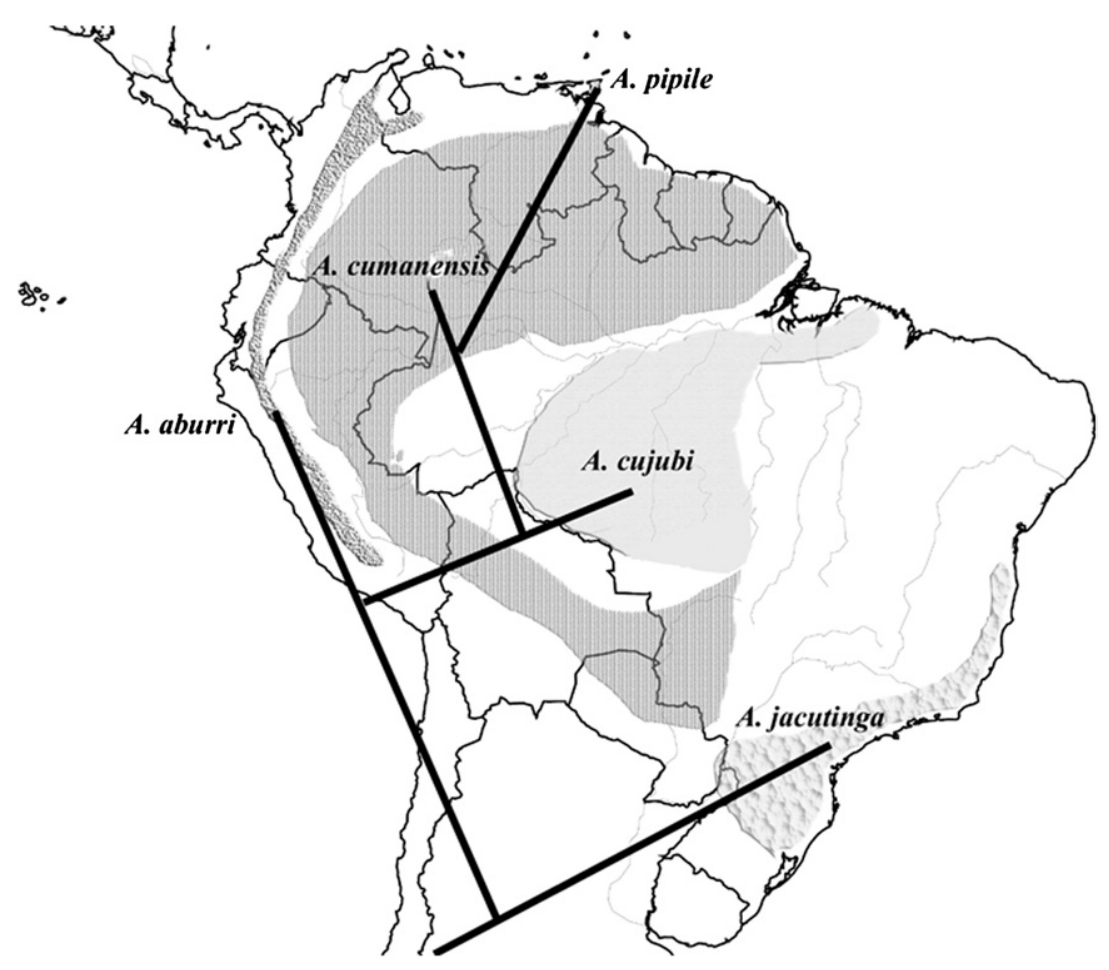

Fig. 1. Phylogeographic distribution of Aburria spp. Modified from Delacour and Amadon (1973) and phylogenetic relationships as estimated in the present study based on mitochondrial DNA sequences. 
cumanensis largely distributed in French Guyana, Guyana, Suriname, Venezuela, NW Brazil and in the lowlands of C and E Colombia, E Ecuador and E Peru, and Pipile cumanensis grayi with a more limited distribution in SE Peru, NC Bolivia, SW Brazil, and NE Paraguay. This species is replaced in the Brazilian Amazon south of the Amazon river by the Red-throated Piping-guan $(P$. cujubi), also with two subspecies recognized: Pipile cujubi cujubi, which can be found from the lower Madeira river to N Pará state and Pipile cujubi nattereri, which inhabits the forests in W Brazil (del Hoyo et al., 1994).

Therefore, in this paper we investigated relationships among piping guans (Aburria and Pipile genera) based on mitochondrial DNA sequences and morphological characters to assess their status as distinct genera. We also estimated divergence time for this group and propose a phylogeographic hypothesis for their evolution.

\section{Materials and Methods}

\subsection{Molecular data}

\subsubsection{Taxa sampling}

Approximately $0.1 \mathrm{ml}$ of blood was taken by venipuncture from seven Cracidae species (Table 1) and kept in $0.5 \mathrm{ml}$ of absolute ethanol at room temperature. All sampled birds are kept in captivity by private conservationist or zoological gardens in Latin America. Samples are deposited at the Laboratório de Genética e Evolução Molecular de Aves, Instituto de Biociências, of the Universidade de São Paulo, Brazil.

\subsubsection{DNA amplification sequencing, and alignment}

Some cytochrome (cyt) $b$ and subunit 2 of NADH dehydrogenase (ND2) sequences used here were obtained previously by Pereira et al. (2002) and are indicated in Table 1 . For cyt $b, \mathrm{ND} 2$ and control region (CR) sequences obtained for this study, amplification, sequencing, and sequence alignment were performed as described in Grau et al. (2003). Primers used for PCR amplification are described in Grau et al. (2003) and Pereira and Baker (2004a).

\subsubsection{Distances and saturation}

Tamura-Nei distances assuming $\gamma$-distributed rates of DNA substitution $(\mathrm{TN}+\mathrm{G})$ was chosen as the best model of DNA substitution for the concatenated data set and the ND2 sequences according to a likelihood ratio test as implemented in MODELTEST 3.0 (Posada and Crandall, 1998). For control region and cyt $b$, the best model chosen was the Hasegawa-Kishino-Yano, also assuming $\gamma$ distribution for rate variation across sites $(\mathrm{HKY}+\mathrm{G})$. For each gene and the concatenated data set, pairwise uncorrected ( $p$-distances) and corrected distances were estimated among all seven species studied using Mega 2.0 (Kumar et al., 2001) and plotted against each other to check for saturation.

\subsubsection{Phylogenetic analysis}

Phylogenetic reconstructions were performed with $P$. cujubi, $P$. cumanensis, $P$. jacutinga, $P$. pipile, and $A$. aburri as the ingroup and Penelope obscura and Penelope superciliaris as outgroup. Homogeneity of base composition using variable sites only was tested in TREEPUZZLE 5.0 (Strimmer and von Haeseler, 1996) prior to phylogenetic inference. PAUP 4.0 b10 (Swofford, 2001) was used for the phylogenetic reconstructions. A Maximum Parsimony (MP) tree was obtained with an exhaustive search. Maximum Likelihood (ML) tree was estimated using an exhaustive search under the model of DNA evolution selected by data analysis with MODELTEST 3.0 (Posada and Crandall, 1998). Branch support was estimated by bootstrapping of 100 replicates of 10 random sequence additions for both MP and ML analysis. Bayesian analysis (BA) with Markov chain Monte Carlo (MCMC) sampling was performed using partitioned likelihood (Lee and Hugall, 2003) in MrBayes 3.0 (Ronquist and Huelsenbeck, 2003). The substitution model chosen for ML analysis for each gene partition

Table 1

Species sequences used in the present study with their respective voucher number and GenBank accession numbers for the control region (CR), cytochrome $b$ (cyt $b$ ) and NADH reductase (ND2)

\begin{tabular}{|c|c|c|c|c|c|c|}
\hline & Voucher & Aviary & Origin & CR & ND2 & Cyt $b$ \\
\hline Aburria aburri & $\mathrm{C} 172 / \mathrm{C} 173$ & Tropicus & Unknown & AF165430 & AY140740* & AF165466* \\
\hline Pipile cujubi cujubi & $\mathrm{C} 156$ & Collected by R. Antonelli & Jacareacanga, Pará & AY145314 & $\begin{array}{l}\text { AY367098 } \\
\text { AY367092 }\end{array}$ & AY367104 \\
\hline Pipile cumanensis cumanensis & $\mathrm{C} 164$ & $\begin{array}{l}\text { Criadouro Conservacionista } \\
\text { e Cultural Pocos de Caldas }\end{array}$ & Boa Vista, Roraima & AY145319 & $\begin{array}{l}\text { AY367099 } \\
\text { AY367093 }\end{array}$ & AY367105 \\
\hline Pipile jacutinga & $\mathrm{C} 100$ & CESP-Paraibuna & Unknown & AF165431 & AY140744* & AF $165476^{*}$ \\
\hline Pipile pipile & $\mathrm{C} 264$ & Granja La Siberia & Trinidad & AY145320 & $\begin{array}{l}\text { AY367100 } \\
\text { AY367094 }\end{array}$ & AY367106 \\
\hline Penelope obscura & $\mathrm{C} 28 / \mathrm{C} 150$ & CESP-Paraibuna & Paraibuna, São Paulo & AF165432 & AY $140742^{*}$ & AF165474* \\
\hline Penelope superciliaris & $\mathrm{C} 084$ & CESP-Paraibuna & Paraibuna, São Paulo & AY145313 & $\begin{array}{l}\text { AY367096 } \\
\text { AY367090 }\end{array}$ & AY367102 \\
\hline
\end{tabular}

Sequences previously published are indicated as * (Pereira et al., 2002). 
was defined in the Bayesian analysis. We set up three independent runs for three million generations each, with one cold and three heated chains and a burn-in time determined by the time to convergence of the likelihood scores. One tree was sampled in every thousand.

\subsubsection{Molecular dating of divergence time}

Branch lengths for the ML tree were re-estimated while enforcing a molecular clock using PAUP 4.0 b10 (Swofford, 2001). Twice the difference between the likelihoods of ML and the clock ML trees were compared to a $\chi^{2}$ distribution and estimates of divergence time were obtained. The program r8s version 1.6 (Sanderson, 2003) was used to estimate divergence times and confidence intervals. The approach chosen was a semi-parametric penalized likelihood (Sanderson, 2002) that allows rates of evolution to vary across lineages, but a penalty is applied to minimize changes of rates between a node and its descendants through a smoothing parameter. The smaller the smoothing parameter, the more rate variation is observed in the data set. A data-driven cross-validation test was applied to choose the best smoothing parameter (Sanderson, 2002). This procedure prunes lineages from the tree, estimates a smoothing parameter for the remaining lineages and repeatedly tries to predict the smoothing parameter for the pruned lineages until a best smoothing parameter is found (Sanderson, 2002). We assumed the outgroup (Penelope) to have split from the ingroup 10.5 million years ago (MYA; 95\% credible interval 8.8-12.3 MYA), according to the estimates obtained by Pereira et al. (2002) using a large data set including mitochondrial and nuclear DNA sequences. Unfortunately, no non-molecular calibration point, such as a geological one used in Pereira and Baker (2004a), is available to check for the independence of our estimates. However, we are confident that we are using a good calibration point because the divergence dates and associated credibility intervals obtained within curassows (Pereira and Baker, 2004a) were very similar whether a molecular or a independent geological anchor point was used, providing some evidence that the estimates of Pereira et al. (2002) may be appropriate as secondary molecular anchor-points when no other data are available.

\subsection{Morphological data}

\subsubsection{Taxa sampling}

We used 28 skeletons belonging to all recognized species of Pipile and A. aburri, and 17 skeletons of two species of Penelope (P. obscura and P. superciliaris). These data were previously obtained for a larger study of the family Cracidae (Silveira, 2003). The list of all specimens is provided in Appendix A. The complete morphological study of the phylogenetic relationships of the Cracidae will be published elsewhere (Silveira and Höfling, in prep.). Our goal was to gather independent evidence to check the validation of Aburria and Pipile as separate genera and check the usefulness of these characters for inference of phylogeny at species level.

\section{Results}

\subsection{Molecular data}

\subsubsection{DNA amplification and sequencing}

We are confident that our sequences are mitochondrial in origin because (1) A. aburri sequences were obtained in another study using nested amplifications from a large amplification of $3 \mathrm{~kb}$ (Pereira et al., 2004), (2) only single PCR products were obtained and sequenced, and (3) the sequences for Pipile and Penelope species did not have unusual features typical of pseudogenes and were similar to those obtained for $A$. aburri. Moreover, chicken and other eukaryotic genomes sequenced to date do not seem to have a high number of mitochondrial pseudogenes larger than $1 \mathrm{~kb}$ inserted in the nuclear genome compared to human and plant genomes (Pereira and Baker, 2004b; Richly and Leister, 2004). Therefore, if this is a characteristic of avian genomes, mitochondrial pseudogenes will only rarely be amplified. Also, all sequences obtained had similarity to corresponding sequences of other cracid birds deposited in GenBank, and prediction of amino acid sequences for cyt $b$ and ND2 was as expected and the $\mathrm{CR}$ had conserved blocks as found in other cracids (Pereira et al., 2004). The final concatenated data set consisted of $2727 \mathrm{bp}$ (699 bp of cyt $b, 895 \mathrm{bp}$ of ND2, and the complete CR (1133bp)). GenBank accession numbers are listed in Table 1.

\subsubsection{Distances and saturation}

Pairwise $p$ - and TN $+\mathrm{G}$ distances among species studied are listed in Table 2. The sequences compared here did not show any evidence of saturation of DNA substitution (not shown). We then compared congeneric species to check the magnitude of the pairwise distances among genera. $\mathrm{TN}+\mathrm{G}$ distances ranged from 0.7 to $2.9 \%$ with a mean of $2.2 \%$ for the Pipile-Aburria group. These estimates are in the range for accepted species of guans of the genus Penelope (4.4\%; Table 2), and corresponding cyt $b$ and CR fragments of curassows of the genera Crax and Mitu (1.3-3.0\% estimated by Grau et al., 2003).

\subsubsection{Phylogenetic analysis}

Base composition among taxa is homogeneous $(P$ from 0.87 to 0.97 for ingroup, and $P=0.69$ for outgroup). The trees estimated by ML, MP, and BA resulted in the same topology, suggesting that $P$. jacutinga is a sistergroup of a clade containing $A$. aburri plus the other Pipile species. Nodal support was high in all analyses, except for the sister relationship between $A$. aburri and the other Pipile species, in exclusion of $P$. jacutinga (Fig. 2). BA 
Table 2

Pairwise uncorrected $p$-distances and $\mathrm{TN}+\mathrm{G}$ distances, above and below diagonal, respectively

\begin{tabular}{llllllll}
\hline & Aburria aburri & Pipile cujubi & Pipile cumanensis & Pipile jacutinga & Pipile pipile & Penelope obscura & Penelope superciliaris \\
\hline Aburria aburri & - & 0.024 & 0.025 & 0.026 & 0.024 & 0.044 & 0.042 \\
Pipile cujubi & 0.027 & - & 0.012 & 0.023 & 0.012 & 0.043 & 0.045 \\
Pipile cumanensis & 0.028 & 0.013 & - & 0.022 & 0.007 & 0.044 & 0.045 \\
Pipile jacutinga & 0.029 & 0.025 & 0.025 & - & 0.022 & 0.043 & 0.041 \\
Pipile pipile & 0.027 & 0.013 & 0.007 & 0.024 & - & 0.046 & 0.045 \\
Penelope obscura & 0.053 & 0.053 & 0.054 & 0.052 & 0.056 & - & 0.037 \\
Penelope superciliaris & 0.050 & 0.055 & 0.054 & 0.049 & 0.055 & 0.044 & - \\
\hline
\end{tabular}

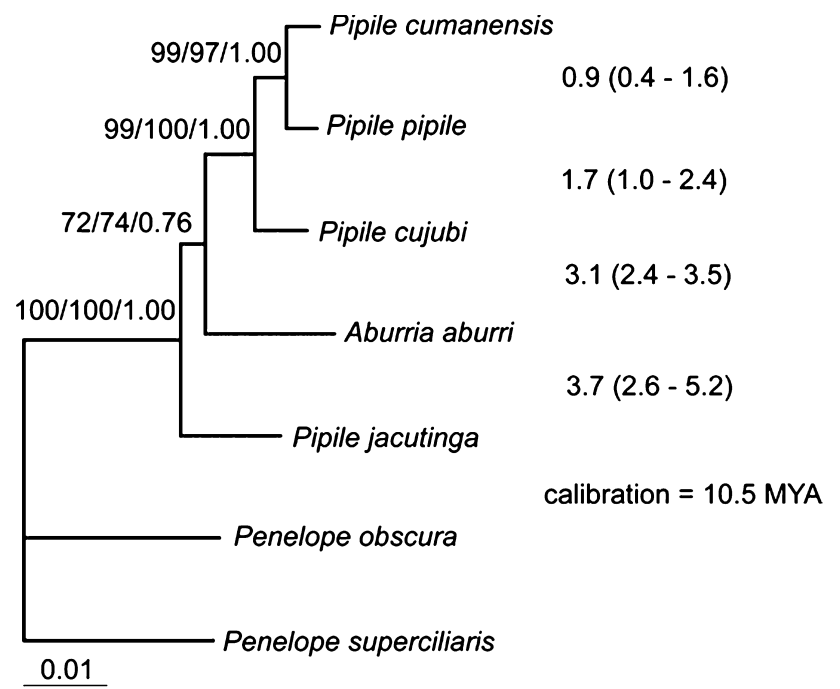

Fig. 2. Bayesian tree topology obtained from the combined analysis of $\mathrm{CR}$, cyt $b$, and ND2 sequences. Bootstrap values obtained for MP and $\mathrm{ML}$ and posterior probabilities from BA for each node are indicated to the left of the tree. Estimates of divergence times (confidence intervals) based on a penalized likelihood approach are also shown to the far right of each node.

recovered only three alternative topologies: (1) one corresponding to our ML/MP/BA topology with posterior probability of 0.76 ; (2) a tree where Aburria was sister to all Pipile with posterior probability of 0.23 ; and (3) a tree where Aburria and P. jacutinga were sister species in exclusion to all other Pipile species, with posterior probability of 0.01 . To further evaluate the three different topologies recovered in the $\mathrm{BA}$, we performed the approximately unbiased (AU) test of Shimodaira (2002) as implemented in CONSEL version 0.1f (Shimodaira and Hasegawa, 2001). The $p$ values for trees 1, 2, and 3 above were $0.710,0.322$, and 0.009 , respectively. Posterior probabilities estimated in this program were 0.984 for our ML/MP/BA tree, 0.016 for Pipile being monophyletic, and virtually zero for the tree where $P$. jacutinga and $A$. aburri were a sister clade to the other species of Pipile.

\subsubsection{Molecular dating of divergence time}

Our results show that there is enough rate variation in DNA substitution among taxa to reject the assumption that these DNA sequences evolve according to a molecu- lar clock (Ln non-clock: 5157.22691; Ln clock: 5710.82762; difference: $553.6007 ; \chi^{2}=11.07$ at 0.05 level; $\mathrm{df}=5$ ). Therefore, we used a method that relaxes the clock assumption to estimate divergence times. The procedure chosen was the semi-parametric penalized likelihood (Sanderson, 2002), with a smoothing parameter set at 0.16 indicating substantial heterogeneity of rate of evolution among the DNA sequences used. Common ancestry of the Aburria-Pipile group dates to the Pliocene, and the most recent divergence of species occurred in the Pleistocene (Fig. 2). Divergence times and confidence intervals are indicated in Fig. 2.

\subsection{Morphological data}

\subsubsection{Osteology}

Although osteological data, as frequently observed, did not show any variation to establish the phylogenetic relationships of $A$. aburri and the four Pipile species, five unambiguous synapomorphies supported our assumption that Aburria and Pipile should be merged in one genus: the presence, in the skull, of a mediocaudal process in the nasolacrimal duct, a conspicuous crest caudally to the auditory chamber, associated with a pair of pits and a narrow choanal fossa of the palatines. In the ulnae, all species have a well-developed impressio brachialis.

\section{Discussion}

Our molecular and morphological data provided complementary data on the taxonomic status of Pipile and Aburria. Morphological data revealed the presence of five synapomorphies defining Aburria and Pipile as a distinct group within Cracidae, rejecting the inclusion of both genera in Penelope as suggested by Vuilleumier (1965). These morphological characters have been used to infer the phylogenetic relationships within Cracid genera (Silveira, 2003), and did not provide any further resolution for the phylogenetic relationships within piping-guans. Osteological data have proved to be noninformative below generic level in this clade. The DNA sequences indicated that $A$. aburri has a more recent common ancestry with ( $P$. cujubi, ( $P$. cumanensis, $P$. pipile)) but excluding $P$. jacutinga. Low nodal support 
obtained from the phylogenetic analyses performed for the sister relationships of $A$. aburri with other Pipile species may reflect nearly simultaneous events of diversification, which prevented that enough DNA substitutions were accumulated to support this association. However, the AU test and posterior probabilities for sampled trees indicated that the tree where A. aburri is embedded within Pipile was the most likely one.

A complementary approach to our phylogenetic analysis is the comparison of genetic distances obtained for piping guans with other similar taxonomic ranks within Cracidae. Similar approaches have been used to check the taxonomic status of a number of genera and species (e.g., Aleixo, 2002; Grau et al., 2003; Zink and BlackwellRago, 2000). Although a general pattern has not been detected among different groups at the same taxonomic level, molecular data can be an important tool in these studies for closely related taxa. The percent sequence divergence between $A$. aburri and species of Pipile approximates that between non-disputed species of guans of the genus Penelope (Table 2), and curassows of the genera Crax and Mitu (Grau et al., 2003). DNA sequences for the CR, cyt $b$, and ND2 have diverged 1.3$3.0 \%$ for congeneric species of Cracidae whose taxonomic status is not questioned. Therefore, we recommend that Aburria and Pipile should be merged in one genus, as proposed two decades ago by Delacour and Amadon (1973) based on plumage, and bare part characters.

Following the rules of chronological priority (Article 23) of the International code of zoological nomenclature (1999, p. 24) the genus Pipile Bonaparte, 1856 should be considered a synonym of Aburria Reichenbach (1853), and all taxa currently allocated in the genus Pipile should then be transferred to the genus Aburria, in agreement with Delacour and Amadon (1973) and Silveira (2003). Thus, following the taxonomy adopted by del Hoyo et al. (1994), the genus Aburria Reichenbach (1853) includes the following species: A. aburri Lesson, 1828; Aburria cujubi Pelzeln, 1858; Aburria cumanensis Jacquin, 1784; Aburria jacutinga Spix, 1825 and Aburria pipile Jacquin, 1784. Hereafter, we use this classification.

\subsection{Biogeography and divergence time}

We estimated that intrageneric diversification in the Aburria clade occurred between 0.4 and 5.2 MYA based on confidence intervals. These dates, which correspond to the Pliocene and Pleistocene, postdate the formation of major topographic features of South America that have been evoked as vicariant agents for the diversification of birds, including cracids (Nores, 2004; Pereira and Baker, 2004a; Pereira et al., 2002). Geological events, such as the uplift of the northern Cordillera of the Andes, formation of the Brazilian and Guyana shields, and current river drainage systems, have already been established at 8MYA (Clapperton, 1993; Lundberg et al., 1998). However, their influence in the formation of present-day South America extended into the following geological periods, and may also have influenced the diversification of flora and fauna, including the pipingguans. Here, we propose a biogeographic hypothesis for speciation of piping-guans based on known events of the geological and geographic history of South America that were consequences of these older changes, as well as other independent events of global influence.

The main paleogeographic events during PliocenePleistocene epochs are related to the Milankovitch cycles, resulting in glaciation and interglaciation periods (Haffer, 1974; Haffer and Prance, 2001; Marroig and Cerqueira, 1997; Nores, 1999). In this context two main hypotheses have been forwarded to explain the richness of species seen in the Neotropical region. One of them, the refuge hypothesis, states that Neotropical forest became fragmented during dry glacial periods and expanded during the humid interglacial climatic conditions. This would isolate populations in pockets of remnant forest, called refuges, and promote differentiation between them and consequently lead to allopatric speciation (Haffer, 1974; Haffer and Prance, 2001). An alternative mechanism of habitat fragmentation and species diversification has been proposed based on evidence of sea transgressions (Nores, 1999) and the formation of the Amazon Lagoon during interglacial epochs (Marroig and Cerqueira, 1997). The existence of an Amazon Lagoon has been suggested previously by several authors (e.g., Guerra, 1956; Haffer, 1974; Irion, 1984; Paula Couto, 1956; Sioli, 1957).

The warm interglacial periods of the Pliocene-Pleistocene have been claimed to cause the elevation of sea level to up to $180 \mathrm{~m}$ above present-day level at around 2.5 MYA (Klammer, 1984). In South America, ancient sea transgressions affected three main areas (Lundberg et al., 1998: (1) the lowlands of Argentina, Uruguay, Paraguay and southern and central Brazil affecting the basins of the La Plata and Paraná rivers, (2) Central Venezuela, Colombia and Northern Peru at the present Orinoco river basin, and (3) the lower basin of the Amazon river in northern South America. Also, for the last two areas, the simultaneous formation of a fresh water lagoon, termed the Amazon Lagoon, may have affected ecosystems in most of the Amazon Forest as the invading waters occupied all lowlands below the sea level. This lagoon resulted from an increased rate of rainfall and melting of Andean glaciers. The total water discharge has been considered as sufficient to prevent the marine transgression at the Amazon delta (Marroig and Cerqueira, 1997). The current distribution of Aburria species together with our estimates of their divergence times suggest that ancestral populations of these birds became isolated and speciated in the elevated areas of the Atlantic Forest in eastern South America (A. jacutinga), in the 
slopes of the Andes (A. aburri), and the Brazilian and Guyana shields (A. cujubi and A. cumanensis, respectively) as a consequence of marine and fresh water invasions of lowlands. This hypothesis is consistent with the biogeographic hypothesis proposed for curassows (Pereira and Baker, 2004a), as Atlantic representatives of two curassow genera and A. jacutinga split from their Amazonian sister species around the same time. The split of A. cujubi and of A. cumanensis and A. Pipile around 2.41.0 MYA is in agreement with the divergence times estimated for the curassow species living in the same areas (Pereira and Baker, 2004a), and corresponds to the estimated time (2.5 MYA) for the maximum sea transgression of $180 \mathrm{~m}$ above sea level (Klammer, 1984).

We also hypothesize that $A$. cumanensis, during the water regression epochs, occupied the lowland territories and that the several glacial/interglacial periods led to the formation of its two subspecies $A$. c. cumanensis and $A$. c. grayi. A similar situation is also proposed for $A$. cujubi, with the ancestral population surviving on the Brazilian Shield, where it likely occupied the gallery forests because a considerable part of the shield has been historically occupied by cerrado (Brazilian savannah) and caatinga, both poor in arboreal covering. $A$. cujubi is today represented by A. c. cujubi and A. c. nattereri occurring preferentially alongside gallery forests. Moreover, the presence of $A$. cumanensis grayi and $A$. cujubi nattereri in the Pantanal, in Mato Grosso state in Brazil, indicate that these species expanded their range as this region is a confluence of different biomes (Amazon forest, cerrado, and marsh). However, $A$. $c$. nattereri occurs in the higher forest areas whereas $A$. $c$. grayi occurs in the cerradão/forest transition (Olmos, 1998).

The recent diversification between $A$. cumanensis and A. pipile (restricted to Trinidad) was estimated between 0.4 and 1.6 MYA. This dating is inconsistent with the estimated age of Trinidad at around 11,000 years (Ffrench et al., 1991). However, as Trinidad is an island of continental origin only $10-15 \mathrm{~km}$ from Venezuela and surrounded by a continental platform less than $200 \mathrm{~m}$ below sea level, dispersal of ancestors of $A$. pipile from the mainland of South America to Trinidad is a plausible hypothesis. During glacial ages Pleistocene sea level regression as low as $180 \mathrm{~m}$ below present-day sea level has been reported (Salgado-Labouriau, 1994), which would make Trinidad continuous with the continental surroundings.

The present physiography of Trinidad is very peculiar: most of its area is constituted by lowlands and low hills. However, in the north, a prolongation of the coastal cordillera of Venezuela, where A. pipile can still be found, are high peaks over $1000 \mathrm{~m}$ and steep slopes without any plateau above $500 \mathrm{~m}$. In the centre of the island there are low hills, all with less than $300 \mathrm{~m}$ with flanks whose height rarely reaches $200 \mathrm{~m}$ (Ffrench et al.,
1991). During the large sea transgressions of the past, most of these areas were under water.

Similar dates of divergence time were estimated for congeneric species of curassows (Pereira and Baker, 2004a), monkeys (Collins and Dubach, 2000; CortésOrtiz et al., 2003) and vesper mice (Salazar-Bravo et al., 2001). These studies have shown a separation of Atlantic taxa from their sister-species occurring either in the Amazon or Pantanal/Chaco regions in the Pliocene. Sea transgressions together with the formation of the Amazon Lagoon and acquisition of present day river basins due to the rising of the Andes have been claimed as possible vicariant events leading to diversification in these groups. Thus, these palaeogeographic events might have contributed to Neotropical taxa diversification to a greater extent than previously suspected, unveiling a common temporal pattern of vicariance for organisms with similar geographic distribution in the Neotropics.

\section{Acknowledgments}

Cracidae blood samples were kindly provided by Moacyr de Carvalho Dias (Criadouro Científico e Cultural Poços de Caldas, Brazil); Vitor Fasano (Criadouro Tropicus); Roberto Antonelli; CESP Paraibuna, São Paulo, Brazil; Katya Frank, and J.J. Estudillo Lopez (Granja La Siberia, Mexico). We also acknowledge the curators and staff of the museums visited by LFS (see Appendix A). Dr. Allan J Baker and Dr. Gabriel Marroig, and two anonymous reviewers provided valuable suggestions on an early draft of this manuscript. This work was supported by Conselho Nacional de Desenvolvimento Científico e Tecnológico, CNPq, and Fundação de Amparo à Pesquisa no Estado de São Paulo, FAPESP, Brazil.

\section{Appendix A. Osteological material}

Material is housed in the following institutions: American Museum of Natural History (AMNH), Louisiana State University, Museum of Zoology (LSUMZ), United States National Museum, Smithsonian Institution (USNM), British Museum, Natural History (Tring-BMNH), Muséum National d'Histoire Naturelle, Paris (MNHN), Naturhistorisches Museum Wien (NMW), Museu Paraense Emílio Goeldi (MPEG), Museu de História Natural de Taubaté (MHNT) and Coleção de Aves of the Departamento de Zoologia, Instituto de Biociências of the Universidade de São Paulo (AZ).

Aburria pipile: AMNH 12817; LSUMZ 60835; and LSUMZ 136473. 
Aburria cumanensis: AMNH 2629; LSUMZ 86447; LSUMZ 148871; LSUMZ 148872; USNM 622219; BMNH 1854.3.29.4; BMNH 1858.5.26.21; BMNH 1869.9.12.22; BMNH 1952.2.; MNHN 1876.839; MPEG 591; USNM 345799; AZ 650; and LSUMZ 136697.

Aburria cujubi: MPEG 666; MPEG 755; MPEG 1323; MPEG 1557; and MPEG 3208.

Aburria jacutinga: BMNH 1959.19.2; NMW 179; and MHNT 1785

Aburria aburri: AMNH 2625; LSMUZ 118170; and LSUMZ 112293.

Penelope superciliaris: AMNH 516; AMNH 516b; AMNH 3495; AMNH 8623; AMNH 13639; AMNH 13638; LSUMZ 169273; BMNH 1849.12.6.9; BMNH 1849.6.20.18; BMNH 1866.8.6.6; NMW 4970; and MPEG 569.

Penelope obscura: MNHN 1923.345; NMW 175; MHNT 202; MHNT 594; and MHNT 600.

\section{References}

Aleixo, A., 2002. Molecular systematics and the role of the "Várzea""Terra-Firme" ecotone in the diversification of Xiphorhynchus woodcreepers (Aves: Dendrocolaptidae). Auk 119, 621-640.

BirdLife International, 2004. Threatened Birds of the World 2004. CD Rom. BirdLife International. Cambridge, UK.

Bonaparte, P.L., 1856. Tableaux paralléliques de l'ordre des Gallinacés. Compt. Rendus Acad. Sci. Paris 42, 874-884.

Brooks, D.M., Strahl, S.D., 2000. Curassows, guans and chachalacas. Status, survey and conservation action plans for cracids 2000-2004. IUCN/SSC Cracid Specialist Group. IUCN, Gland, Switzerland and Cambridge UK.

Clapperton, L., 1993. Quaternary Geology and Geomorphology of South America. Elsevier, Amsterdan.

Collins, A.C., Dubach, J.M., 2000. Biogeographic and ecological forces responsible for speciation in Ateles. Int. J. Primatol. 21, 421-444.

Cortés-Ortiz, L., Bermingham, E., Rico, C., Rodriguez-Luna, E., Sampaio, I., Ruiz-Garcia, M., 2003. Molecular systematics and biogeography of the Neotropical monkey genus, Alouatta. Mol. Phylogenet. Evol. 26, 64-81.

del Hoyo, J., Elliott, A., Sargatal, J. (Eds.), 1994. Handbook of the Birds of the World. Vol. 2. New World Vultures to Guineafowl. Lynx Editions, Barcelona.

Delacour, J., Amadon, D., 1973. Curassows and Related Birds. American Museum of Natural History, New York.

Dimcheff, D.E., Drovetski, S.V., Mindell, D.P., 2002. Phylogeny of Tetraoninae and other galliform birds using mitochondrial $12 \mathrm{~S}$ and ND2 genes. Mol. Phylogenet. Evol. 24, 203-215.

Dyke, G.J., Gulas, B.E., Crowe, T.M., 2003. Suprageneric relationships of galliform birds (Aves, Galliformes): a cladistic analysis of morphological characters. Zool. J. Linn. Soc. 137, 227-244.

Ffrench, R., O’Neill, P., Eckelberry, D.R., 1991. A Guide to the Birds of Trinidad and Tobago, second ed. Cornell University Press, Ithaca.

Grau, E.T., Pereira, S.L., Silveira, L.F., Wajntal, A., 2003. Molecular markers contribute in the management of a breeding program of the extinct in the wild Alagoas Curassow Mitu mitu and confirm the validity of the species. Bird Conserv. Int. 13, 115-126.

Guerra, A.T., 1956. Estrutura geológica, relevo e litoral. In: Guerra, A.T. (Org.) Geografia do Brasil: Grande região norte. IBGE, Rio de Janeiro, pp. 17-60.
Haffer, J., 1974. Avian speciation in tropical South America. With a systematic survey of the toucans (Ramphastidae) and jacamars (Galbulidae). Publ. Nuttall. Ornithol. Club 14, Cambridge.

Haffer, J., Prance, G.T., 2001. Climatic forcing of evolution in Amazonia during the Cenozoic: on the refuge theory of biotic differentiation. Amazoniana 16 (3/4), 579-607.

International Commission on Zoological Nomenclature, 1999. International code of zoological nomenclature, London, International Trust for Zoological Nomenclature.

Irion, G., 1984. Sedimentation and sediments of the Amazonian rivers and evolution of the Amazonian landscape since Pliocene times. In: Sioli, H. (Ed.), The Amazon: Limnology and Landscape Ecology of a Mighty Tropical River and Its Basin. Dr. W. Junk Publishers, Dordrecht, pp. 201-214.

Jacquin, J.F., 1784. Beyträge zur Geschichte der Vögel. Vienna.

Klammer, G., 1984. The relief of extra-andean amazon basin. In: Sioli, H. (Ed.), The Amazon: Limnology and Landscape Ecology of a Mightly Tropical River and Its Basin. Dr. W. Junk, Dordrecht, pp. 47-83.

Kumar, S., Tamura, K., Jakobsen, I.B., Nei, M., 2001. MEGA2: Molecular Evolutionary Genetics Analysis Software. Arizona State University, Tempe, Arizona, USA.

Lee, M.S.Y., Hugall, A.F., 2003. Partitioned likelihood support and the evaluation of data set conflict. Syst. Biol. 52, 15-22.

Lesson, R.P., 1828. Manuel d'ornithologie, ou description des genres et des principales especes d'oiseaux. Paris.

Lundberg, J.G., Marshall, L.G., Guerrero, J., Horton, B., Malabarba, M.C.S.L., Wesseleingh, F., 1998. The stage for neotropical fish diversification: a history of tropical South American rivers. In: Malabarba, L.R., Reis, R.E., Varie, R.P., Lucena, Z.N., Lucena, C.A.S. (Eds.), Phylogeny and Classification of Neotropical Fishes. Part 1. EDIPUC/RS, Porto Alegre, pp.13-48.

Marroig, G., Cerqueira, R., 1997. Plio-Pleistocene South American history and the Amazon Lagoon hypothesis: a piece in the puzzle of Amazonian diversification. J. Comp. Biol. 2, 103-119.

Nores, M., 1999. An alternative hypothesis for the origin of the Amazonian bird diversity. J. Biogeogr. 26, 475-485.

Nores, M., 2004. The implications of Tertiary and Quaternary sea level rise events for avian distribution patterns in the lowlands of northern South America. Global Ecol. Biogeogr. 13, 149-161.

Olmos, F., 1998. The Pipile cumanensis grayi-Pipile cujubi nattereri contact zone in Mato Grosso, Brazil. In: Brooks, D.M., Olmos, F., Bergazo, A.J. (Eds.), Biology and Conservation of the Piping Guans (Aves: Cracidae). Special Publication of the Cracid Specialist Group, Houston, pp. 27-30.

Paula Couto, C. de, 1956. Mamíferos fósseis do Cenozóico da Amazônia. Instituto Brasileiro de Bibliografia e Documentação CNPq, Rio de Janeiro Boletim 3, p. 1-121.

Pelzeln, A. von, 1858. (Little-known birds). Sitz. K. Acad. Wiss. Wien 31, 319-331.

Pereira, S.L., Baker, A.J., 2004a. A vicariant hypothesis for the speciation of curassows (Aves, Cracidae) based on mitocondrial DNA phylogeny. Auk 121, 682-694.

Pereira, S.L., Baker, A.J., 2004b. Low number of mitochondrial pseudogenes in the chicken (Gallus gallus) nuclear genome: implications for molecular inference of population history and phylogenetics. BMC Evol. Biol. 4, 17.

Pereira, S.L., Baker, A.J., Wajntal, A., 2002. Combined nuclear and mitochondrial DNA sequences resolve generic relationships within the Cracidae (Galliformes, Aves). Syst. Biol. 51, 946-958.

Pereira, S.L., Grau, E.T., Wajntal, A., 2004. Molecular architecture and rates of DNA substitutions of the mitochondrial control region of cracid birds. Genome 47, 535-545.

Posada, D., Crandall, A., 1998. MODELTEST: testing the model of DNA substitution. Bioinformatics 14, 817-818.

Reichenbach, H.G.L., 1853. Avium Systema Naturale. Friedrich Hofmeister, Leipzig. 
Richly, E., Leister, D., 2004. Numts in sequenced eukaryotic genomes. Mol. Biol. Evol. 21, 1081-1084.

Ridgely, R.S., Greenfield, P.J., 2001. The Birds of Ecuador. Status, Distribution and Taxonomy. Cornell University Press, Ithaca.

Ronquist, F.R., Huelsenbeck, J.P., 2003. MRBAYES: Bayesian inference of phylogeny. Bioinformatics 19, 1572-1574.

Salazar-Bravo, K., Dragoo, J.W., Tinnin, D.S., Yates, T.L., 2001. Phylogeny and evolution of the Neotropical rodent genus Calomys: inferences from mitochondrial DNA sequence data. Mol. Phylogenet. Evol. 20, 173-184.

Salgado-Labouriau, M.L., 1994. História Ecológica Da Terra. Edgard Blücher Ltda, São Paulo.

Sanderson, M.J., 2002. Estimating absolute rates of molecular evolution and divergence times: a penalized likelihood approach. Mol. Biol. Evol. 19, 101-109.

Sanderson, M.J., 2003. r8s: inferring absolute rates of evolution and divergence times in the absence of a molecular clock. Bioinformatics 19, 301-302.

Sick, H., 1993. Birds in Brazil. Princeton University Press, New Jersey.

Silveira, L.F., 2003. Filogenia dos Cracidae (Aves: Galliformes) com base em caracteres osteológicos. São Paulo, Unpublished PhD Thesis. Instituto de Biociências, Universidade de São Paulo.

Silveira, L.F., Olmos, F., Long, A.J., 2003. Birds in Atlantic forest fragments in North-east Brazil. Cotinga 20, 32-46.
Sioli, H., 1957. Sedimentation in Amazonasgerbiet. Geol. Rundschau $45,608-633$.

Shimodaira, H., 2002. An approximately unbiased test of phylogenetic tree selection. Syst. Biol. 51, 492-508.

Shimodaira, H., Hasegawa, M., 2001. CONSEL: for assessing the confidence of phylogenetic tree selection. Bioinformatics 17, 1246-1247.

Spix, J.B., 1825. Avium species novae. Vol. 2. Munich.

Strahl, S.D., Schmitz, A., 1997. A taxonomic reference of the family Cracidae for common use by ornithologists. In: Strahl, S.D., Beaujon, S., Brooks, D.M., Begazo, A.J., Sedaghatkish, G., Olmos, F. (Eds.), The Cracidae - their Biology and Conservation. Hancock House, Blaine, pp. 503-506.

Strimmer, K., von Haeseler, A., 1996. Quartet puzzling: a quartet maximum likelihood method for reconstructing tree topologies. Mol. Biol. Evol. 13, 964-969.

Swofford, D.L., 2001. PAUP*_Phylogenetic Analysis Using Parsimony (* and Related Methods), Version 4.0. Sinauer Associates, Sunderland, MA.

Vaurie, C., 1968. Taxonomy of the Cracidae. Bull. Am. Mus. Nat. Hist. $138,135-243$.

Vuilleumier, F., 1965. Relationships and evolution within the Cracidae. Bull. Mus. Zool. 134, 1-27.

Zink, R.M., Blackwell-Rago, R.C., 2000. Species limit and recent population history in the curve-billed trasher. Condor 102, 881-886. 


\section{ANEXO II - Artigo publicado}

Grau E.T., Pereira S.L., Silveira L.F., Wajntal A., 2003. Molecular markers contribute in the management of a breeding program of the extinct in the wild Alagoas Curassow Mitu mitu and confirm the validity of the species. Bird Conservation International 13: 115-126. 


\title{
Molecular markers contribute to a breeding programme of the extinct-in-the-wild Alagoas Curassow Mitu mitu and confirm the validity of the species
}

\author{
ERWIN TRAMONTINI GRAU, SÉRGIO LUIZ PEREIRA, LUÍS FÁBIO \\ SILVEIRA and ANITA WAJNTAL
}

\begin{abstract}
Summary
Alagoas Curassow Mitu mitu is considered extinct in the wild, having previously inhabited a small area in north-eastern Brazil that has since been replaced by sugar cane farms. Around 50 birds possessing morphological features of this species are still alive in captivity in Brazil, all being descendants from a breeding programme started in 1979, using offspring from a single male and two females captured from the wild. However, this captive population also includes some hybrids with the congeneric Razor-billed Curassow M. tuberosa and their descendants. Furthermore, the validity of Alagoas Curassow as a species is questionable. We used two molecular markers to study the validity of this taxon as a species, to detect potential hybrids present in the stock, and to estimate genetic variability among the remnant specimens. The analysis of 760 base pairs from mitochondrial cytochrome $b$ and control region sequences revealed that at least three of the 20 birds analysed had sequences identical to those of Razor-billed Curassow. The other 17 birds presented sequences that diverged 2.6\% from Razor-billed Curassow. Moreover, a sample from an Alagoas Curassow museum skin collected from the wild in 1951 had cytochrome $b$ sequences identical to those of the 17 birds. These results confirm the Alagoas Curassow as a valid species. DNA fingerprinting profiles of the 20 descendants from the Alagoas Curassow breeding population showed that this group of birds is depauperate in genetic variability. There was an increase in genetic variability of birds born after 1990, attributed to the hybrid mating of Alagoas Curassow with Razor-billed Curassow. We suggest that birds born before 1990 should be handled separately from the others. However, if a decrease in chick harvest among birds of this group is detected due to inbreeding depression or ageing, cross-breeding between this group and the group of birds most closely related to it should be considered in order to enrich the progeny with the Alagoas Curassow genome.
\end{abstract}

\section{Introduction}

Most cracids are endemic to the Neotropics, and are important bioindicators of the health of their habitat (Brooks and Strahl 2000). The family encompasses 11 genera and approximately 50 species. Among these latter, 19 species are listed as Vulnerable, Endangered or Critically Endangered, mainly due to excessive hunting and habitat destruction (Brooks and Strahl 2000, BirdLife International 2000). The most threatened species of this family is Alagoas Curassow Mitu mitu. 
Its former habitat was the Atlantic Forest in the state of Alagoas, north-eastern Brazil, but the last large forest remnants were replaced by sugar cane in the $1970 \mathrm{~s}$ and 1980 s. Its population size was estimated at less than 60 individuals in the late 1970s (Teixeira 1986) but now this species is considered extinct in the wild (Collar et al. 1992, BirdLife International 2000, L. F. Silveira unpublished data).

Linnaeus described the Alagoas Curassow in 1766, naming it Crax mitu, based on texts and illustrations published in 1648 by the German naturalist J. Marcgrave, in his famous "Historia Rerum Naturalium Brasiliae" (Teixeira 1992). For about three centuries, the species was not recorded in the wild, until Oliverio Pinto captured a single female in 1951. This specimen is now housed at the Museu de Zoologia da Universidade de São Paulo, (MZUSP $n^{\circ}$ 37.188) in São Paulo, Brazil. Despite being considered a monotypic species (Collar et al. 1992, Nardelli 1993, del Hoyo et al. 1994, Sick 1997), many ornithologists have questioned its validity as a species, mainly because of its rarity and morphological similarity to Razor-billed Curassow M. tuberosa, an inhabitant of the Amazon Forest (Pinto 1952, Coimbra-Filho 1970, Sick 1980). Silveira (unpublished data) compared the single adult female specimen of Alagoas Curassow, collected in 1951, with nine females of the closely related Razor-billed Curassow and confirmed the validity of the former as a full species based on diagnostic characters of a bi-coloured bill, a bare auricular patch and a tail with buff rather than white tips and nearly all-black central rectrices.

In 1979, five birds were collected from the wild in the municipality of Barra de São Miguel ( $\left.0^{\circ} 50^{\prime} \mathrm{S}, 35^{\circ} 54^{\prime} \mathrm{W}\right)$, Alagoas, Brazil, to be used in a captive breeding programme (Nardelli 1993). At the time of writing, all surviving birds are descendants of this breeding programme developed by Nardelli (1993) who successfully bred two females with a single male. In 1990, after the death of this single male, Nardelli began to cross some Alagoas Curassows with Razor-billed Curassows. After a deplorable misunderstanding between the breeder and official authorities, the original records of the breeding data became unavailable. Thus, only the birds that were born before 1990 can be considered as "pure" Alagoas Curassow. In 2000, the whole population of surviving birds (44 birds) was split between two different breeders. We had the opportunity to collect blood samples from the 20 birds held by one breeder. This group consisted of three birds born before 1990 and 17 born after.

To evaluate the status of Alagoas Curassow as a species and to detect hybrid birds, we sequenced fragments of the mitochondrial control region and cytochrome $b$ genes of 20 birds possessing morphological features diagnostic of Alagoas Curassow and compared their sequences to those of other valid congeners. Similar procedures based on mtDNA sequences have been used by other researchers to ascertain specific status of birds and mammals (Zink and Blackwell-Rago 2000, Bradley and Baker 2001). In cracids, this approach has been applied before among several species of curassow, to check the validation of Crax viridirostris and C. estudilloi described solely on the basis of single specimens. In this case, the sequences of $C$. viridirostris and C. estudilloi were found to be identical to those obtained for Blue-billed Curassow C. alberti and Yellow-knobbed Curassow $C$. daubentoni substantially diminishing the possibility that they are valid species (Joseph et al. 1999). 
We also sequenced $166 \mathrm{bp}$ of the cytochrome $b$ from a skin fragment extracted from a museum specimen of Alagoas Curassow collected from the wild in 1951, to evaluate if the sequences obtained for most of the studied birds represented the sequence from this species.

The genetic variability of the 20 Alagoas Curassows was estimated utilizing DNA fingerprinting techniques, which have proved useful in estimating overall genetic variability in many groups of birds, including gallinaceous birds (Hanotte et al. 1992) and Cracidae (Pereira et al. 1996, Pereira and Wajntal 1999, 2001a,b). Based on the results obtained in this study, we present management recommendations in order to ameliorate further degradation of genomic variability in the captive population of Alagoas Curassow.

\section{Materials and methods}

Taxa

Approximately $0.1 \mathrm{ml}$ of blood was taken by venipuncture from 20 birds belonging to Nardelli's original stock. All these birds possessed phenotypic characteristics of Alagoas Curassow. Blood samples were also taken from three Razor-billed Curassows and one Crestless Curassow, M. tomentosa and kept in $0.5 \mathrm{ml}$ of absolute ethanol at room temperature. All birds sampled were from private aviaries. A skin sample of Alagoas Curassow was obtained from the Museu de Zoologia da Universidade de São Paulo (MZUSP $n^{\circ}$ 37.188) in São Paulo, Brazil. All specimens of Alagoas Curassow found in other museums and private collections have been donated by Nardelli from his captive breeding programme, and were not considered in this study.

\section{DNA sequencing from blood samples}

DNA was extracted from the 24 blood samples following standard protocols (Sambrook et al. 1989). Two mitochondrial DNA fragments were isolated by polymerase chain reaction (PCR) with primers Dloop L (5'-TTG TTC TCA ACT ACG GGA AC-3') and Dloop H (5'-GTG AGG TGG ACG ATC AAT AAA T-3') for the first domain of the control region (G. Rowe, pers. comm.) and primers reverse cyt $b$ L (Kornegay et al. 1993) and CBH15764 (Miyaki et al. 1998) for the cytochrome $b$. DNA amplification was performed in $10.0 \mu \mathrm{l}$ of $2.0 \mathrm{mM}$ of each dNTP, 10.0 $\mu \mathrm{M}$ of each primer, 1-50 ng of genomic DNA, 0.5 U of Taq DNA polymerase (Amersham Pharmacia Biotech) and 1.o $\mu$ l of buffer 10X supplied with Taq DNA polymerase. The reaction was performed for $5 \mathrm{~min}$ at $95{ }^{\circ} \mathrm{C}$ for denaturation, followed by 30 cycles of $95{ }^{\circ} \mathrm{C}$ for $40 \mathrm{~s}, 54{ }^{\circ} \mathrm{C}$ for $30 \mathrm{~s}$, and $72{ }^{\circ} \mathrm{C}$ for $30 \mathrm{~s}$, and a final extension of 10 min at $72{ }^{\circ} \mathrm{C}$. Products were purified with $15 \mathrm{U}$ of exonuclease I (USB) and $1.5 \mathrm{U}$ of shrimp alkaline phosphatase (USB) for 60 min at $37^{\circ} \mathrm{C}$ followed by $10 \mathrm{~min}$ at $80^{\circ} \mathrm{C}$. Sequencing reactions and purifications were performed according to the manufacturer's recommended protocol (Big Dye terminator cycle sequencing kit; Applied Biosystems) and loaded in an automated DNA sequencer ABI Prism 377 (Applied Biosystems). Both strands of each DNA fragment were sequenced. 


\section{DNA sequencing from skin sample}

All procedures for DNA extraction and sequencing of the skin fragment from the museum specimen were done in a laboratory where bird samples had not been manipulated, to avoid contamination. DNA was extracted using QIAamp DNA Mini Kit as recommended by the manufacturer (Qiagen Inc.). We performed two concomitant extractions, one containing fragments of the skin sample and the other performed without any DNA source, to verify that there was no possible contamination. New reagents were used in these isolations. A fragment of the cytochrome $b$ was amplified by PCR, with primers CBH15764 (Miyaki et al. 1998) and CBL15562 (5'-TAT TTC TCC YTA AAA GAC CTG TTA GGG TT-3', C. Y. Miyaki pers. comm.) in the same conditions as described above for DNA extracted from blood samples. Following this, a second amplification was performed in the same conditions using $2 \mu \mathrm{l}$ from the first reaction, for both the previous reactions containing the museum skin and the one without any DNA source. Sequencing reaction and purification were performed as described for blood samples and loaded in an automated DNA sequencer ABI Prism 377 (Applied Biosystems).

\section{Sequences analysis}

Both strands of the DNA fragments of each bird were visually aligned and corrected for ambiguities in Sequence Navigator (Applied Biosystems). The control region and cyt $b$ sequences of each bird were concatenated before further analysis. The cyt $b$ sequence from the skin sample was visually aligned with the corresponding cyt $b$ sequences obtained from the other 24 birds. Uncorrected p-distances were estimated in PAUP 4.ob8 (Swofford 2001). Sequences obtained in this study have been deposited in GenBank under accession numbers AYo98533-AYo98580.

\section{DNA fingerprinting}

Multilocus DNA fingerprints were performed as described in Bruford et al. (1992). Briefly, $4 \mu \mathrm{g}$ of genomic DNA from each of the 20 captive Alagoas Curassows was completely digested with 15 units of $M b o$ I for a period of $16-18 \mathrm{hrs}$. The fragments were electrophorized through a $30-\mathrm{cm}$ long horizontal $1 \%$ agarose gel, until the $\gamma$-HindIII molecular marker of $2.3 \mathrm{~kb}$ loaded in the first lane had migrated to the anodal end of the gel. Digested DNA sample of the same bird was loaded in the second and in the last lane of the gel to estimate band migration distortion and provide a better scoring of the bands. The fractionated DNA fragments were transferred onto a nylon membrane (Hybond Nfp, Amersham) by capillary Southern blotting (Sambrook et al. 1989).

The human multilocus minisatellite probe 33.15 (Jeffreys et al. 1985a) was radiolabelled by the random priming method with $\left[\alpha-{ }^{32} \mathrm{P}\right] \mathrm{dCTP}$. The membrane was pre-hybridized for one hour at $65^{\circ} \mathrm{C}$ in a solution containing only $0.263 \mathrm{M}$ $\mathrm{Na}_{2} \mathrm{PO}_{4}$ and $7 \%$ SDS. The probe was added to this solution and left overnight at the same temperature. The membrane was then washed in $2 \times$ SSC, $0.1 \%$ SDS and in $1 \times$ SSC, $0.1 \%$ SDS at $65^{\circ} \mathrm{C}$, for $20 \mathrm{~min}$ each. Autoradiographs were 
Table 1 . Variable sites found in the 24 curassows sampled. Numbers are written vertically and correspond to position in the mtDNA sequence analysed. Dots and a dash represent, respectively, the same base and a gap in the sequence related to the most frequent Alagoas Curassow haplotype shown on the top.

\begin{tabular}{|c|c|c|c|}
\hline Species & $\begin{array}{l}\text { Number } \\
\text { of birds }\end{array}$ & Control region haplotype & Cyt $b$ haplotype \\
\hline & & OOOI11222223333333 & 00011122233333 \\
\hline & & 158359022581111223 & 18806923812245 \\
\hline & & 376661879834567451 & 11344149113674 \\
\hline Alagoas Curassow & 16 & TGGTCTCCCCCAGCTTAC & GTATCTCCGTCCAT \\
\hline Alagoas Curassow & 1 & $\ldots \ldots$. . . . & $\ldots \ldots \ldots$ \\
\hline Alagoas Curassow & 3 & ...C.CAT . TTGA. . .GT & ACGC.CTTACT . . . \\
\hline Razor-billed Curassow & 3 & . . .C.CAT . TTGA . . .GT & ACGC.CTTACT . . . \\
\hline Crestless Curassow & 1 & CA-CT . . ТT TT . . TCС . . & A.GCTCTT.C.TGC \\
\hline
\end{tabular}

obtained after one to three days of exposure at $-80{ }^{\circ} \mathrm{C}$ using X-ray film and two intensifying screens.

Bands in the range of 3.8 to $15.5 \mathrm{~kb}$ were marked on acetate overlays according to Westneat (1990). The band-sharing coefficient (BSC), or index of similarity, between individuals was calculated as: $x=2 N_{\mathrm{AB}} /\left(N_{\mathrm{A}}+N_{\mathrm{B}}\right)$ where $N_{\mathrm{AB}}$ is the number of bands shared by $A$ and $B, N_{\mathrm{A}}$ and $N_{\mathrm{B}}$ are the number of bands present in birds $A$ and $B$, respectively (Wetton et al. 1987, Bruford et al. 1992). The genetic variability was therefore the reciprocal of the index of similarity. Assuming that the bands scored were independent markers, the mean probability that all $n$ bands in an individual's fingerprint were present by chance in a second random unrelated individual was conservatively estimated as $<X^{\mathrm{n}}$ (Jeffreys et al. $1985 \mathrm{~b}$, Bruford et al. 1992). Mean heterozygosity $(\mathrm{H})$ was given by $\mathrm{H}=2 \mathrm{q}(1-\mathrm{q}) /\left(2 \mathrm{q}-\mathrm{q}^{2}\right)$ (Sundt et al. 1994), where q, the mean allelic frequency of bands, is obtained from $x=2 \mathrm{q}-\mathrm{q}^{2}$ (Jeffreys et al. 1995b).

\section{Results}

\section{DNA sequencing}

Amplification of each mitochondrial DNA region resulted in single PCR products for each bird. From these PCR products we obtained unambiguous sequences with similarity to corresponding sequences of other birds deposited in GenBank. The reading frame for cytochrome $b$ sequences did not show any stop codon or changes in amino acid sequence that could indicate that they were of nuclear instead of mitochondrial origin. Contamination did not occur as no amplification was observed in the negative control reactions.

The concatenated sequences obtained for each of the 24 birds were $760 \mathrm{bp}$ long ( $390 \mathrm{bp}$ for cytochrome $b$ and $370 \mathrm{bp}$ for control region). Thirty-two variable sites were found (Table 1 ). The sequences from the Razor-billed and the Crestless Curassows differed by $2.8 \%(21 / 760)$. Three different haplotypes were found in the 20 birds presumed to be Alagoas Curassow on the basis of phenotypic characteristics. Three individuals among 20 individuals of Alagoas Curassow had sequences identical to those of Razor-billed Curassow. Among the other 17 individuals, 16 possessed identical haplotypes, including two birds born before 
1990, and a single male born in 1984 differed by a single transition nucleotide substitution in the control region. Uncorrected $p$-distance between the haplotypes of Alagoas and Razor-billed Curassows was 2.6\% (20/760) and between Crestless and Alagoas Curassows was 3.0\% (23/760).

The cytochrome $b$ fragment obtained from the skin sample had a size of 202 $\mathrm{bp}$, producing an analysable sequence of $166 \mathrm{bp}$ that was found to be identical to those 17 birds presenting the most common haplotype. This sequence differed by $2.4 \%$ (4/166) from Razor-billed Curassow and by 3.0\% (5/166) from Crestless Curassow sequences.

\section{DNA fingerprinting}

The mean number of bands detected by the human multilocus minisatellite probe 33.15 for the 20 captive-kept Alagoas Curassows was $14.4 \pm 3.2$ (range from 9 to 16 bands). Among these an average of $5.2 \pm 2.1$ fragments were shared, providing an average BSC of $0.358 \pm 0.12$. Considering only the birds born before 1990 (prior to the inclusion of Razor-billed Curassow in the breeding programme) the mean BSC was $0.501 \pm 0.17$. After Razor-billed Curassows were introduced in the breeding programme, the mean BSC decreased to $0.354 \pm 0.12$. Excluding the three Alagoas Curassows whose mitochondrial DNA sequences were identical to that of Razor-billed Curassow (see above), the mean BSC was $0.327 \pm 0.11$. The probability of two unrelated birds sharing identical profiles by chance was extremely remote and had a probability in the order of 1 in $10^{-5}$ to $10^{-7}$. Mean heterozygosity was lower for birds born before $1990(\mathrm{H}=0.82)$ compared with those born after this date $(\mathrm{H}=0.89)$.

\section{Discussion}

Is the Alagoas Curassow Mitu mitu a valid species?

The status of Alagoas Curassow as a species has been questioned in the last three centuries mostly because of its rarity and morphological similarity to Razor-billed Curassow (Pinto 1952, Coimbra-Filho 1970, Sick 1980). Our research addressed this question, which is of extreme importance for the management of this highly endangered taxon, by comparing the distances of mitochondrial genes between three different but closely-related lineages of the genus Mitu: Alagoas Curassow, Razor-billed Curassow and Crestless Curassow. The estimated distance of $2.6 \%$ between Alagoas and Razor-billed Curassow is almost the same as that between Alagoas and Crestless Curassow (3.0\%), as well as between Razor-billed and Crestless Curassow (2.8\%). Similar divergence for these same two mitochondrial DNA regions has been found between other recognizable congeneric species of the family Cracidae: $1.3 \%$ between Bare-faced Curassow Crax fasciolata and Black Curassow C. alector; 2.6\% between Bare-faced Curassow and Red-billed Curassow C. blumenbachii; and $1.4 \%$ between Chestnut-bellied Guan Penelope ochrogaster and Duskylegged Guan P. obscura (E. T. Grau unpubl. data). Distances equivalent or higher than the distance between valid species should help to validate questionable congeneric species (Zink and Blackwell-Rago 2000, Bradley and Baker 
2001). Thus, as Crestless Curassow is clearly a distinct species from the other two and the distances between the three species are almost equivalent, our data favour the hypothesis that Alagoas Curassow is indeed a distinct species from Razor-billed Curassow. Moreover, the findings presented here are concordant with sequence data collected from other mitochondrial genomic regions that show the uniqueness of the Alagoas Curassow when compared with 13 other recognizable curassow species (S. L. Pereira and A. J. Baker subm.).

\section{Interspecific hybridization}

Our DNA sequencing results showed that three birds of the breeding programme born after 1990 have mitochondrial sequences identical to Razor-billed Curassow. In addition, our DNA fingerprinting results showed an increase in the genetic variability among the birds born after 1990. Taken together, these results constitute strong evidence that hybridization has occurred between Alagoas and Razor-billed Curassows after 1990. Since mitochondrial DNA is maternally transmitted, our findings confirm that hybridization occurred between females of Razor-billed Curassow and males of Alagoas Curassow, and that at least one female Razor-billed Curassow was involved in the breeding. It would be useful to detect the ancestral male genome as well; however, the necessary tools are not available to us at present.

\section{Management}

Our DNA fingerprinting results showed that the birds born before 1990, which we are assuming to represent "pure" Alagoas Curassows, had a similarity index expected for first-degree relatives. This result is not surprising since all birds alive today are the outcome of only three birds captured from the wild (one male and two females). The increase in the genetic variability detected after 1990 to levels found for other non-threatened curassows (Pereira and Wajntal 1999, 2001a,b) can be attributed to the crosses of Alagoas Curassow with Razor-billed Curassow in captivity (Nardelli 1993). The best management programme for the conservation of Alagoas Curassow should include all surviving birds, especially those with a "pure" Alagoas Curassow background. The programme should aim to preserve the genetic constitution present in the "pure" surviving birds, but should also carefully consider the potential ill-effects that can arise due to inbreeding, such as decreased fertility and survival, as well as other possible effects due to the greater age of the three birds born before 1990. It is also possible that the surviving birds have already overcome the effects of inbreeding depression in a similar way as achieved experimentally in Speke's gazelle Gazella spekei as reported by Templeton and Read (1983). They demonstrated that after several rounds of consanguineous matings, there was a reduction in lethal equivalents in the outcome of inbred parents as compared with that of non-inbred parents. As a practical result, the reduction in inbreeding depression resulted in decreased mortality rates and increased birth weight of the offspring, demonstrating that animals can quickly adapt to even extreme inbreeding and that this adaptation can occur in relatively small populations. 
However, as the breeding success among the "pure" Alagoas Curassows cannot be assured and the genetic constitution of the remaining birds is unknown, the best strategy available at this time is to detect the birds that, through the technology used in the present work, showed the higher similarity with the "pure" birds, with similarity indexes higher than 0.5. Analysing the data in Table 2, it is possible to identify a group of two males and three females that show high genetic similarity to the birds born before 1990 (BSC $=0.577 \pm$ 0.03 ) as well as between males and females from this group (BSC $=0.624 \pm 0.02$ ). Mating between these selected birds has a higher chance of preserving most of the Alagoas Curassow genome than other matings and the outcome of these couples, or between them and the "pure" Alagoas Curassows, should be encouraged. It is interesting to point out that similarity indices between these selected birds and the birds that inherited a Razor-billed Curassow mitochondrial genome are much lower (BSC $=0.297 \pm 0.05$ ), as expected for birds that have an enriched Alagoas Curassow constitution when compared with birds with the Razor-billed Curassow contribution.

Three birds born after 1990 had DNA sequences and morphological features of Alagoas Curassow but a BSC > 0.5 with the three "hybrid" birds and a BSC of $0.283 \pm 0.07$ when compared with those three "pure" birds born before 1990 .

Thus, among the 20 birds, three are "pure" Alagoas Curassow, five have a higher probability of also being pure or having a higher contribution of the Alagoas Curassow genome and 12 may be considered as being of mixed genomic constitution between Alagoas and Razor-billed Curassow genomes. The lower indices in comparison with the pure or selected group probably represent a higher contribution of the Razor-billed Curassow genome, but as those 12 birds have the typical morphological features of Alagoas Curassow, they certainly harbour some of the original Alagoas Curassow genome. Thus, they should not be excluded from the programme, as the main objectives are the preservation of most of the genetic constitution of this extinct-in-the-wild species as well as to try to establish a viable population in protected areas within its original distribution.

We have previously shown that the lack of genetic variability was not a problem for the establishment of a wild population of two other cracid species, Dusky-legged Guan and Rusty-margined Guan P. superciliaris in reforested areas (Pereira and Wajntal 1999). However, the success of establishing a viable population in the wild by reintroducing captive-bred birds with low genetic variability is unpredictable (Rave et al. 1994, Rave 1995, Tegelstrom and Sjoberg 1995). These birds and their descendants would appear to be limited in their ability to adapt to habitat and climatic variations and moreover it seems unlikely that natural selection could improve this condition because of the genetic uniformity of this population. Thus, the progeny of the 12 birds with both variable contributions from the Alagoas Curassow genome and with a high genetic variability, might represent in the future an important contribution to the reintroduction programme, in the same way that the introgression of foreign genetic contribution seems to have been important for preserving the Florida panther genome (Roelke et al. 1993). 
Species validity and conservation biology of M. mitu

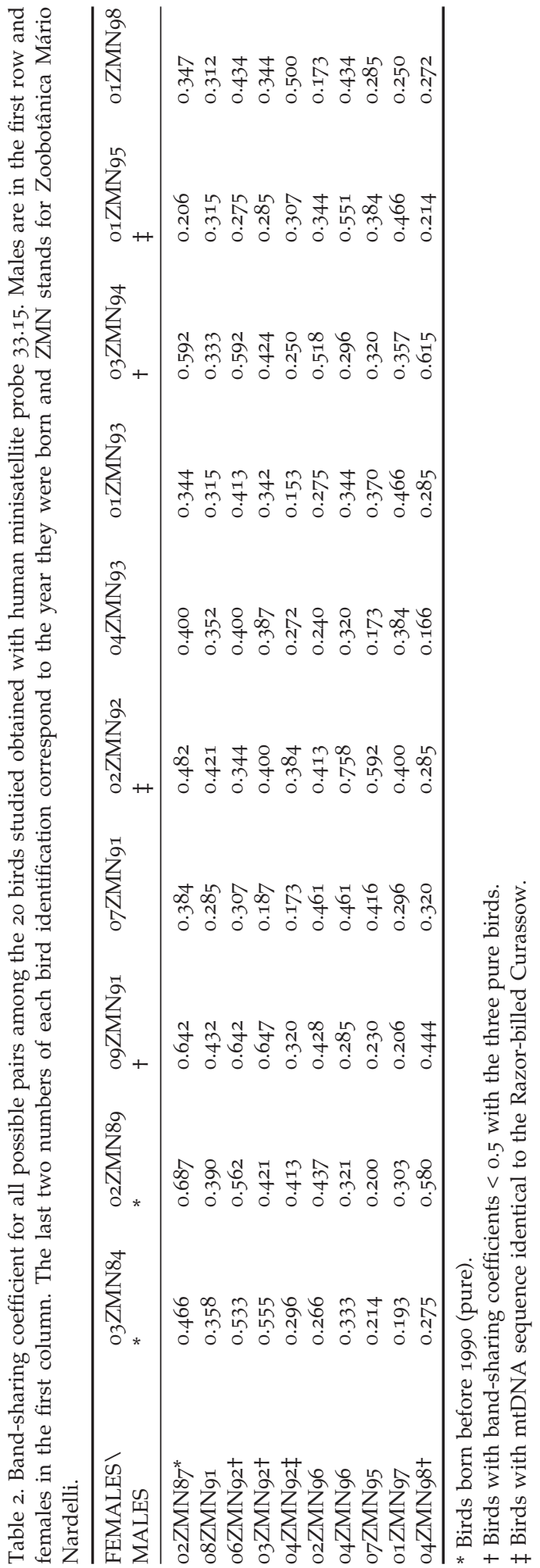




\section{Habitat availability for reintroduction}

During September and October 2001 one of us (LFS) and field ornithologist Fábio Olmos conducted surveys in forest fragments in Alagoas State. The objective was to assess the conservation status of the selected fragments, search for some north-eastern Atlantic Forest endemics and try to gather evidence of the survival of Alagoas Curassow in the wild.

The results (Silveira and Olmos unpublished data) showed that most remnants of forest are small and are restricted to steep valleys, which have proven to be unsuitable for sugar cane plantations, or have been preserved intentionally to keep water resources intact. However, intensive hunting and selective logging are common in these remaining forest fragments. Despite their efforts, no evidence of the existence of Alagoas Curassow was found.

However, some fragments of mature forest were discovered, the best conserved being that located at Fazenda Petrópolis in Usina Santo Antônio, a sugar cane plantation. This fragment has many freshwater creeks and fruit trees and would seem to be a suitable habitat that should be considered for a reintroduction programme for Alagoas Curassows.

A reintroduction programme, however, takes time to be effectively implemented. The owners of the selected areas (despite being private or government owned, e.g. state parks or reserves) must guarantee real protection, and an educational programme must be implemented involving the local population, before one can begin a reintroduction programme. The reintroduction of cracids in Brazil has been successful previously (Pereira and Wajntal 1999, R. Azeredo pers. comm.), and one can use these examples as an incentive for the re-establishment of a population of the Alagoas Curassow in its original habitat.

\section{Acknowledgements}

The authors thank Moacyr de Carvalho Dias for blood samples of 20 M. mitu, one $M$. tuberosa and one M. tomentosa; Roberto Azeredo for blood samples of two M. tuberosa. Dr Cristina Y. Miyaki, Maryann L. Burbidge, Dr Eugene Harris, Dr Paulo A. Otto, Dr Seb Buckton and an anonymous referee provided valuable suggestions. This work was performed with grants from FAPESP and CNPq. Dr Marie-Anne van Sluys (Department of Botany, University of São Paulo) kindly allowed the use of her laboratory to manipulate the sample of the museum skin. The Jeffrey's probe 33.15 is the subject of patent number GBA 2166445 and worldwide patents (pending) for commercial diagnostic use. Fieldwork in Alagoas was supported by BirdLife International, Neotropical Bird Club, Wetland Fund, WPA and ZGAP. Our tanks to Jaqueline Goerck and Nigel Collar for raising the necessary funding and to the Manomet Bird Observatory (Birder's Exchange) for donating field equipment. Field surveys in Alagoas were possible thanks to Fernando Pinto (IPMA), Marcelo Souza, S/A Usina Coruripe Açúcar e Álcool (Cícero Almeida e Magno Túlio Madeiro); Usina Leão S/A, Vila Utinga (John William Buyers Júnior), Usina Cachoeira (Leonardo Pinto Costa); Usina Serra Grande (Clodoaldo José Bakker); Usina Camaragibe (Cláudia Maranhão) and João Maram. 


\section{References}

BirdLife International (2000) Threatened birds of the world. Barcelona and Cambridge, U.K.: Lynx Editions and BirdLife International.

Bradley, R. D. and Baker, R. J. (2001) A test of the genetic species concept: cytochrome-b sequences and mammals. J. Mammal. 82: 960-973.

Brooks, D. M. and Strahl, S. D., compilers (2000). Curassows, Guans and Chachalacas. Status survey and conservation action plan for Cracids 2000-2004. Cambridge, U.K.: IUCN/SSC Cracid Specialist Group. IUCN Publication Services Unit.

Bruford, M. W., Hanotte, O., Brookfield, J. F. Y. and Burke, T. (1992) Single-locus and multilocus DNA fingerprinting. Pp. 225-269 in A. R. Hoelzel, ed. Molecular genetic analysis of populations. a practical approach. New York: IRL Press and Oxford University Press.

Coimbra-Filho, A. F. (1970) Sobre Mitu mitu (Linnaeus, 1766) e a validez das suas raças geográficas (Cracidae, Aves) Rev. Brasil. Biol. 30: 101-109.

Collar, N. J., Gonzaga, L. P., Krabbe, N., Madroño Nieto, A., Naranjo, L. G., Parker III, T. A. and Wege, D. C. (1992) Threatened birds of the Americas. The ICBP/IUCN red data book. Third edition, part 2. Washington, D.C.: Smithsonian Institution Press.

del Hoyo, J., Elliott, A. and Sargatal, J., eds. (1994) Handbook of the birds of the world, 2. New World vultures to guineafowl. Barcelona: Lynx Editions.

Hanotte, O., Bruford, M.W. and Burke, T. (1992) Multilocus DNA fingerprinting in gallinaceous birds: general approaches and problems. Heredity 68: 481-494.

Jeffreys, A. J., Wilson, V. and Thein, S. L. (1985a) Hypervariable 'minisatellite' regions in human DNA. Nature 314: 67-73.

Jeffreys, A. J., Wilson, V. and Thein, S. L. (1985b) Individual-specific 'fingerprinting' of human DNA. Nature 316: 76-79.

Joseph, L. Slikas, B., Rankin-Baransky, K., Bazartseren, B., Alpers, D. and Gilbert, A. E. (1999) DNA evidence concerning the identities of Crax viridirostris Sclater, 1875, and C. estudilloi Allen, 1977. Ornit. Neotrop. 10: 129-144.

Kornegay, J. R., Kocher, T. D., Willians, L. A. and Wilson, A. C. (1993) Pathways of lysozyme evolution inferred from the sequences of cytochrome $b$ in birds. J. Mol. Evol. 37: 367-379.

Miyaki, C. Y., Matioli, S. R., Burke, T. and Wajntal, A. (1998) Parrot evolution and paleogeographical events: mitochondrial DNA evidence. Mol. Biol. Evol. 15: 544-551.

Nardelli, P. M. (1993) A preservação do Mutum-de-Alagoas, Mitu mitu. Queimados, RJ: Semana Ilustrada Editorial.

Pereira, S. L. and Wajntal, A. (1999) Reintroduction of guans of the genus Penelope (Cracidae, Aves) in reforested areas in Brazil: assessment by DNA fingerprinting. Biol. Conserv. 87: 31-38.

Pereira, S. L. and Wajntal, A. (2001a) Studies of captive stocks of the endangered Redbilled Curassow (Crax blumenbachii) suggest that this species in not depleted of genetic variability. Pp. 112-123 in D. M. Brooks and F. Gonzalez-Garcia, eds. Cracid ecology and conservation in the new millenium. Houston, TX: Houston Museum (Misc. Publ. Nat. Sci. 2).

Pereira, S. L. and Wajntal, A. (2001b) Estimates of the genetic variability in a natural population of Bare-faced Curassow Crax fasciolata (Aves, Galliformes, Cracidae). Bird Conserv. Internatn. 11: 301-308.

Pereira, S. L., Miyaki, C. Y. and Wajntal, A. (1996) DNA fingerprinting in the rare BlackFronted Piping Guan Pipile jacutinga (Cracidae. Aves) Rev. Brasil. Biol. 56: 783-791.

Pinto, O. (1952) Redescobrimento de Mitu mitu (Linné) no nordeste do Brasil (Est. de Alagoas). Prova da independência de Mitu tuberosus (Spix) como espécie à parte. Pap. Avuls. Dep. Zool. São Paulo 10: 325-334. 
Rave, E. (1995) Genetic analysis of wild populations of Hawaiian geese using DNA fingerprinting. Condor 97: 82-90.

Rave, E., Fleischer, R. C., Duvall, F. and Black, J. M (1995) Genetic analysis through DNA fingerprinting of captive populations of Hawaiian geese. Conserv. Biol. 8: 744-751.

Roelke, M. E., Martenson, J. S. and O'Brien, S. J. (1993) The consequences of demographic reduction and genetic depletion in the endangered Florida panther. Curr. Biol. 3: 340350.

Sambrook, J., Fritsch, F. and Maniats, T. (1989) Molecular cloning: a laboratory manual. Second edition. Cold Spring Harbor, NY: Cold Spring Harbor Laboratory Press.

Sick, H. (1997) Ornitologia Brasileira, uma introdução. Rio de Janeiro: Ed. Nova Fronteira.

Sick, H. (1980) Characteristics of the Razor-billed Curassow Mitu mitu mitu. Condor 82: 227-228.

Sundt, R. C., Dahle, G. and Naevdal, G. (1994) Genetic variation in the hooded seal, Cystophora cristata, based on enzyme polymorphism and multi-locus DNA fingerprinting. Hereditas 121: 147-155.

Swofford, D. L. (2001) PAUP*, Phylogenetic Analysis Using Parsimony (*and related methods), version 4.o b8. Sunderland, MA: Sinauer Associates.

Tegelstrom, H. and Sjoberg, G. (1995) Introduced Swedish Canada geese (Branta canadensis) have low levels of genetic variation as revealed by DNA fingerprinting. $J$. Evol. Biol. 8: 195-207.

Teixeira, D. M. (1986) The avifauna of the north-eastern Brazilian Atlantic Forest: a case of mass extinction? Ibis 128, 167-168.

Teixeira, D. M. (1992) As fontes do paraíso - um ensaio sobre a ornitologia no Brasil holandês (1624-1654). Rev. Nordestina Biol. 7: 1-219.

Templeton, A. R. and Read, B. (1983) The elimination of inbreeding depression in a captive herd of Speke's gazelle. Pp. 241-261 in C. M. Schoenwald-Cox, S. M. Chambers, B. MacBryde and L. Thomas, eds. Genetics and conservation: a reference for managing wild animal and plant populations. London: Benjamin/Cummings.

Westneat, D. F. (1990) Genetic parentage in the Indigo Bunting: a study using DNA fingerprinting. Behav. Ecol. Sociobiol. 27: 67-76.

Wetton, J. H., Carter, R. E., Parkin, D. T. and Walters, D. (1987) Demographic study of a wild House Sparrow population by DNA fingerprinting. Nature 327: 147-149.

Zink, R. M. and Blackwell-Rago, R. C. (2000) Species limit and recent population history in the Curve-billed Trasher. Condor 102: 881-886.

ERWIN TRAMONTINI GRAU, SÉRGIO LUIZ PEREIRA and ANITA WAJNTAL ${ }^{1}$

Departamento de Biologia, Instituto de Biociências, Universidade de São Paulo. Rua do Matão, 277, São Paulo, SP, Brazil, CEP: 05508-900.

LUÍS FÁBIO SILVEIRA

Departamento de Zoologia, Instituto de Biociências, Universidade de São Paulo, São Paulo. Rua do Matão 321, Travessa 14, São Paulo, SP, Brazil, CEP: 05508-90o. E-mail: lfsilveira@uol.com.br

${ }^{1}$ Author for correspondence; e-mail: aniwa@usp.br; fax: 551130917553. 


\section{ANEXO III - Artigo publicado}

Pereira S.L., Grau E.T., Wajntal A., 2004. Molecular architecture and rates of DNA substitutions of the mitochondrial control region of cracid birds. Genome 47: 535-545. 


\title{
Molecular architecture and rates of DNA substitutions of the mitochondrial control region of cracid birds
}

\author{
Sergio L. Pereira, Erwin T. Grau, and Anita Wajntal
}

\begin{abstract}
The control region (CR) plays an important role in replication and transcription in the mitochondrial genome. Its supposedly high rate of DNA substitution makes it a suitable marker for studies of population and closely related species. Three domains can be identified in CR, each having its own characteristics regarding base composition, pattern of variability and rate of DNA substitution. We sequenced the complete CR for 27 cracids, including all 11 genera to characterize its molecular organization, describe patterns of DNA substitution along the gene, and estimate absolute rates of DNA substitution. Our results show that cracid CR organization and patterns of DNA substitution are typical of other birds. Conserved blocks $\mathrm{C}$ and B, fused CSB2/3, and a putative segment for bidirectional replication not usually present in birds were identified in cracids. We also suggest a new delimitation for domains to allow better comparisons among CRs at different taxonomic ranking. Our estimates of absolute rates of DNA substitution show that, in general, CR evolves at a rate slower than that of two protein-coding genes (CR, 0.14\%-0.3\%; ND2, $0.37 \%-$ $0.47 \%$; and cytochrome $b, 0.29 \%-0.35 \%$ per site per million years within genera). Within CR domains, rates within genera ranged from $0.05 \%$ to $0.8 \%$ per site per million years.
\end{abstract}

Key words: mitochondrial control region, molecular evolution, Cracidae, Aves.

Résumé : La région de contrôle (CR) joue un rôle important dans la réplication et la transcription du génome mitochondrial. Le fait qu'on y rapporte un taux de substitutions nucléotidiques élevé en fait un bon marqueur pour l'étude de populations ou d'espèces très apparentées. Trois domaines sont identifiables au sein de la CR, chacune ayant ses propres caractéristiques en matière de composition en bases, du type de variabilité observée et du taux de substitutions. Les auteurs ont séquencé la CR complète chez 27 cracidés comprenant l'ensemble des 11 genres afin de caractériser son organisation moléculaire, de décrire les types de substitutions rencontrées et d'estimer les taux absolus de substitutions. Ces résultats montrent que l'organisation et les types de substitutions observés au sein de la CR chez les cracidés est typique de ceux observés chez d'autres oiseaux. Une conservation des blocs $\mathrm{C}$ et $\mathrm{B}$, une fusion CSB2/3 et un segment potentiel de réplication bidirectionnelle, lesquels ne sont pas présents habituellement chez les oiseaux, ont été observés chez les cracidés. Les auteurs suggèrent également une nouvelle délimitation des domaines afin de permettre de meilleures comparaisons entre CR à différents niveaux taxinomiques. Les estimations des taux absolus de substitutions montrent que les $\mathrm{CR}$ évoluent plus lentement, en général, que deux gènes codant pour des protéines $(\mathrm{CR}, 0,14 \%$ à $0,3 \%$; ND2, $0,37 \%$ à $0,47 \%$; et cytochrome $b, 0,29 \%$ à $0,35 \%$ par site par million d'années au sein des genres). $\mathrm{Au}$ sein des domaines de la CR, les taux au sein des genres variaient entre $0,05 \%$ et $0,8 \%$ par site par million d'années.

Mots clés : région de contrôle mitochondrial, évolution moléculaire, Cracidae, Aves.

[Traduit par la Rédaction]

\section{Introduction}

In contrast to the high variability displayed by the organization of the mitochondrial (mt) genome of lower eukaryotes and plants, evolution shaped the metazoan mt genome into a molecule characterized by 13 protein-coding genes, 22 transfer RNAs (tRNAs), two ribosomal genes (rDNA), and a control region $(\mathrm{CR})$ or D-loop-containing region (D-loop) (e.g.,

Received 12 September 2003. Accepted 9 January 2004. Published on the NRC Research Press Web site at http://genome.nrc.ca on 21 May 2004.

Corresponding Editor: B. Golding.

S.L. Pereira, ${ }^{1,2}$ E.T. Grau, and A. Wajntal. Departamento de Biologia, Instituto de Biociências, Universidade de São Paulo, Rua do Matão, 277, São Paulo, SP 05508-900, Brazil.

${ }^{1}$ Present address: Centre for Biodiversity and Conservation Biology, Royal Ontario Museum, 100 Queen's Park, Toronto, ON M5S 2C6, Canada.

${ }^{2}$ Corresponding author (e-mail: sergio.pereira@utoronto.ca). 
Saccone et al. 1999; Pereira 2000; Rest et al. 2003), responsible for the regulation of transcription and replication of the mtDNA (e.g., Taanman 1999).

The rate of evolution of CR for human mtDNA seems to evolve faster than the rest of $\mathrm{mt}$ genome (Aquadro and Greenberg 1983; Cann et al. 1984). This finding was accepted as a general rule for metazoan CRs, making it of common use in population genetic studies (e.g., Avise et al. 1987; Baker and Marshall 1997), whereas other mt genes were chosen for phylogenetic studies at the species level and above (e.g., Kocher et al. 1989; Zink et al. 1998). However, this apparent faster rate of DNA substitution of CR is not a general characteristic among metazoans (Brown et al. 1986; Desjardins and Morais 1991). Examples of slower rates of DNA substitution in the CR of gulls (Crochet and Desmarais 2000) and galliformes (Kimball et al. 1997; Randi and Lucchini 1998) compared with other mt regions have been reported.

Moreover, length variation has imposed an alignment problem and limited the use of CR in phylogenetic studies, even for congeneric taxa. Most avian CR sequenced to date are between 1000 and 1500 bp (Baker and Marshall 1997; Ruokonen and Kvist 2002), but it can reach as long as 1758 bp in Adélie penguins (Ritchie and Lambert 2000), and $2040 \mathrm{bp}$ in the Little Blue penguin (Slack et al. 2003). Length variation is mainly due to insertion or deletion of a few nucleotides and varying numbers of tandem repeats or microsatellites (Baker and Marshall 1997; Sbisá et al. 1997). For example, the Little Blue penguin CR has two sets of tandem repeats, one consisting of 79 bp repeated 9,12 , or 13 times, plus an incomplete repeat of $49 \mathrm{bp}$, and the other set consisting of a 7-bp string repeated 13,14, 18, or 20 times, followed by an incomplete 6-bp string (Slack et al. 2003). The CR of the Adélie penguin has an 81-bp string repeated five times and 30 copies of a four nucleotide-long microsatellite (Ritchie and Lambert 2000).

Three domains can be recognized in the CR of vertebrates: termination-associated sequences (TAS) at the $5^{\prime}$ end, a central conserved domain (central), and a conserved sequence block (CSB) at the $3^{\prime}$ end. They are identified according to the distribution of variable nucleotides positions, base frequency, and conserved sequence regions, and the insertion of repeats and microsatellites (Anderson et al. 1981; Baker and Marshall 1997; Berg et al. 1995; Brown et al. 1986; Saccone et al. 1999) (Fig. 1). In mammals, the conserved sequence regions identified (e.g., Anderson et al. 1981; Sbisá et al. 1997) in the CR are the extended terminationassociated sequence blocks (ETAS), conserved sequence blocks (B- to F-boxes, CSB-1, CSB-2, and CSB-3), heavystrand replication origin $\left(\mathrm{O}_{\mathrm{H}}\right)$, and the transcription promoters for both the heavy and light strands (HSP and LSP). Not all conserved features of mammals are also found in birds. A variable number of termination-associated sequences (TAS) can be found in the TAS domain (Desjardins and Morais 1990; Baker and Marshall 1997; Randi and Lucchini 1998; Ruokonen and Kvist 2002), conserved blocks C, D, and F in the central domain are generally present, but conserved blocks E and B are not found in all groups studied (Baker and Marshall 1997; Ruokonen and Kvist 2002). In the CSB domain, only CSB-1 and the $\mathrm{O}_{\mathrm{H}}$ are found in birds, although in some species the putative bidirectional promoter for tran- scription of the heavy and light strands and a fused CSB2/3 are present (Desjardins and Morais 1990; L'Abbé et al. 1991; Baker and Marshall 1997; Randi and Lucchini 1998; Ruokonen and Kvist 2002). Moreover, Ruokonen and Kvist (2002) compared the CR in birds and mammals and stated that only two conserved motifs, D box and CSB-1, show considerable sequence conservation across avian and mammalian taxa. They also identified a specific conserved block in the avian central domain, and named it the Bird-box.

In this paper, we sequenced the complete $\mathrm{mt} \mathrm{CR}$ of 27 cracids (Aves, Galliformes), representing all 11 genera within this endangered Neotropical family. Our goals were (i) to identify conserved blocks, (ii) to characterize the dynamics of DNA substitution of each of the three typical domains of the CR, (iii) to estimate the rate of DNA substitution for the CR and for each domain based on published estimates of divergence time for cracids using molecular data (Pereira et al. 2002), and (iv) compare with those rates for the second subunit of NADH reductase (ND2) and cytochrome $b$. Also, we propose changes in domain definition to ease comparison among different taxonomic levels.

\section{Materials and methods}

\section{Taxa sampling}

We sampled 27 species of cracid birds belonging to all 11 genera in the family (Table 1). Blood samples are deposited at the Laboratório de Genética e Evolução Molecular de Aves (LGEMA) at the University of São Paulo, Brazil, except Mitu salvini, which was deposited at the Royal Ontario Museum, Toronto, Ont. DNA was extracted following standard protocols (Sambrook et al. 1989).

\section{DNA amplification and sequencing}

Some sequences used here were obtained previously by Pereira et al. (2002) and Pereira and Baker (2004), and are indicated in Table 1. For those obtained in the present study, the following primers were used for amplification and sequencing: D-loop L and D-loop H (Grau et al. 2003); H774, H1251, and L436 (Sorenson et al. 1999) and D-loop 774L (GAGACGGTTGGCGTATATGG) reversed from the original 774H (Sorenson et al. 1999) for the control region; H5766, H6313, and 5143L (Sorenson et al. 1999) and ND25766L (CGWAAAATCCTAGCCTTCTCATCC) reversed from primer H5766 (Sorenson et al. 1999) for the second subunit of NADH reductase (ND2); and reverse L (Cheng et al. 1994), internoH2 (Miyaki et al. 1998), universal L, and universal $\mathrm{H}$ (Kocher et al. 1989) for cytochrome $b$ (cyt $b$ ). DNA amplifications and sequencing reactions were performed as described in Grau et al. (2003). Sequencing reactions were loaded in an ABI Prism 377 automated DNA sequencer (Applied Biosystems). To verify that we were amplifying genes of mitochondrial origin and not nuclear inserts, we amplified a large fragment of about $3 \mathrm{~kb}$ with primers L15710 (Sorenson et al. 1999) and 12Send (Haddrath and Baker 2001) for Aburria aburri, Chamaepetes goudotti, and Mitu tuberosa. These primers are located at the end of cyt $b$ and at the end of $12 \mathrm{~S}$ rDNA genes, respectively, and the fragment corresponding to this region contains the ND6, the CR, and three tRNAs. Nested amplifications were then performed with the same primers used for the shorter amplifica- 
Fig. 1. General molecular organization of the mitochondrial control region of birds and mammals. TAS, termination associated sequences, found in varying number of copies; ETAS, extended TAS; R1-R3, tandem repeats; B-F and Bird, conserved sequence blocks; $\mathrm{O}_{\mathrm{H}}$, origin of replication of $\mathrm{H}$ strand; CSB, conserved sequence block; LSP and HSP, light and heavy strand transcription promoters; MS, microsatellite and (or) tandem repeats. C-string is also known as goose hairpin and can be present in two copies in some birds. Glu, Pro, and Phe are tRNAs for glutamine, proline, and phenylalanine, respectively.

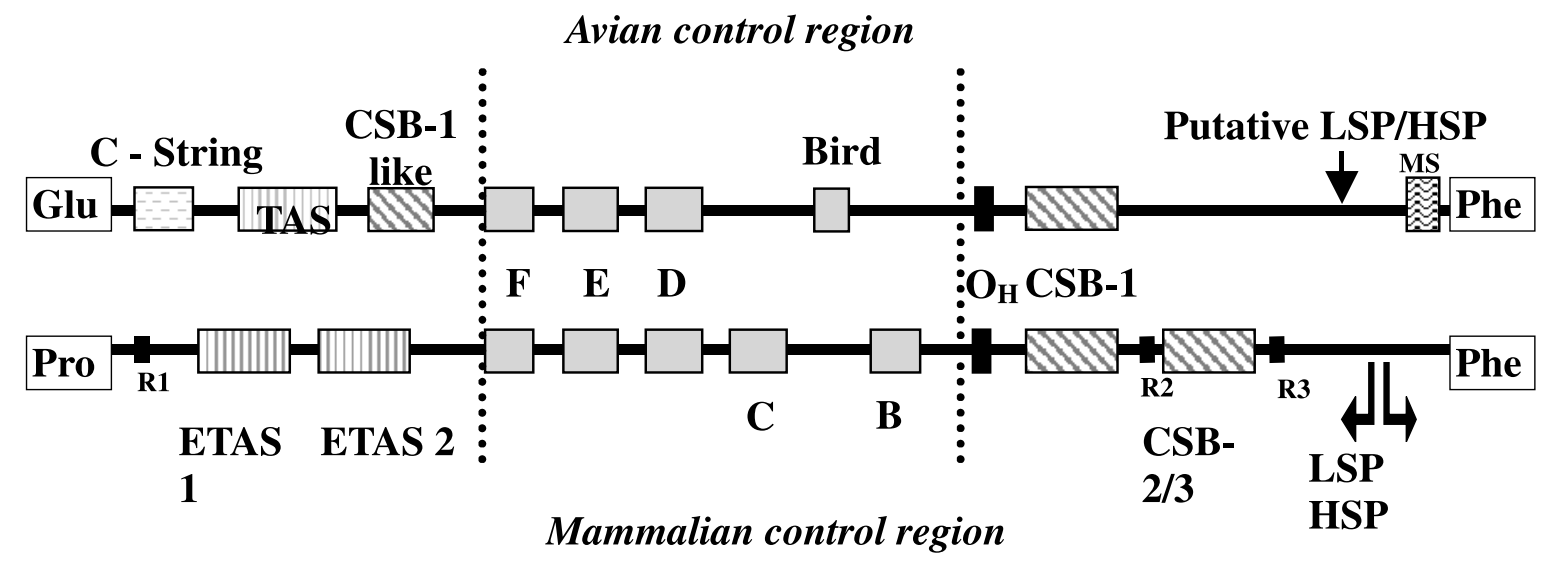

tions given above for $\mathrm{CR}$ and cyt $b$. Conditions for long PCR were the same as described in Grau et al. (2003) except that extension time in each cycle was for $3 \mathrm{~min}$.

\section{Sequence alignment and identification of conserved motifs in Cracidae CR}

Both strands of each DNA fragment were visually aligned and corrected for ambiguities in Sequence Navigator 1.0.1 (Applied Biosystems). Then, the L-strand of each species was exported as text and imported into MacClade 4.0 (Maddison and Maddison 2000) to be visually aligned. To delimit domains and conserved motifs of the CR in Cracidae birds, we compared our sequences to those corresponding CR of other avian and vertebrates previously published (e.g., Desjardins and Morais 1990; Randi and Lucchini 1998; Ruokonen and Kvist 2002; Sbisá et al. 1997; Steinborn et al. 1998). We followed domain nomenclature based on Sbisá et al. 1997.

\section{Base composition and patterns of substitution}

For all 27 species, heterogeneity of base composition using variable sites only was checked by a $\chi^{2}$ test $(P=0.05)$ as implemented in TreePuzzle (Strimmer and von Haeseler 1996) and overall mean base frequencies and distribution of variable sites was estimated using MEGA 1.0 or 2.0 (Kumar et al. 2001). Uncorrected ( $p$ ) distances and model-based distances were estimated in PAUP 10.0 (Swofford 2002). These model-based distances were chosen according to a hierarchical likelihood ratio tests as implemented in Modeltest (Posada and Crandall 1998).

\section{Saturation and comparisons of absolute substitution rates between CR and ND2 or cyt $b$}

Saturation of DNA substitution for each gene was examined by plotting pairwise uncorrected $p$ distance against model-based distances. We estimated "absolute" rates of DNA substitution per site per million years for the CR and for its three domains, and ND2 and cyt $b$ dividing branch lengths estimated through model-based likelihood distances by the time of duration of that branch, as implemented in r8s (Sanderson 2002). In this case, a data-driven cross-validation test was performed to choose the best smoothing parameter under a semi-parametric approach (penalized likelihood) that will account for variation in rate of DNA substitution among lineages (Sanderson 2002). Generic diversification within Cracidae was estimated by Pereira et al. (2002) to have started 33.3 million years ago and was used as the calibration point for estimating absolute rates of DNA substitution.

\section{Results}

DNA amplification, sequencing, and gene order

The sequences used here are authentic mitochondrial in origin for the following reasons: $(i)$ nested amplification of $\mathrm{CR}$ and the $3^{\prime}$ end of cyt $b$ from large PCR products of about $3 \mathrm{~kb}$ encompassing the region between the ends of cyt $b$ and $12 \mathrm{~S}$ rDNA resulted in identical sequences when comparisons were made between these sequences and those of short amplifications for Aburria aburri, Chamaepetes goudotti, and Mitu tuberosa. In all cases, amplification resulted in single PCR products that provided unambiguous sequences, which showed similarity to corresponding sequences of other birds deposited in GenBank; (ii) CR has typical characteristics of mitochondrial CR such as conserved motifs and gene organization as detected in other Galliformes and differential base composition and relative substitution rates among domains (e.g., Desjardins and Morais 1990; Ruokonen and Kvist 2002; Sbisá et al. 1997); and (iii) the reading frame for both ND2 and cyt $b$ did not show any unexpected stop codon, changes in amino acid sequence or frame shift mutations. The primers D-Loop L and H1251Phe are located in the tRNAs for glutamic acid and phenylalanine, respectively; as no intervening sequences were present between the $\mathrm{CR}$ and any of these tRNAs, the gene order around the control region for the Cracidae species studied here is probably the same as that found in most birds studied so far, including Galliformes and Anseriformes (review in Pereira 2000).

\section{Characterization of the control region for Cracidae birds}

Cracidae CR sequences ranged from 1145 bp in Penelope ochrogaster to 1197 bp in Pauxi pauxi with a mean size of 
Table 1. Species used in the present study with their respective voucher number and GenBank accession numbers for the control region (CR), NADH reductase (ND2), and cytochrome $b$ (cyt $b$ ).

\begin{tabular}{|c|c|c|c|c|}
\hline & Voucher & $\mathrm{CR}$ & ND2 & Cyt $b$ \\
\hline Aburria aburri & $\mathrm{C} 172 / \mathrm{C} 173$ & AF165430 & AY $140740 *$ & AF165466* \\
\hline Chamaepetes goudotii & C189 & AF165434 & AY140741* & AF165467* \\
\hline Crax alberti & $\mathrm{C} 168 / \mathrm{C} 169$ & AY145304 & AY141930 & AY141920 \\
\hline Crax alector & $\mathrm{C} 160$ & AY145315 & AY141931 ${ }^{\dagger}$ & AY $141921^{\dagger}$ \\
\hline Crax blumenbachii & $\mathrm{C} 118 / \mathrm{C} 186$ & AF165438 & AY140747* & AF165468* \\
\hline Crax daubentoni & C195 & AY145305 & AY141932 & AY $141922^{\dagger}$ \\
\hline Crax rubra & $\mathrm{C} 170$ & AY145307 & AY141935 & AY $141925^{\dagger}$ \\
\hline Mitu mitu & C201/C202 & AY145308 & AY141936 & AY $141926^{\dagger}$ \\
\hline Mitu salvini & $\mathrm{C} 261 / \mathrm{C} 262$ & AY145309 & AY141937 ${ }^{\dagger}$ & AY $141927^{\dagger}$ \\
\hline Mitu tomentosa & C159 & AY145310 & AY141938 & AY $141928^{\dagger}$ \\
\hline Mitu tuberosa & $\mathrm{C} 176 / 177$ & AF165437 & AY140748* & AF165469* \\
\hline Nothocrax urumutum & $\mathrm{C} 60 / \mathrm{C} 157$ & AF165440 & AY140749* & AF165470* \\
\hline Pauxi unicornis & $\mathrm{C} 263$ & AY145317 & AY141939 ${ }^{\dagger}$ & AY141929 \\
\hline Penelope obscura & $\mathrm{C} 28 / \mathrm{C} 150$ & AF165432 & AY140742* & AF165474* \\
\hline Penelope ochrogaster & C197 & AY145311 & AY367095, AY367089 & AY367101 \\
\hline Penelope purpuracens & C196 & AY145312 & AY367097, AY367091 & AY367103 \\
\hline Penelope supercilliaris & $\mathrm{C} 084$ & AY145313 & AY367096, AY367090 & AY367102 \\
\hline Penelopina nigra & C193/C192 & AF165433 & AY140743* & AF165475* \\
\hline Pipile cujubi & $\mathrm{C} 156$ & AY145314 & AY367098, AY367092 & AY367104 \\
\hline Pipile cumanensis & $\mathrm{C} 164$ & AY145319 & AY367099, AY367093 & AY367105 \\
\hline Pipile jacutinga & $\mathrm{C} 50 / \mathrm{C} 100$ & AF165431 & AY140744* & AF165476* \\
\hline Pipile Pipile & $\mathrm{C} 264$ & AY145320 & AY367100, AY367094 & AY367106 \\
\hline
\end{tabular}

*Obtained previously by Pereira et al. (2002).

${ }^{\dagger}$ Pereira and Baker (2004).

1154 bp. The alignment was 1206 bp long, including gaps owing to deletions or insertions (indels) ${ }^{3}$. Indels were no longer than $3 \mathrm{bp}$, except for two large indels in the CSB domain. One of them is characterized by an insertion of $11 \mathrm{bp}$ in Crax alberti (CGCTTTACAAA) and 12 bp in Crax daubentoni (CGCTTTACAAAA) from site 947 to 958. The other large indel is due to a 49-bp string in Pauxi pauxi (AAACCAACCAAAACAAACAAACTTTTTTTTCACTTT CACAACCCTGGCT), and 9 bp in Crax blumenbachii and Crax globulosa (AAATCGGCC) from site 1128 to 1176. Nucleotide frequencies were homogeneous among taxa $(P=$ 1.0): $\mathrm{A}=25.8 \%, \mathrm{C}=27.5 \%, \mathrm{G}=15.5 \%$, and $\mathrm{T}=31.3 \%$. However, these frequencies are not reflected in each domain, as shown in Fig. 2. Figure 3 shows the molecular organization of conserved blocks along the CR of Cracidae birds, and the alignment of the conserved regions is given for all 27 species studied. Of the 1206 aligned sites, 929 $(77.0 \%)$ are invariable.

\section{TAS domain}

We delimited the TAS domain between base 1 and 379 in our alignment. It has a similar percentage of $\mathrm{A}, \mathrm{C}$, and $\mathrm{T}$ and is low in $\mathrm{G}$ (Fig. 2). We detected a C-rich region, the $\mathrm{C}$ string, from positions 56 to 77 , and 5 repeats of a TA motif (TAS) that may be responsible for the termination of the replication of the mtDNA (Doda et al. 1981) stretching from position 124 to 174 . They are separated by $12,2,4$, and 3 nucleotides, respectively. A GYRCAT motif is normally associated with TAS for correct function (Dufresne et al. 1996; Douzery and Randi 1997) and was found upstream of TAS1 in cracids. Cracids have one copy of a 29-bp segment between positions 287 and 315 named "CBS-1 like", which shows similarity to CSB-1 present in the CBS domain. This segment is found in multiple copies in other Galliformes and in Anseriformes (Desjardins and Morais 1990; Randi and Lucchini 1998; Quinn and Wilson 1993).

\section{Conserved central domain}

This region, which starts at base 380 and ends at base 830 , is well conserved among cracids. The central domain has a lower percentage of $\mathrm{A}$ and $\mathrm{G}$ compared with $\mathrm{C}$ and $\mathrm{T}$ (Fig. 2). Conserved blocks F (positions 380-407), E (425444), and D (484-508) and the Bird box (770-784) were easily identified in cracids. The $\mathrm{C}$ and $\mathrm{B}$ boxes usually found

\footnotetext{
${ }^{3}$ Supplementary data for this article are available on the Web site or may be purchased from the Depository of Unpublished Data, Document Delivery, CISTI, National Research Council Canada, Ottawa, ON K1A 0S2, Canada.
} 
Fig. 2. Base composition of the mitochondrial control region (CR) and its domains (TAS, central, and CBS) in Cracidae birds.

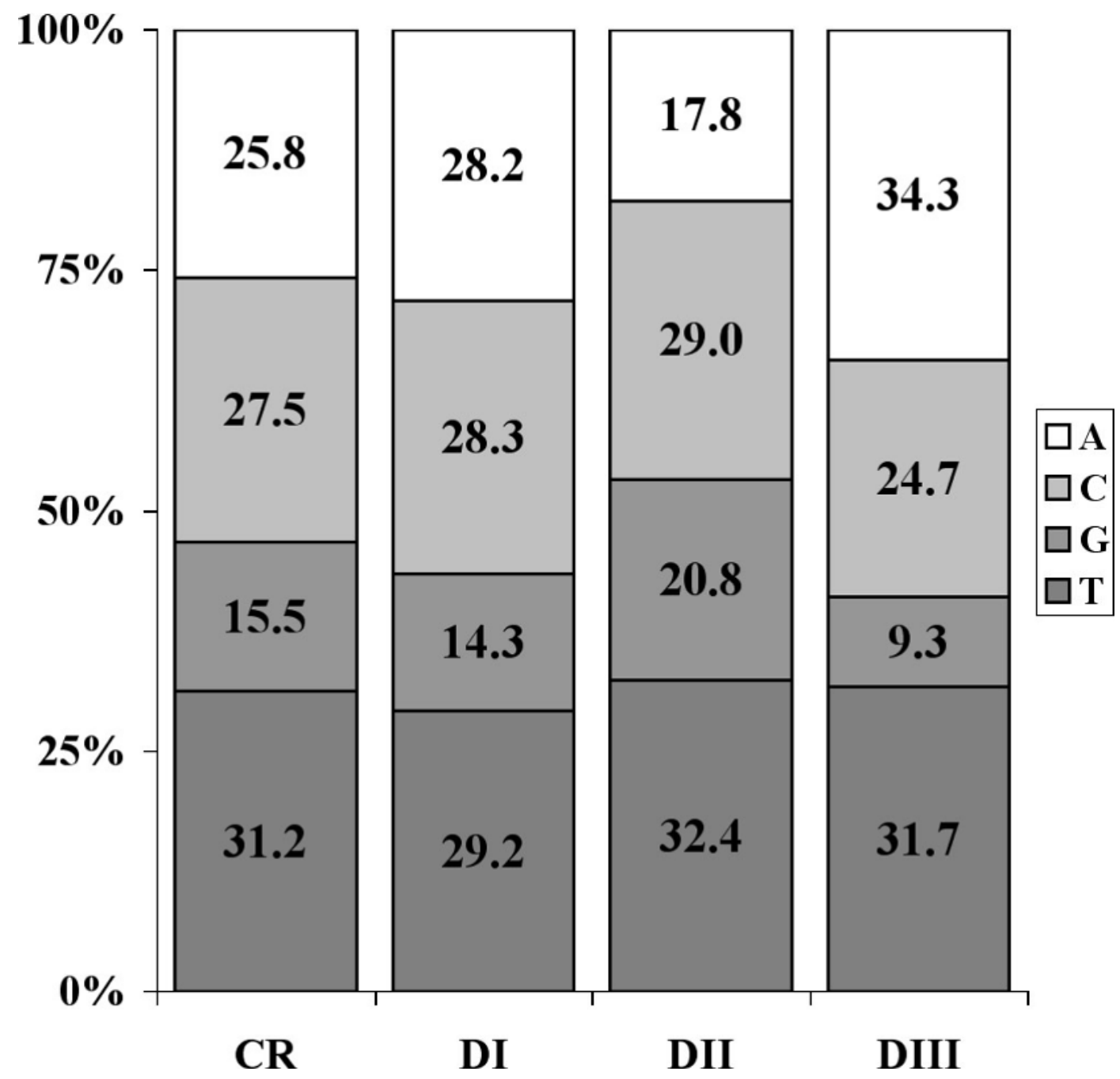

in mammals, but not all birds, were found in all cracids sequenced here, in positions 540-558 and 787-804, respectively. Although these two boxes are conserved in cracids, they present less similarity with other identified avian and mammalian C and B boxes (e.g., Douzery and Randi 1997; Randi and Lucchini 1998; Buehler and Baker 2003). Another conserved region among cracids located between positions 602 and 638 is similar to what was described by Saunders and Edwards (2000) as the B box in New World Jays. The origin for replication of the $\mathrm{H}$-strand, $\mathrm{O}_{\mathrm{H}}$, is located between positions 808 and 819 .

\section{CBS domain}

This domain is 376 bp long, ranging from base 831 to 1206 in our alignment. This domain is A and T rich, but $\mathrm{G}$ poor (Fig. 2). CSB-1 was detected in all cracids analyzed between positions 831 and 856. A region similar to the fused CSB-2 and CSB-3 found in some mammals (Douzery and Randi 1997) was also identified from position 885 to 912. The putative bidirectional promoter (L'Abbé et al. 1991) was also found in cracids (1026-1055). Although microsatellite sequences are common at the CSB domain in some avian taxa (e.g., Berg et al. 1995; Ritchie and Lambert 2000; Slack et al. 2003; Buehler and Baker 2003), no microsatellite sequences are present in cracids. However, the insertion present at the $3^{\prime}$ end of the CBS domain in Pauxi pauxi described at the beginning of this section shows an imperfect AACC motif repeated four times.

\section{Patterns of substitution in conserved blocks}

Among the conserved regions detected in cracids, the $\mathrm{D}$, B, and Bird boxes, and the B box of Saunders and Edwards (2000), as well as termination-associated sequences TAS1, TAS2, and TAS4, did not show any DNA substitution (Fig. 3). Most DNA substitutions in other conserved regions are transitions (Fig. 3). Distribution of variable sites along the CR of cracid birds is shown in Fig. 4. TAS and central domains are the most and least variable, respectively. Distribution of variable sites is more homogeneous along the CSB domain than in the other two domains. In a 50-bp sliding window, the two most variable segments in the CR are present in the TAS domain (windows 1-50 and 301-350) and no conserved sequence regions are presented in these ranges. The third most variable 50-bp segment is in the central do- 

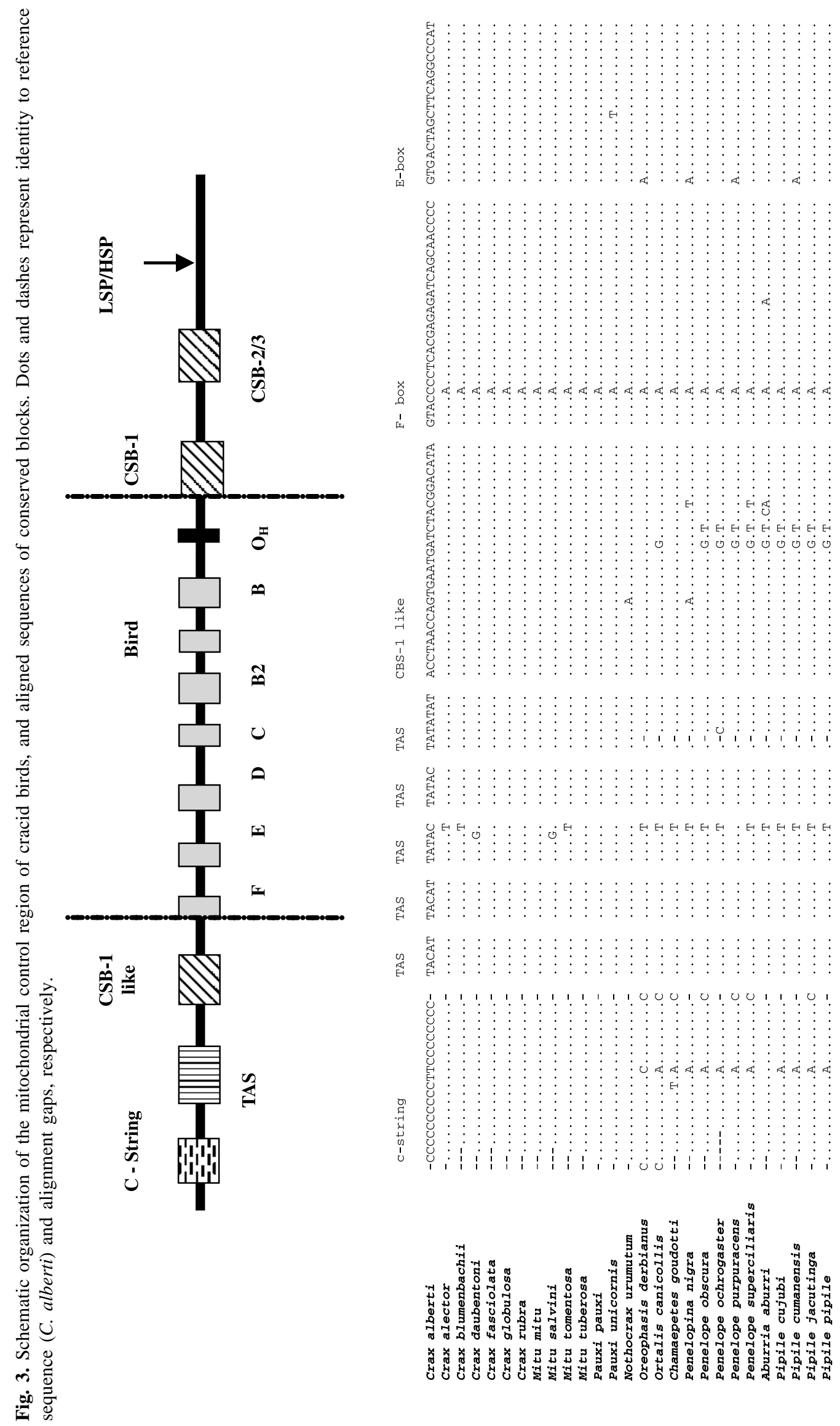


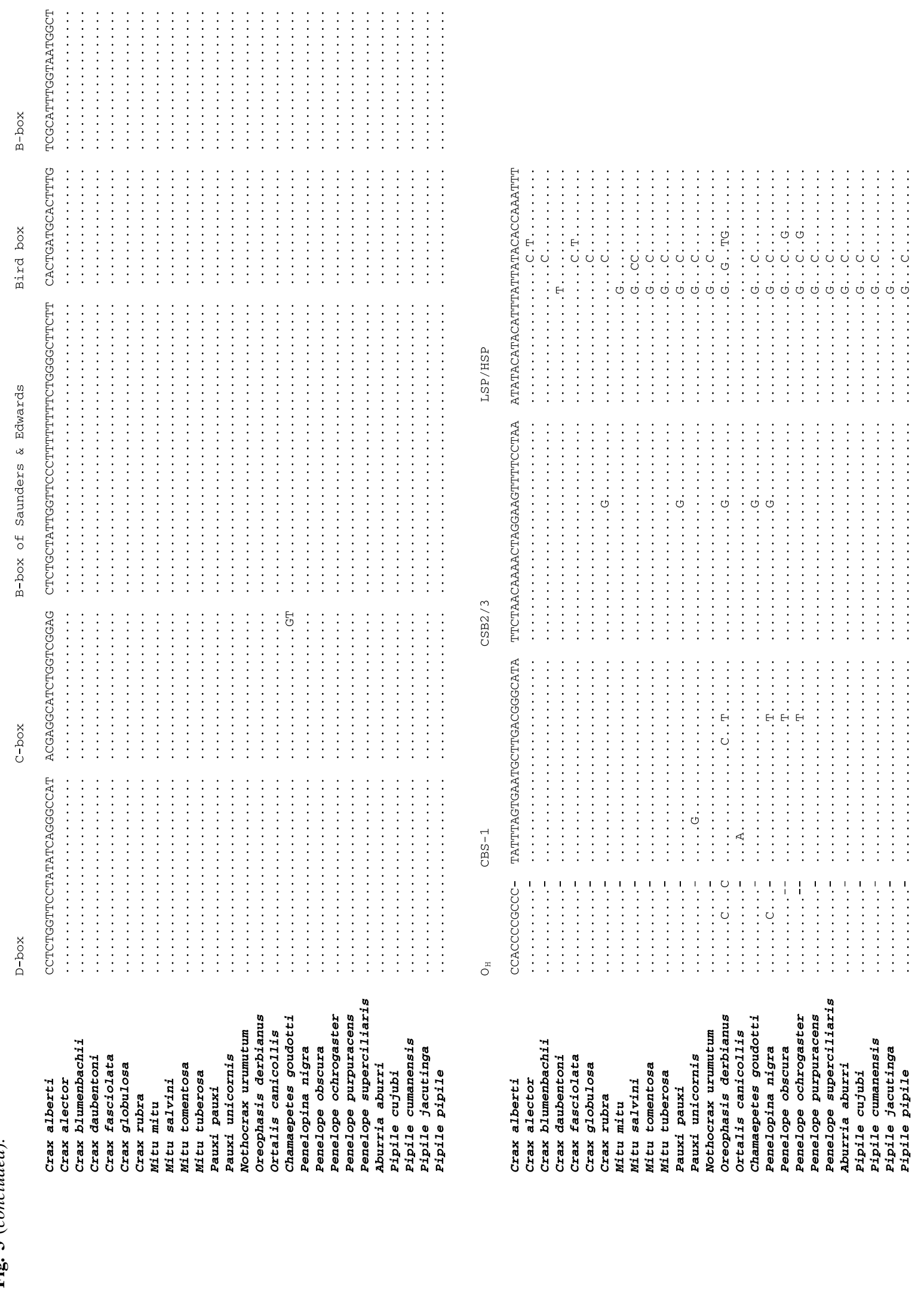

(C) 2004 NRC Canada 
Fig. 4. Distribution of variable sites along cracid control region based on a 50-bp window, excluding gapped positions. Domain limits are indicated.

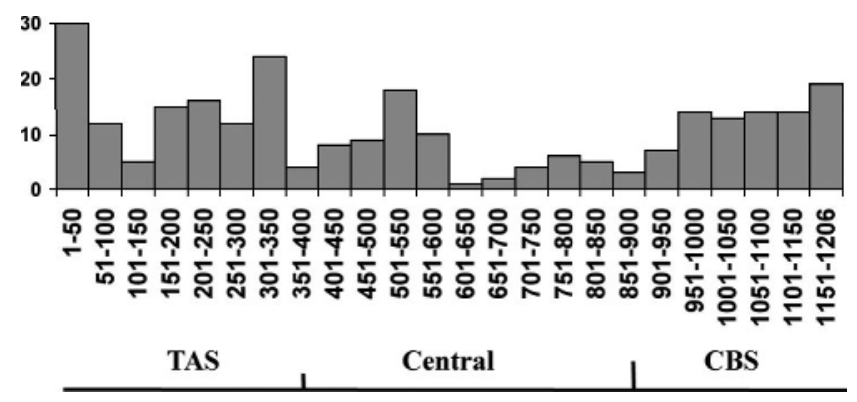

main (501-550) and contains the $C$ box. The variation in this case is due mostly to the segment upstream from the $\mathrm{C}$ box $^{3}$.

\section{Saturation and absolute rates of DNA substitution}

Significant saturation was neither detected for the whole CR, ND2, cyt $b$ (Fig. 5), nor for any of the domains independently (not shown). The best-fitting DNA substitution models chosen by hierarchical likelihood ratio tests are shown in Table 2. Based on divergence dates and confidence intervals estimated by Pereira et al. (2002), and on the model-based distances we estimated "absolute" rates of DNA substitution for cracid CR (and its domains), and for ND2 and cyt $b$ (Table 2). For the complete CR averaged across all 27 species analyzed, this rate was estimated to be around $0.16 \%$ per site per million years, much lower than the overall $0.40 \%$ and $0.32 \%$ per site per million years estimated for ND2 and cyt $b$, respectively. However, CSB domain in general evolves at a similar or faster rate than the protein-coding genes. Within genera estimates are also provided (Table 2). In this case, we grouped Mitu and Pauxi in one cluster because they seem not to be reciprocally monophyletic genera (Pereira and Baker 2004). Also, Aburria and Pipile were also considered a group, as the monoespecific Aburria seems to be embedded within Pipile (Grau et al. unpublished). In general, curassows (Crax, Mitu, and Pauxi), chachalacas (Ortalis), and the horned guan (Oreophasis) have higher absolute rates of DNA substitution than guans for CR, ND2 and cyt $b$. Ortalis have higher general rates compared to any other genus.

\section{Discussion}

\section{Molecular architecture of the mitochondrial control region of cracid birds}

In the present work, we sequenced the control region, the main non-coding region of the mitochondrial genome, for 27 species of cracid birds, representing all 11 genera in the family. Our goal was to characterize its molecular organization and compare its rate of DNA substitution to that of other two mitochondrial genes (ND2 and cyt $b$ ).

The detection of conserved sequence regions was performed by comparison with other previously published studies, especially Randi and Lucchini (1998), Ruokonen and Kvist (2002), Sbisá et al. (1997), and Steinborn et al. (1998). No unusual features were detected for the CR in cracids, and
Fig. 5. Saturation plots for cracid control region, ND2 and cyt $b$. $x$ axis, corrected distances for each gene as shown in Table 2; $y$ axis, $p$ distances.
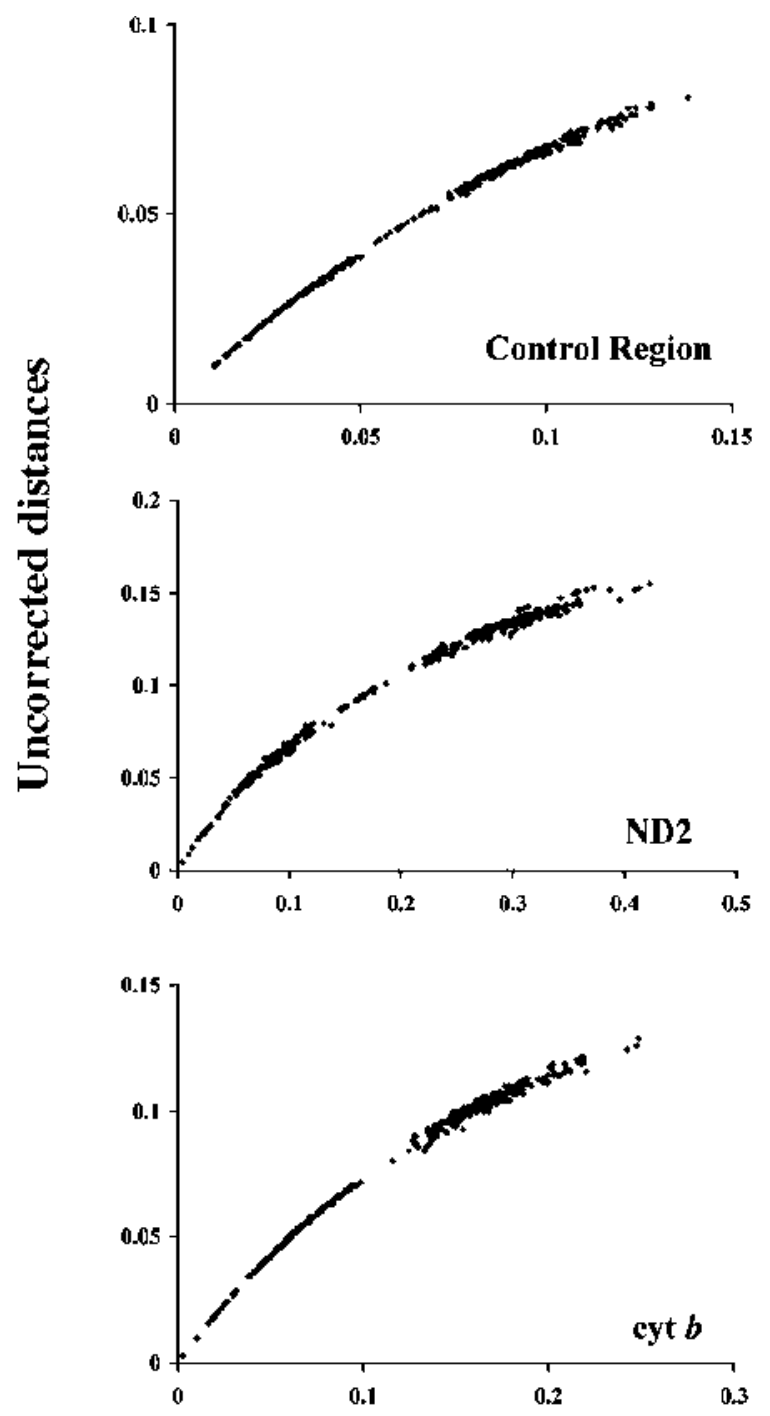

Corrected distances

this region seems to be highly conserved among the species studied, even though the intergeneric divergence times are as old as 40 million years and as recent as 3 million years (Pereira et al. 2002). In fact, this region showed $77 \%$ of identical nucleotide positions among all species, mostly distributed throughout the central domain and in the conserved sequence regions in TAS and CSB domains. All of the conserved sequence regions usually found in vertebrate CRs were detected in cracids, including blocks not identified in other avian species (e.g., Eberhard et al. 2001; Ruokonen and Kvist 2002; Buehler and Baker 2003), namely a CSB-1like block in TAS, blocks $\mathrm{E}, \mathrm{C}$, and $\mathrm{B}$ in central, and the bidirectional promoter and fused CSB2/3 in the CSB domain.

Comparing cracid to other avian and mammalian CRs led us to notice that domain and block definitions are not well characterized and this might reflect comparisons made to mammals in earlier studies, and even to avian taxonomic 
Table 2. Model of DNA evolution for each mitochondrial DNA partition and absolute rates of DNA substitution in percentage per site per million years for cracids (overall rate and for each genus).

\begin{tabular}{|c|c|c|c|c|c|c|}
\hline & $\mathrm{CR}$ & TAS & Central & CSB & ND2 & Cyt $b$ \\
\hline Model of DNA substitution* & GTR & HKY & HKY & $\mathrm{TN}$ & $\mathrm{TN}$ & HKY \\
\hline Proportion of invariable sites & 0.63 & 0.48 & 0.76 & NA & NA & 0.60 \\
\hline Shape parameter of gamma distribution & 0.86 & 0.69 & 1.05 & 0.20 & 0.27 & 3.01 \\
\hline Overall rate & 0.160 & 0.175 & 0.063 & 0.479 & 0.401 & 0.323 \\
\hline Crax & 0.166 & 0.179 & 0.054 & 0.807 & 0.426 & 0.345 \\
\hline Mitu-Pauxi group & 0.180 & 0.223 & 0.060 & 0.679 & 0.418 & 0.347 \\
\hline Nothocrax & 0.166 & 0.117 & 0.063 & 0.371 & 0.443 & 0.339 \\
\hline Ortalis & 0.297 & 0.323 & 0.128 & 0.287 & 0.471 & 0.337 \\
\hline Oreophasis & 0.217 & 0.213 & 0.049 & 0.254 & 0.430 & 0.334 \\
\hline Chamaepetes & 0.200 & 0.256 & 0.063 & 0.164 & 0.380 & 0.307 \\
\hline Penelopina & 0.186 & 0.265 & 0.074 & 0.217 & 0.398 & 0.295 \\
\hline Penelope & 0.141 & 0.212 & 0.056 & 0.130 & 0.368 & 0.296 \\
\hline Aburria-Pipile group & 0.150 & 0.251 & 0.064 & 0.320 & 0.370 & 0.295 \\
\hline
\end{tabular}

*GTR, general time reversible, Rodriguéz et al. (1990); TN, Tamura and Nei (1993); HKY, Hasegawa et al. (1985); NA, not applicable for that partition.

ranks above the generic level, making the recognition of those regions difficult. For example, the B block present in cracids and some other birds (Baker and Marshall 1997; Ruokonen and Kvist 2002) is located between the Bird box and the $\mathrm{O}_{\mathrm{H}}$, and seem to be more variable than in mammals, (Ruokonen and Kvist 2002), which hindered earlier identification of the B box in birds. Another B box, as defined by Saunders and Edwards (2000) between C and Bird box in New World Jays, is T rich and does not have similarity with the corresponding mammalian B box. Interestingly, both the B box of Saunders and Edwards (2000) and the mammalian B box are present in cracids and several other birds, although previous publications on $\mathrm{CR}$ of other birds did not identify their presence. For example, in the alignment presented in Randi and Lucchini, (1998) for partridges, the B box as defined by Saunders and Edwards (2000) can be located around positions 590 to 620 , and the B box around positions 750 to 780 in their published alignment. Similarly, these blocks can be found, respectively, around positions 1160-1180 and 1330-1350 in parrots (Eberhard et al. 2001). We did not try to make a comprehensive comparison of CR in birds and other vertebrates, as our findings in cracid birds do not change any of the conclusions about avian CR presented recently by Ruokonen and Kvist (2002).

However, it is clear that for future comparisons and studies of evolution of CR in vertebrates, a better proposal for delimitation of domains and conserved blocks is necessary. This is a difficult task to perform, as the variability of CR above generic taxonomic ranking may impose serious alignment problems. However, we suggested domain limitation to be done by looking at conserved blocks easily identified in each domain in a wider range of taxonomic groups. Therefore, we proposed that the beginning of the central domain should be delimited at the $5^{\prime}$ end by the $\mathrm{F}$ box and the beginning of the CSB domain to be limited at the $5^{\prime}$ end by CSB1. The F box and CSB1 seem to be a very conserved feature of CR across several taxonomic rankings. This delimitation avoids the problem of not identifying a minimum conserved string in the variable regions that characterize the $3^{\prime}$ end of both TAS and central domains in comparisons above generic levels. The functional importance of some conserved blocks are not yet known and future biochemical research may help to improve our understanding about $\mathrm{CR}$ evolution and functionality.

\section{Rates of DNA substitution of the mitochondrial control region of cracid birds}

CR did not show saturation of DNA substitutions. This is not surprising, given that our comparisons of DNA substitution rates with ND2 and cyt $b$ showed that CR evolves at a slower rate than these two genes, and neither of these protein-coding genes were shown to be saturated at the generic level as analyzed previously by Pereira et al. (2002). This result is interesting as cracids are among the oldest groups of modern birds and consistent with the findings that some lineages at the base of the avian tree have slower rates of evolution compared to more recent avian lineages (van Tuinen and Dyke 2004). Comparing both mt protein-coding genes to each domain in CR showed that CSB has higher or similar rate of DNA substitution, and TAS and especially central domain, are evolving at a much slower rate than ND2 and cyt $b$. These results add to a body of evidence (Kimball et al. 1997; Randi and Lucchini 1998; Zink et al. 1998; Ruokonen and Kvist 2002) that, at least in birds, the CR is not evolving faster than protein-coding genes. Our estimates of absolute rates of DNA substitution (Table 2) are in the same order of magnitude as estimates for other galliform birds (0.7 and $0.5 \%$ per million years for the TAS domain and cyt $b$, respectively; Kimball et al. 1997) and mammals $(0.48 \%$ per million years for the whole CR of cervids, or $0.17 \%$ per million years excluding saturated transitions; Douzery and Randi 1997).

Estimates of divergence time and absolute rates of evolution for birds are problematic in many cases owing to the lack of reliable paleontological or biogeographic data that could be used as calibration point. In the case of cracid birds, divergence time estimates in Pereira et al. (2002) were based on a large number of mitochondrial and nuclear sequence data and assuming a split between Anseriformes and Galliformes 85 million years ago (Haddrath and Baker 2001; similar to the estimate of 90 milion years ago obtained by van Tuinen and Hedges 2001). Another study by Pereira and 
Baker (2004) based on mitochondrial DNA sequences and using an internal biogeographic calibration point within curassows has shown congruence with the estimates of Pereira et al. (2002). Therefore, we believe that the calibration point used here, and consequently the estimates of rates of DNA substitution, is reliable. Hence, the slow rates of evolution found for cracid CR and protein-coding genes reflect the old evolutionary age of cracids and comparisons with other groups will only be valid if the estimates of divergence time and rates of evolution for these groups were obtained based on well-justified calibration points and applying a model of DNA substitution that reflects the evolutionary dynamic of those sequences.

Intraspecific variation was not measured in the present study and it could underestimate the rates of evolution estimated here. However, a previous analysis showed the presence of only two haplotypes for the TAS domain and no intraspecific variation for cyt $b$ in 17 Mitu mitu and no intraespecific variation was found for any of these genes in three individuals of M. tuberosa (Grau et al. 2003). This indicates that intraspecific variation in this group is low and certainly would not negatively affect the results of our estimates.

We have shown that CR is evolving at a slower pace than ND2 and cyt b in cracids and we suggest that unless one has empirical evidence that one specific gene in a group of organisms is evolving at a similar rate in another group, extrapolation of absolute rates should be avoided. Rate variation of DNA substitution is known to occur across several organisms (Vawter and Brown 1986), and those extrapolations would do anything but provide unreliable estimates of rates of evolution or of time of divergence.

\section{Acknowledgements}

Cracidae blood samples deposited at the Department of Biology, University of São Paulo, Brazil, were kindly provided by Carlos Keller and Vitor Fasano (Criadouro Tropicus, Brazil), Maurício dos Santos (Criadouro Chaparral, Brazil), Moacyr de Carvalho Dias (Criadouro Poços de Caldas, Brazil), Roberto Azeredo (Fundação CRAX, Brazil), CESP-Paraibuna and Porto Primavera, (São Paulo, Brazil), Fernando Gonzalez-Garcia (Instituto de Ecología and Fundacion Ara, Mexico), and Katya Frank and José Jesus Estudillo-Lopez (Granja La Siberia, Mexico). Mitu salvini samples were kindly donated by Fernando Angulo Pratolongo (Zoocriadero Barbara D'Achille, Peru) and are deposited at the Royal Ontario Museum, Toronto, Ont. This work was supported by CNPq and FAPESP. We thank Dr. Tara A. Paton and two anonymous reviewers for useful suggestions on early versions of this manuscript and Dr. Allan J. Baker for several discussions on the issue of control region evolution in birds.

\section{References}

Anderson, S., Bankier, A.T., Barrel, B.G., de Bruijn, M.H., Coulson, A.R. et al. 1981. Sequence and organization of the human mitochondrial genome. Nature (London), 290: 457-465.
Aquadro, C.F., and Greenberg, B.D. 1983. Human mitochondrial DNA variation and evolution: analysis of nucleotide sequences from seven individuals. Genetics, 103: 287-312.

Avise, J.C., Arnold, J., Ball, R.M., Bermingham, E., Lamb, T., Niegel, J.E., Reeb, C.A., and Saunders, N.C. 1987. Intraespecific phylogeography: the mitochondrial bridge between population genetics and systematics. Annu. Rev. Ecol. Syst. 18: 489-522.

Baker, A.J., and Marshall, H.D. 1997. Mitochondrial control region sequences as tools for understanding evolution. In Avian molecular systematics. Edited by D.P. Mindell. Academic Press, San Diego, Calif. pp. 51-82.

Berg, T., Moum, T., and Johansen, S. 1995. Variable number of simple tandem repeats make birds of the order Ciconiformes heteroplasmic in their mitochondrial genomes. Curr. Genet. 27: 257-262.

Brown, G.G., Gadaleta, G., Pepe, G., Saccone, C., and Sbisá, E. 1986. Structural conservation and variation in the D-loopcontaining region of vertebrate mitochondrial DNA. J. Mol. Biol. 192: $503-511$.

Buehler, D.M., and Baker, A.J. 2003. Characterization of the red knot (Calidris canutus) mitochondrial control region. Genome, 46: $565-572$.

Cann, R.L., Brown, W.M., and Wilson, A.C. 1984. Polymorphic sites and the mechanism of evolution in human mitochondrial DNA. Genetics, 106: 479-499.

Cheng, S., Higuchi, R., and Stoneking, M. 1994. Complete mitochondrial genome amplification. Nat. Genet. 7: 350-351.

Crochet, P.A., and Desmarais, E. 2000. Slow rate of evolution in the mitochondrial control region of gulls (Aves: Laridae). Mol. Biol. Evol. 17: 1797-1806.

Desjardins, P., and Morais, R. 1990. Sequence and gene organization of the chicken mitochondrial genome - a novel gene order in higher vertebrates. J. Mol. Biol. 212: 599-634.

Desjardins, P., and Morais, R. 1991. Nucleotide sequence and evolution of coding and noncoding regions of a quail mitochondrial genome. J. Mol. Evol. 32: 153-161.

Doda, J.N., Wright, C.T., and Clayton, D.A. 1981. Elongation of displacement-loop strands in human and mouse mitochondrial DNA is arrested near specific template sequences. Proc. Natl. Acad. Sci. USA. 78: 6116-6120.

Douzery, E., and Randi, E. 1997. The mitochondrial control region of Cervidae: evolutionary patterns and phylogenetic content. Mol. Biol. Evol. 14: 1154-1166.

Dufresne, C., Mignotte, F., and Guéride, M. 1996. The presence of tandem repeats and the initiation of replication in rabbit mitochondrial DNA. Eur. J. Biochem. 235: 593-600.

Eberhard, J.R., Wringht, T.F., and Bermingham, E. 2001. Duplication and concerted evolution of the mitochondrial control region in the parrot genus Amazona. Mol. Biol. Evol. 18: 1330-1342.

Grau, E.T., Pereira, S.L., Silveira, L.F., and Wajntal, A. 2003. Molecular markers contribute to a breeding programme of the extinct in the wild Alagoas Curassow Mitu mitu and confirm the validity of the species. Bird Conserv. Int. 13: 115-126.

Haddrath, O., and Baker, A.J. 2001. Complete mitochondrial DNA genome sequences of extinct birds: ratite phylogenetics and vicariance biogeography hypothesis. Proc. R. Soc. Lond. B Biol. Sci. 268: 939-945.

Hasegawa, M., Kishino, H., and Yano, T. 1985. Dating of the human-ape splitting by a molecular clock of mitochondrial DNA. J. Mol. Evol. 21: 160-174.

Kimball, R.T., Braun, E.L., and Ligon, J.D. 1997. Resolution of the phylogenetic position of the Congo peafowl, Afropavo 
congensis: a biogeographic and evolutionary enigma. Proc. R. Soc. Lond. B Biol. Sci. 264: 1517-1523.

Kocher, T.D., Thomas, W.K., Meyer, A., Edwards, S.V., Pääbo, S., Villablanca, F.X., and Wilson, A.C. 1989. Dynamics of mitochondrial DNA evolution in animals: amplification and sequencing with conserved primers. Proc. Natl. Acad. Sci. USA. 86: 6196-6200.

Kumar, S., Tamura, K., Jakobsen, I.B., and Nei, M. 2001. MEGA2: molecular evolutionary genetics analysis software. Arizona State University, Tempe, Ariz.

L'Abbé, D.L., Duhaime, J.-F., Lang, B.F., and Morais, R. 1991. The transcription of DNA in chicken mitochondria initiates from one major bidirectional promoter. J. Biol. Chem. 266: 10844 10850.

Maddison, D.R., and Maddison, W.P. 2000. MacClade 4.0. Sinauer Associates, Inc., Sunderland, Mass.

Miyaki, C.Y., Matioli, S.R., Burke, T., and Wajntal, A. 1998. Parrot evolution and paleogeographical events: mitochondrial DNA evidence. Mol. Biol. Evol. 15: 544-551.

Pereira, S.L. 2000. Mitochondrial genome organization and vertebrate phylogenetics. Genet. Mol. Biol. 23: 745-752.

Pereira, S.L., and Baker, A.J. 2004. A vicariant hypothesis for the speciation of curassows (Aves, Cracidae) based on mitochondrial DNA phylogeny. Auk, 121: In press.

Pereira, S.L., Baker, A., and Wajntal, A. 2002. Combined nuclear and mitochondrial DNA sequences resolve generic relationships within the Cracidae (Galliformes, Aves). Syst. Biol. 51: 946958.

Posada, D., and Crandall, K.A. 1998. ModelTest: testing the model of DNA substitution. Bioinformatics, 14: 817-818.

Quinn, T.W., and Wilson, A.C. 1993. Sequence evolution in and around the mitochondrial control region in birds. J. Mol. Evol. 37: 417-425.

Randi, E., and Lucchini, V. 1998. Organization and evolution of the mitochondrial DNA control region in the avian genus Alectoris. J. Mol. Evol. 47: 449-462.

Rest, J.S., Ast, J.C., Austin, C.C., Waddell, P.J., Tibbetts, E.A., Hay, J.M., and Mindell, D.P. 2003. Molecular systematics of primary reptilian lineages and the tuatara mitochondrial genome. Mol. Phylogenet. Evol. 29: 289-297.

Ritchie, P.A., and Lambert, D.M. 2000. A repeat complex in the mitochondrial control region of Adélie penguins from Antarctica. Genome, 43: 613-618.

Rodriguéz, F., Oliver, J.L., Marín, A., and Medina, J.R. 1990. The general stochastic model of nucleotide substitution. J. Theor. Biol. 142: 485-501.

Ruokonen, M., and Kvist, L. 2002. Structure and evolution of the avian mitochondrial control region. Mol. Phylogenet. Evol. 23: 422-432.

Saccone, C., De Giorgio, C., Gissi, C., Pesole, G., and Reyes, A. 1999. Evolutionary genomics in Metazoa: the mitochondrial DNA as a model system. Gene, 238: 195-209.
Sambrook, J., Fritsch, F., and Maniats, T. 1989. Molecular cloning: a laboratory manual. 2nd ed. Cold Spring Harbor Laboratory Press, Cold Spring Harbor, N.Y.

Sanderson, M.J. 2002. Estimating absolute rates of molecular evolution and divergence times: a penalized likelihood approach. Mol. Biol. Evol. 19: 101-109.

Saunders, M.A., and Edwards, S.V. 2000. Dynamics and phylogenetic implications of mtDNA control region sequences in New World jays (Aves: Corvidae). J. Mol. Evol. 51: 97-109.

Sbisá, E., Tanzariello, F., Reyes, A., Pesole, G., and Saccome, C. 1997. Mammalian mitochondrial D-loop region structural analysis: identification of new conserved sequences and their functional and evolutionary implications. Gene, 205: 125-140.

Slack, K.E., Janke, A., Penny, D., and Arnason, U. 2003. Two new avian mitochondrial genomes (penguin and goose) and a summary of bird and reptile mitogenomic features. Gene, 302: 4352.

Sorenson, M.D., Ast, J.C., Dimcheff, E.D., Yuri, T., and Mindell, D.P. 1999. Primers for a PCR-based approach to mitochondrial genome sequencing in birds and other vertebrates. Mol. Phylogenet. Evol. 12: 105-114.

Steinborn, R., Muller, M., and Brem, G. 1998. Genetic variation in functionally important domains of the bovine mtDNA control region. Biochim. Biophys. Acta, 1397: 295-304.

Strimmer, K., and von Haeseler, A. 1996. Quartet puzzling: a quartet maximum likelihood method for reconstructing tree topologies. Mol. Biol. Evol. 13: 964-969.

Swofford, D.L. 2002. PAUP*. Phylogenetic analysis using parsimony (*and related methods). Version 4.10b. Sinauer Associates, Sunderland, Mass.

Taanman, J.-W. 1999. The mitochondrial genome: structure, transcription, translation and replication. Biochim. Biophys. Acta, 1410: $103-123$

Tamura, K., and Nei, M. 1993. Estimation of the number of nucleotide substitutions in the control region of mitochondrial DNA in humans and chimpanzees. Mol. Biol. Evol. 10: 512-526.

van Tuinen, M., and Dyke, G.J. 2004. Calibration of galliform molecular clocks using multiple fossils and genetic partitions. Mol. Phylogenet. Evol. 30: 74-86.

van Tuinen, M., and Hedges, S.B. 2001. Calibration of avian molecular clocks. Mol. Biol. Evol. 18: 206-213.

Vawter, L., and Brown, W.M. 1986. Nuclear and mitochondrial DNA comparisons reveal extreme rate variation in the molecular clock. Science (Washington, D.C.), 234: 194-196.

Zink, R.M., Weller, S.J., and Blackwell, R.C. 1998. Molecular phylogenetics of the avian genus Pipilo and a biogeographic argument for taxonomic uncertainty. Mol. Phylogenet. Evol. 10: 191-201. 
Crax_alberti Crax_alector Crax_blumenbachii Crax daubentoni Crax fasciolata Crax globulosa Crax_rubra Mitumitu Mitu_salvini Mitu_tomentosa Mitu_tuberosa Pauxi unicornis Pauxi_pauxi

Nothocrax urumutun

Oreophasis derbianus Ortalis canicollis Chamaepetes_goudoti Penelopina nigra Penelope_obscura Penelope_ochrogaster Penelope superciliar Penelope_purpuracens Aburria aburri Pipile cujubi Pipile_cumanensis Pipile_jacutinga Pipile pipile

\section{Crax_alberti} Crax alector Crax_blumenbachii Crax_daubentoni Crax_fasciolata Crax_globulosa Crax_rubra Mitu_mitu

Mitu_salvini

Mitu tomentosa

Mitu-tuberosa

Pauxi_unicornis

Pauxi_pauxi

Nothocrax_urumutun Oreophasis derbianus Ortalis_canicollis Chamaepetes_goudoti Penelopina nigra Penelope_ōbscura Penelope_ochrogaster Penelope_superciliaris Penelope_purpuracens Aburria_aburri

Pipile cumanensis

Pipile jacutinga Pipile_pipile
TAS Domain begins

C - string (goose hairpin)

AACTCAATTT TTAACTTAAC CCCCCTAC-C AGAGCACATC TCTCTTTAGA GAGGG-CCCC CCССССTTCC CCCCCC-AGA GGGGGTGTGC TATGTATAAT CGTGCATATT

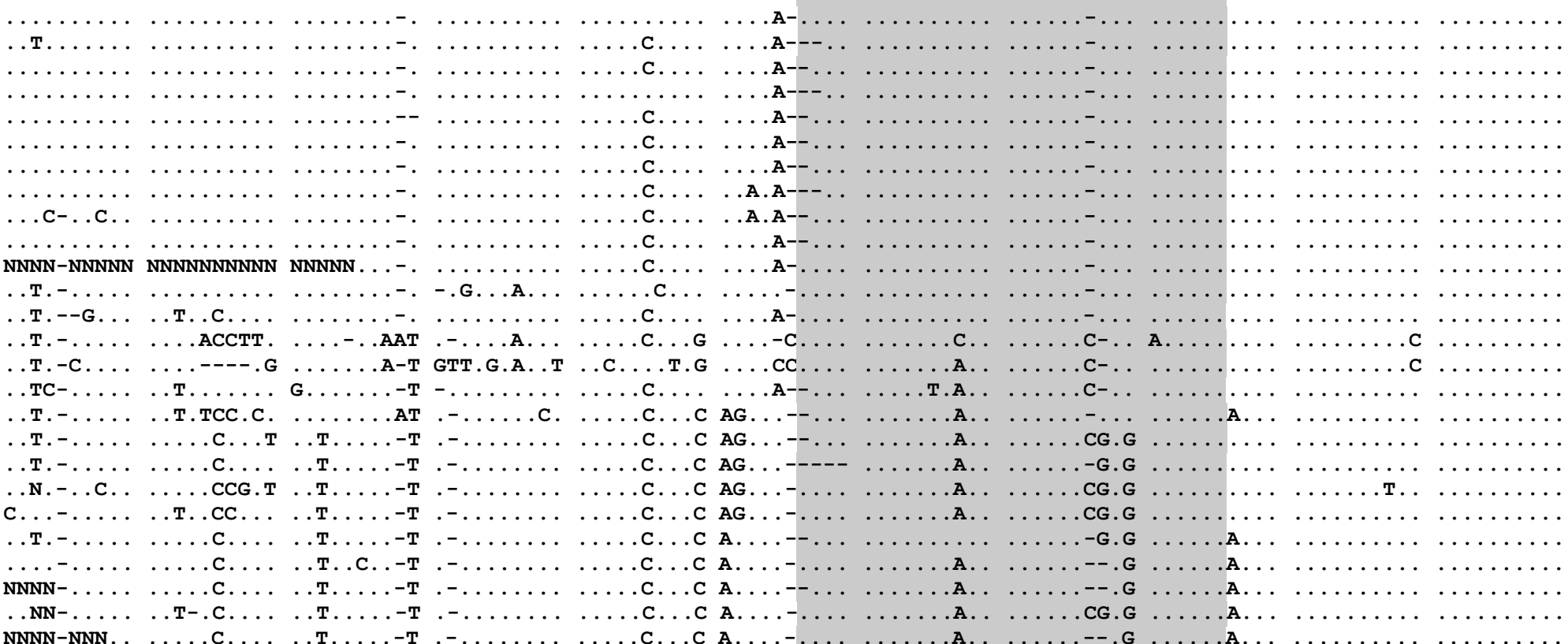

TAS1

TAS2 TAS3

TAS4

TAS5

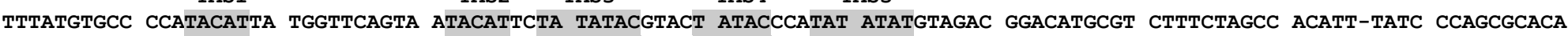

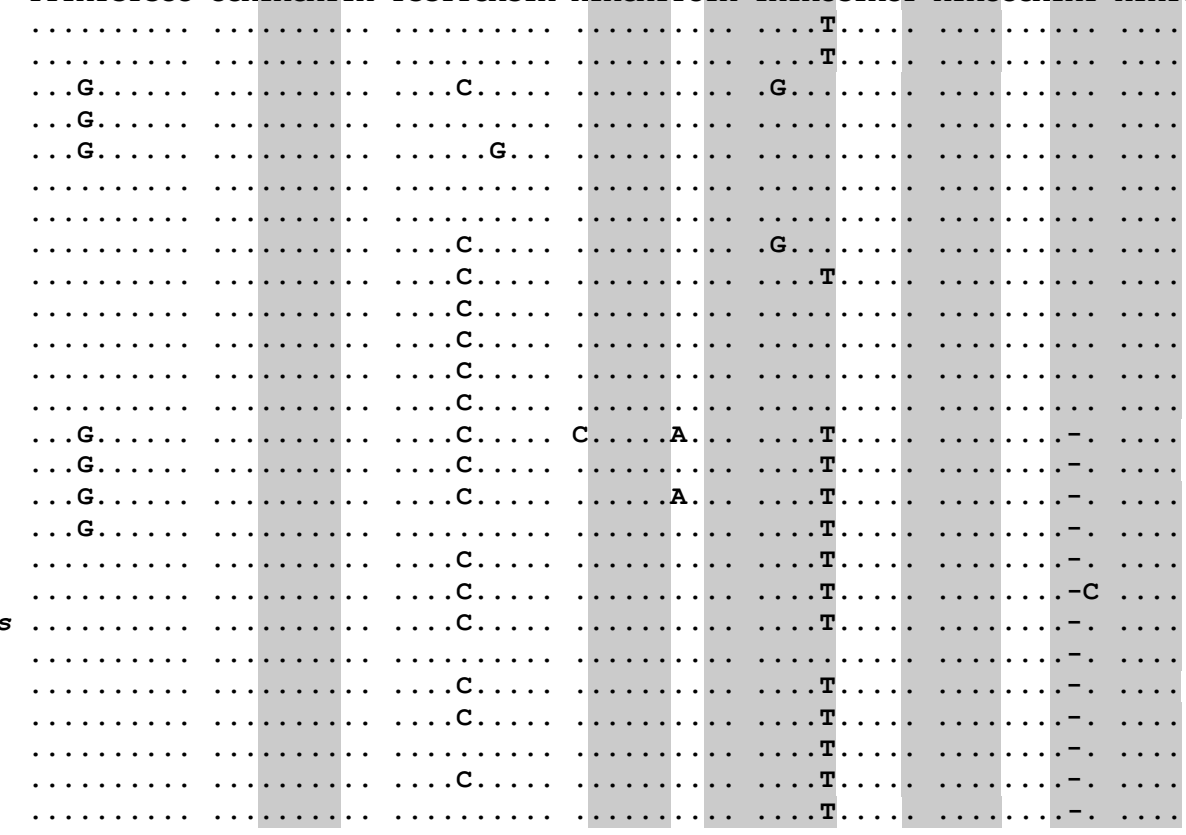

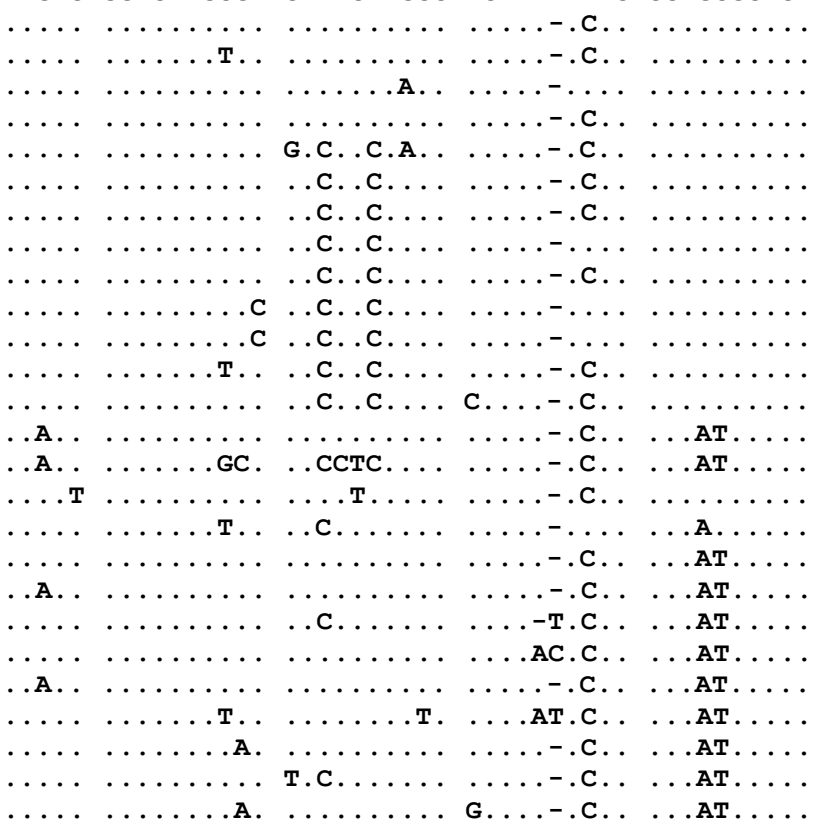


Crax_alberti Crax_alector Crax_blumenbachii Crax daubentoni Crax fasciolata Crax_globulosa Crax_rubra Mitu_mitu

Mitusalvini

Mitu_tomentosa

Mitu_tuberosa

Pauxi unicornis

Pauxi_pauxi

Nothocrax urumutun

Oreophasis derbianus ortalis canicollis Chamaepetes_goudoti Penelopina nigra Penelope_obscura Penelope_ochrogaster Penelope superciliaris Penelope_purpuracens Aburria aburri Pipile cujubi Pipile_cumanensis Pipile_jacutinga pipile_pipile

\section{Crax_alberti} Crax alector Crax_blumenbachii Crax_daubenton. Crax_fasciolata Crax_globulosa

Crax_rubra

Mitu_salvini

Mitu tomentosa

Mitu_tuberosa

Pauxi_unicornis

Pauxi_pauxi

Nothocrax_urumutun

Oreophasis_derbianus Ortalis canicollis Chamaepetes_goudoti

Penelopina_nigra Penelope obscura

Penelope_ochrogaster

Penelope_superciliar

Penelope_purpuracens

Aburria_aburri

Pipile cujubi

Pipile_cumanensis

Pipile_jacutinga

Pipile_pipile
TTAACATGCA TGCTCTAGGA CCAACTAGAA ATAT-C-ACC TACTCACGAC CCAGCACATT CAAGTCACCT AACCAGTGAA TGATCTACGG ACATAAACTT AATACCATAG

$\begin{array}{lllll}\ldots & \end{array}$
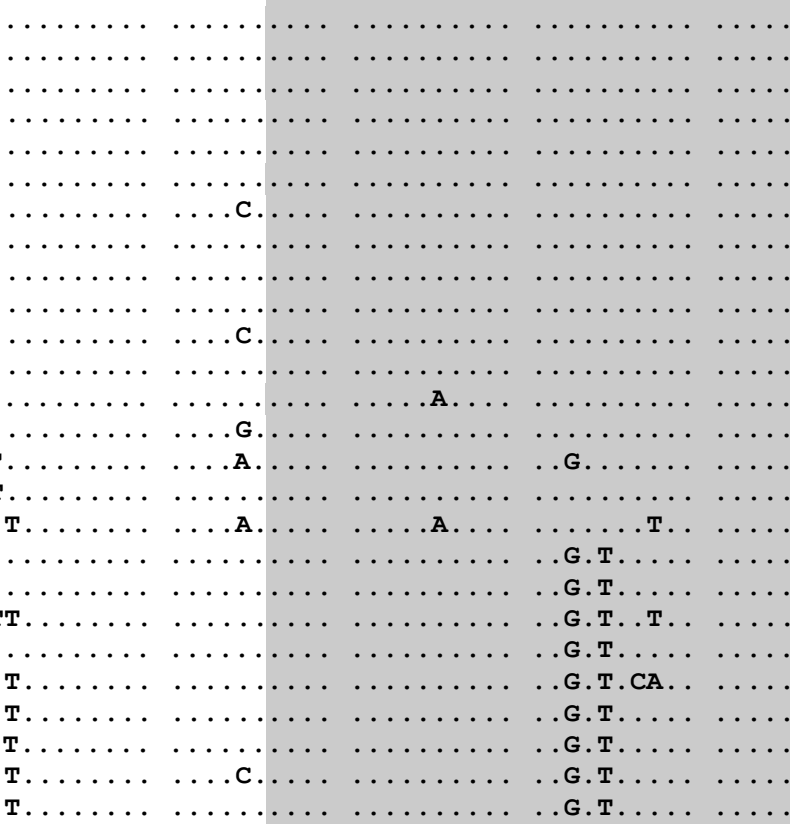

TA

\begin{tabular}{|c|c|}
\hline & $I I$ \\
\hline & .TT. \\
\hline BTC & . T. \\
\hline & TTG \\
\hline & $\ldots T$. \\
\hline & .TT. \\
\hline & ...TT. \\
\hline & . . тт. \\
\hline & TA. \\
\hline & . \\
\hline & $\begin{array}{l}\text {.....T. } \\
\text { т...Tт. }\end{array}$ \\
\hline & ... TT.C \\
\hline & .С. .TT.C \\
\hline & . . TT. \\
\hline & AT. \\
\hline & .С.AT. \\
\hline & . AT \\
\hline & \\
\hline
\end{tabular}

TAS Domain ends | Central Domain starts $F$ box

E box

TTCT-TCCTC ATTTGGTTAT GCTCGACGTA TCAGATGGAT TTATTGATCG TACCCCTCAC GAGAGATCAG CAACCCCTGC CCGTAATGTC CTACGTGACT AGCTTCAGGC
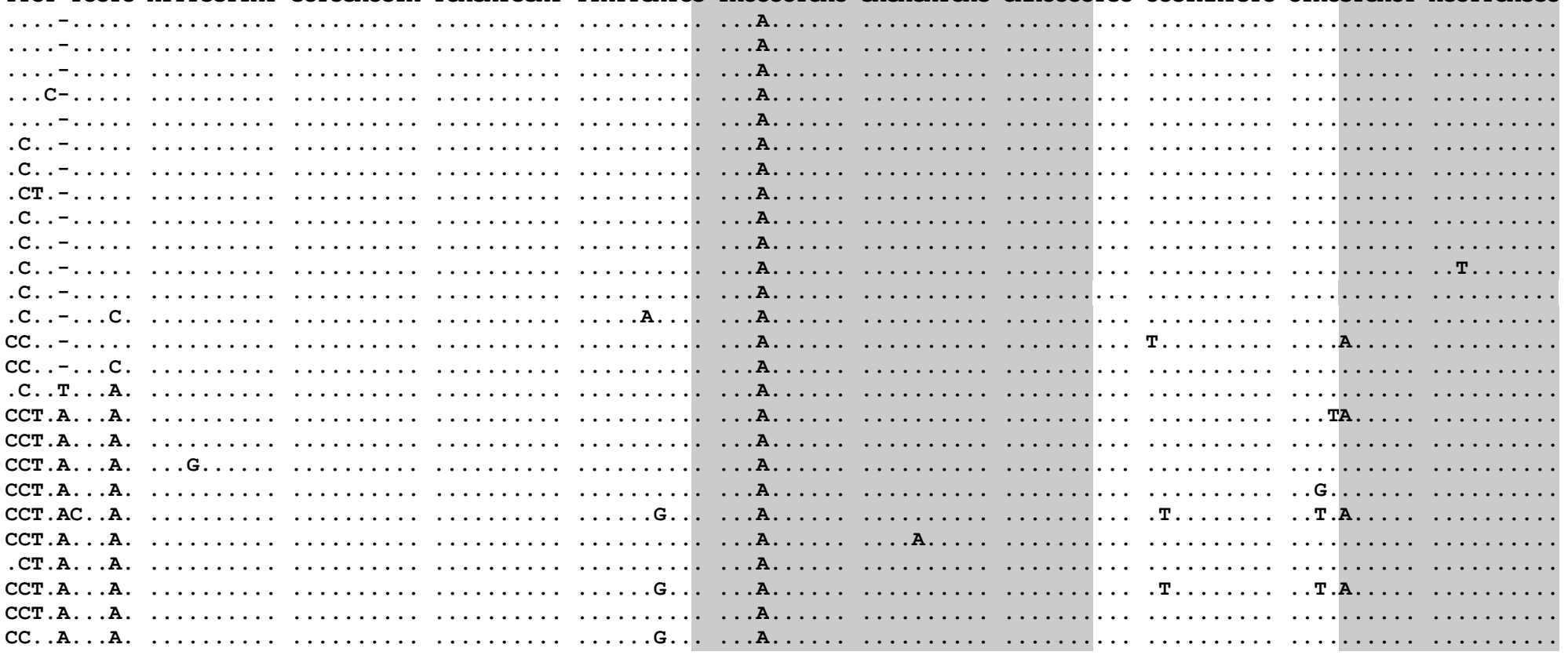
Crax_alberti Crax_alector Crax_blumenbachii Crax daubentoni Crax fasciolata Crax_globulosa Crax_rubra Mitumitu Mitusalvini Mitu_tomentosa Mitu_tuberosa Pauxi unicornis Pauxi_pauxi

Nothocrax urumutun

Oreophasis derbianus ortalis canicollis Chamaepetes_goudoti Penelopina_nigra Penelope_obscura Penelope_ochrogaster Penelope superciliaris Penelope purpuracens Aburria_aburri Pipile cujubi Pipile_cumanensis Pipile_jacutinga Pipile_pipile

\section{Crax alberti} Crax alector Crax_blumenbachii Crax_daubenton Crax_fasciolata Crax_globulosa Crax_rubra

Mitusalvin

Mitu tomentosa Mitu_tuberosa Pauxi_unicornis Pauxi_pauxi Nothocrax urumutun Oreophasis_derbianus Ortalis canicollis Chamaepetes_goudoti Penelopina_nigra Penelope obscura Penelope_ochrogaster Penelope_superciliaris Penelope_purpuracens Aburria_aburri

Pipile cujubi

Pipile_cumanensis

Pipile jacutinga

Pipile pipile
$E$ box (cont.)

D box

C Box

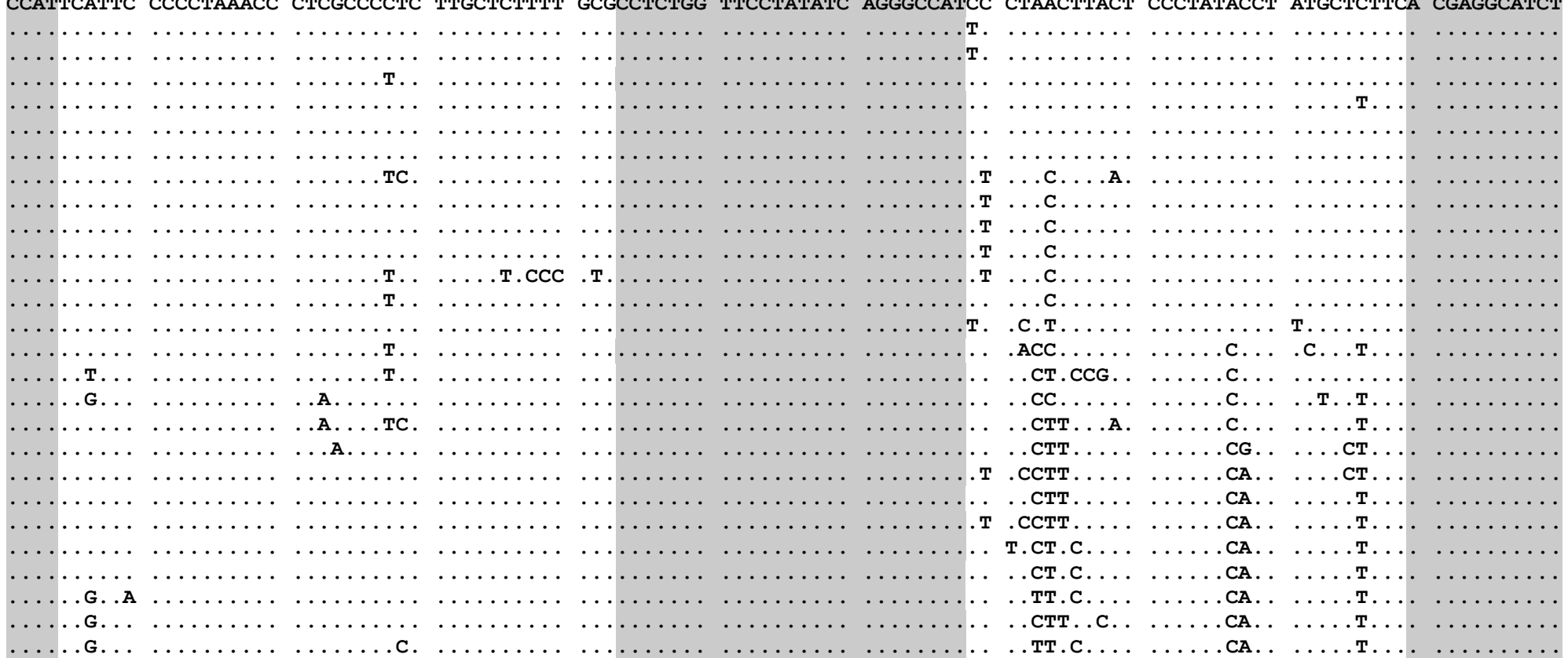

B box of Saunders \& Edwards

GGTCGGAGA TACCCACCAT TTTAGTCCGT GATCGCGGCA TCTTATCTCT TCTCTGCTAT TGGTTCCCTT TTTTTTCTGG GGCTTCTTCA CAGCTGGCAT TTCCAGTGCC

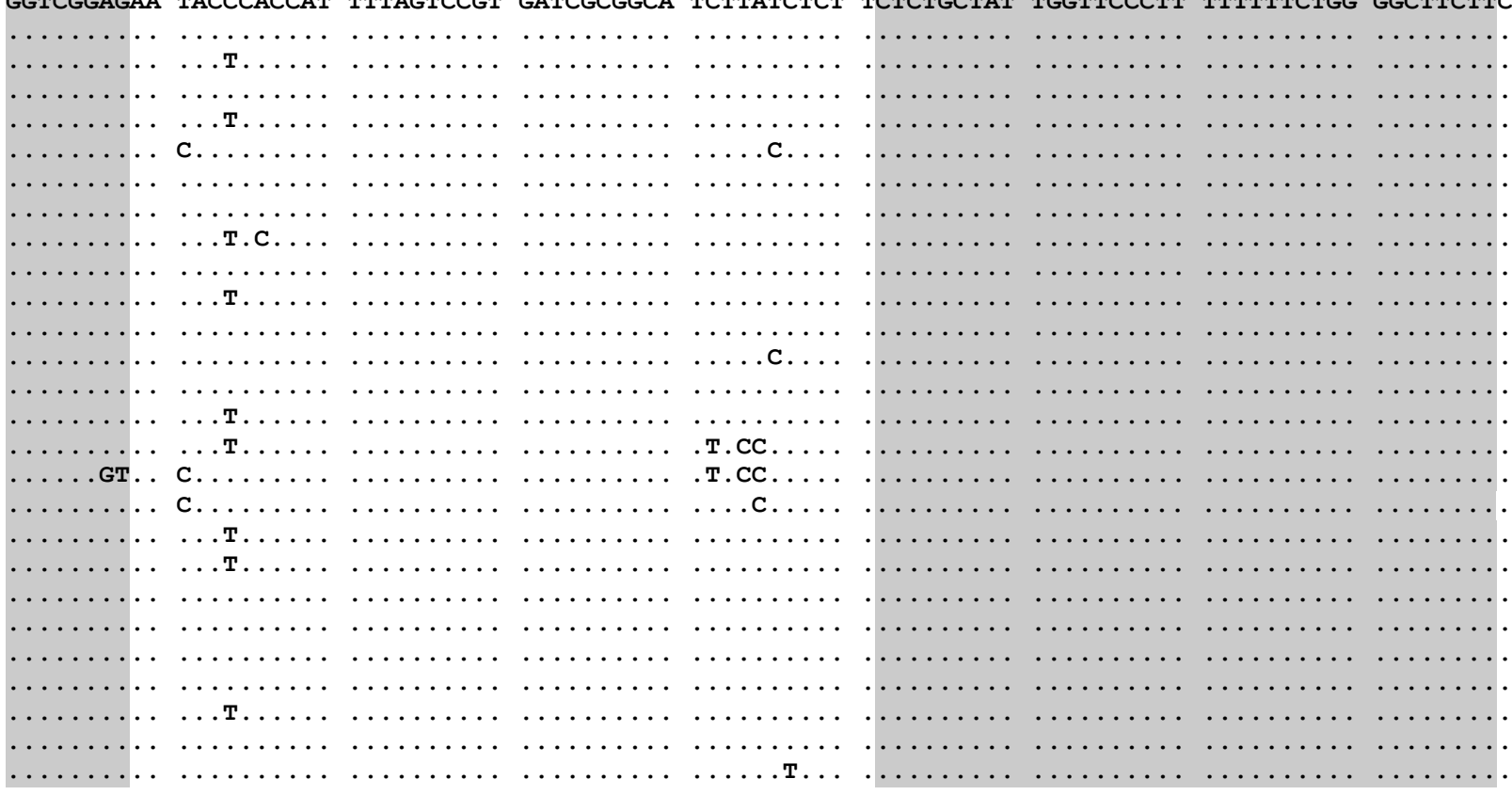

A.

A.

$\ldots+\cdots \cdots$
.A. 
Crax_alberti Crax_alector Crax_blumenbachii Crax daubentoni Crax fasciolata Crax_globulosa Crax rubra Mitumitu Mitusalvini Mitu_tomentosa Mitu_tuberosa Pauxi unicornis Pauxi_pauxi

Nothocrax urumutun

Oreophasis derbianus Ortalis cañicollis Chamaepetes_goudoti Penelopina_nigra Penelope_obscura Penelope_ochrogaster Penelope superciliaris Penelope_purpuracens Aburria aburri Pipile cujubi Pipile_cumanensis Pipile_jacutinga Pipile pipile

\section{Crax alberti} Crax alector Crax_blumenbachii Crax_daubenton Crax_fasciolata Crax_globulosa

Crax rubra

Mitu_salvini

Mitu tomentosa Mitu_tuberosa Pauxi_unicornis Pauxi_pauxi Nothocrax urumutun Oreophasis_derbianus Ortalis canicollis Chamaepetes_goudoti Penelopina_nigra Penelope obscura Penelope_ochrogaster Penelope superciliari Penelope_purpuracens Aburria_aburri

Pipile cujubi

$P$ ipile_cumanensis

Pipile jacutinga

Pipile pipile

GTTGCGGAGT GCACTCAATC TAGGTCTGGA CATCTCCTGG TTTGCGTCCT ATTCTAGACC TCAGGCGTCC CTCGATGAGA CGGTTTGCGT GTATGCGGAA TCATTTTGAC

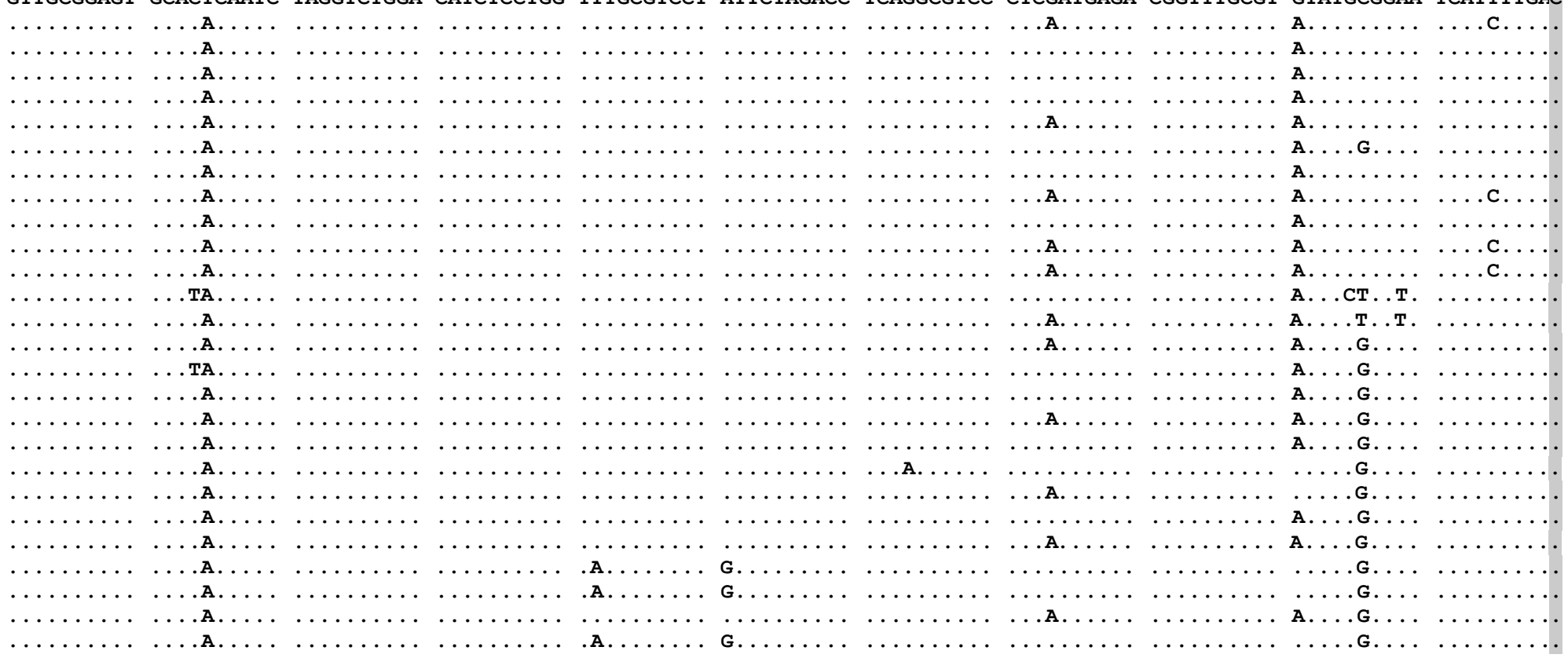

Bird Box B Box $\quad \mathrm{O}_{\mathrm{H}}$ Central Domain ends I CSB Domain begins CBS-1

ACTGATGCAC TTTGGATCGC ATTTGGTAAT GGCTCTTCCA CCCCGCCC-A AACATGGTGC TATTTAGTGA ATGCTTGACG GGCATATTTT TGCAAATTTT CACTTCCTCT

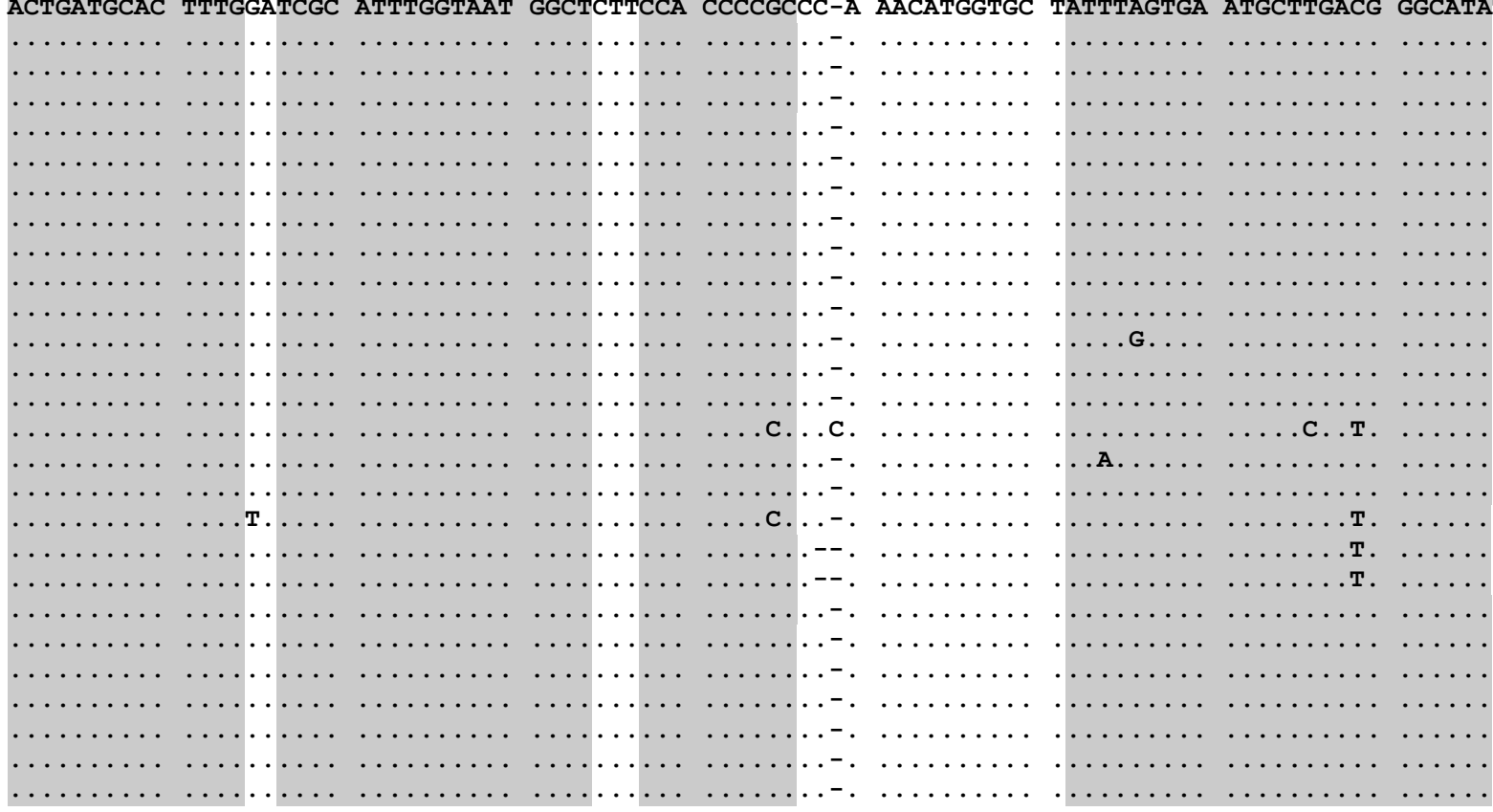


Crax_alberti Crax_alector Crax_blumenbachii Crax daubentoni Crax fasciolata Crax_globulosa Crax_rubra Mitumitu

Mitu salvini

Mitu_tomentosa

Mitu_tuberosa

Pauxi unicornis

Pauxi_pauxi

Nothocrax urumutun

Oreophasis derbianus Ortalis canicollis Chamaepetes_goudoti Penelopina_nigra Penelope_obscura Penelope_ochrogaster Penelope superciliari Penelope purpuracens Aburria aburri Pipile cujubi Pipile_cumanensis Pipile_jacutinga Pipile pipile

\section{Crax_alberti} Crax alector Crax_blumenbachii Crax_daubenton. Crax_fasciolata Crax_globulosa

Crax_rubra

Mitu_salvini

Mitu tomentosa

Mitu_tuberosa

Pauxi_unicornis

Pauxi_pauxi

Nothocrax_urumutun

Oreophasis_derbianus Ortalis canicollis Chamaepetes_goudoti

Penelopina_nigra Penelope obscura

Penelope_ochrogaster

Penelope_superciliar Penelope_purpuracens Aburria_aburri

Pipile cujubi

$P$ ipile_cumanensis

Pipile jacutinga

Pipile pipile
CSB $-2 / 3$

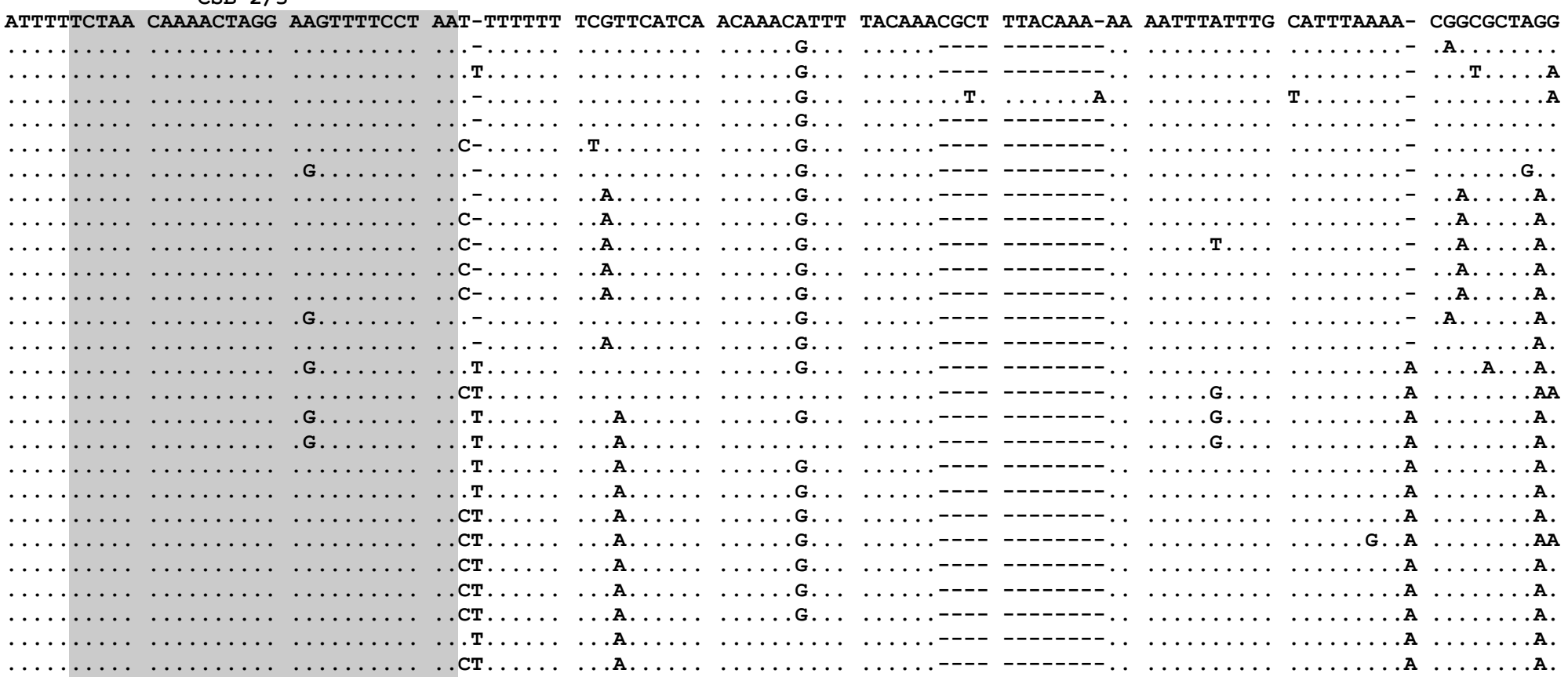

LSP/HSP

GTTCCCTTAA CATCGTCCAA -AAACGTTTG CATTCATATA CATACATTTA TTATACACCA AATTTATTAG AGAAACTCCA CTACCAAAAC CAACCATCAC AAACAAACTT

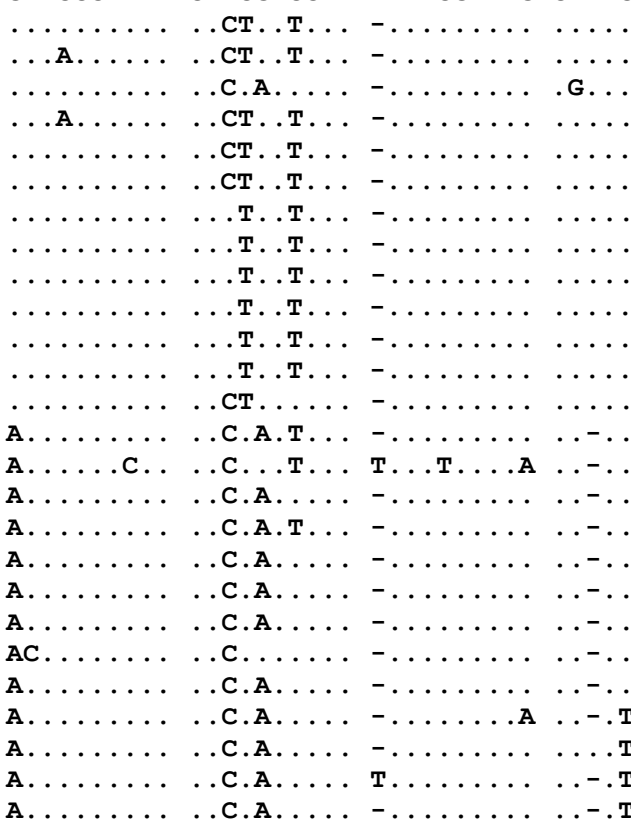

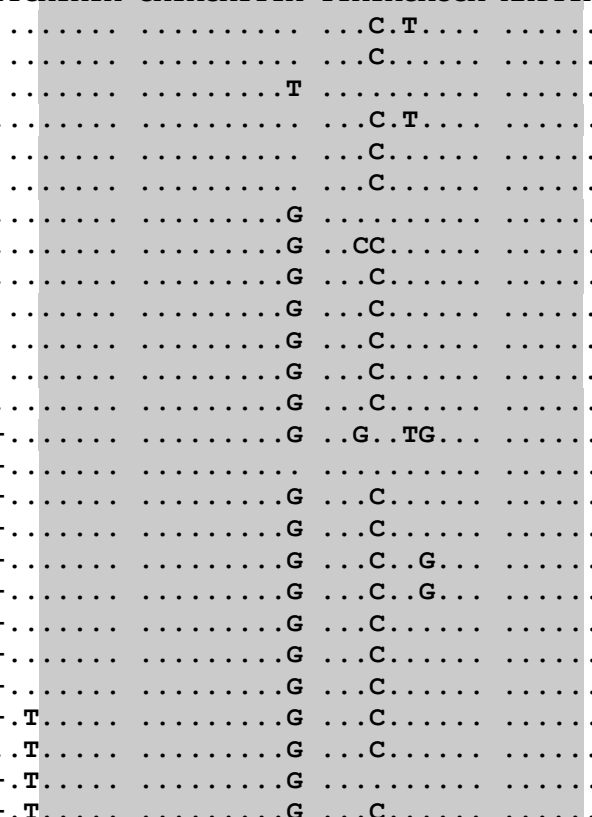

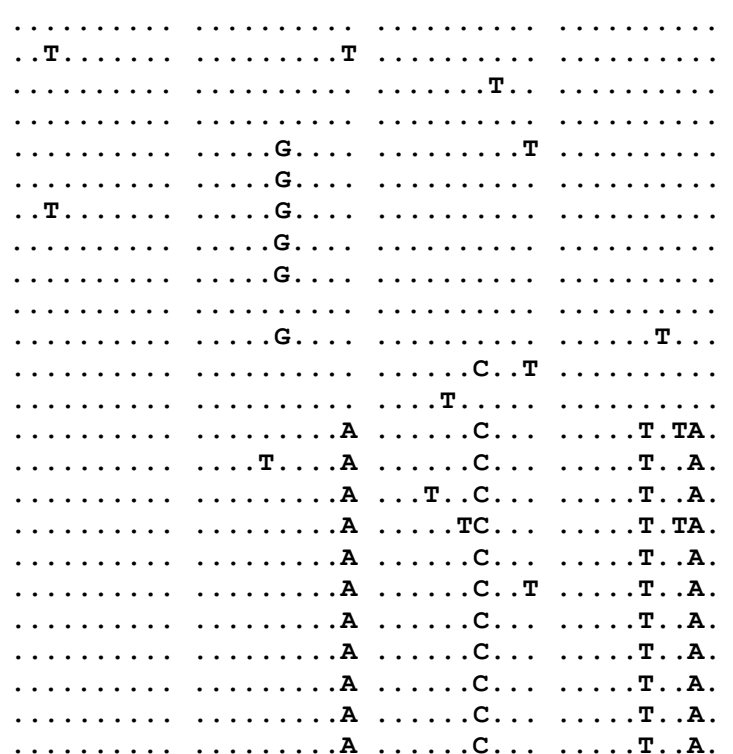


Crax_alberti

\section{Crax_alector}

Crax_blumenbachii

Crax daubentoni

Crax fasciolat

Crax_globulosa

Crax rubra

Mitu_mitu

Mitu_salvini

Mitu_tomentosa

Mitu_tuberosa

Pauxi unicornis

Pauxi_pauxi

Nothocrax urumutun

Oreophasis derbianus Ortalis_canicollis

Chamaepetes_goudoti

Penelopina_nigra

Penelope_ōbscura

Penelope_ochrogaster

Penelope_superciliaris

Penelope purpuracen

Aburria_aburri

Pipile cujubi

Pipile_cumanensis

Pipile_jacutinga

Pipile_pipile
TT-TTTTTCA CTTTCACAAC CCTGGCT---

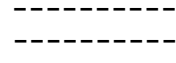

AAAT CGACCAAAA CAAACCATCA CCCC-G

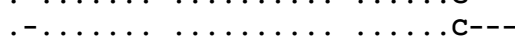

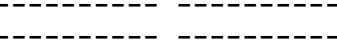

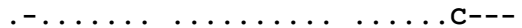

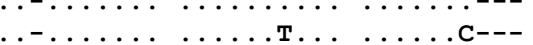

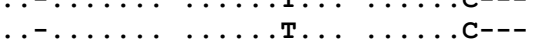

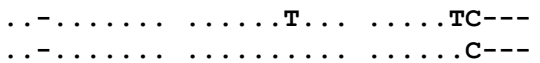

.......... . . . . . . . тC---

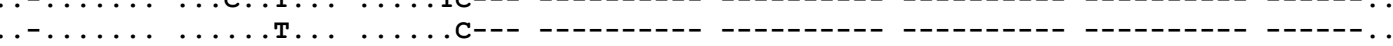

AAA CCAACCAAAA CAAACAAACT TTTTTTTCAC TTTCACAACC CTGGCT....

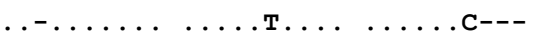

- . . т. . . . . . . .

.AC.C... T. .T- . . . . . TC-

C. AC T... Th-......

--.С. TC т.....

-.C..TC T_..T-..T

.-.C..TC T...T-...

..-.C..TC T........ . T...C--

.-.C. .TC T...... . . . . C--

- -. . TC T....... … . AC-

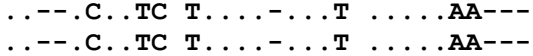

$\ldots-$. . . TC T...... $\ldots$. . . AC--

..-.C. .TC T...-..T ....AA---

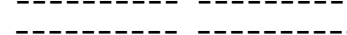

... T....... .

.AG..... . . T. . . . TCA

AG.........

$\ldots \ldots \ldots-\ldots$ T. . . . .

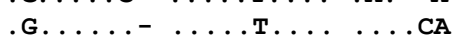

$\ldots \ldots \ldots$. . . . . . .

A.......... . T. .

А..... . . . . . . . .

$\ldots \ldots \ldots-\ldots$. T. . T . .A

A..... . . T. . T. .

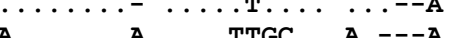

A. T.... . . G.TTGC. ...-A

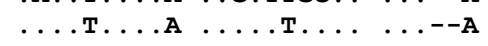

…

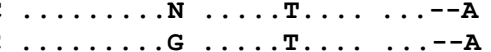

$\ldots \ldots$ A $\ldots$ T. $\ldots$.

A . . . . A

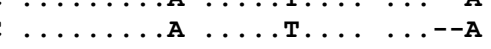

$\begin{array}{llll}\text { С } & \ldots \ldots & \ldots \text { A } & \ldots\end{array}$

. C $\ldots \ldots \ldots$ A $\ldots$ T. . . .

Supplementary material. Alignment of the complete mitochondrial control region for 27 cracid birds. 


\section{Referências Bibliográficas}

AB'SABER, A. N. A Amazônia: do Discurso à Praxis. São Paulo, Editora da Universidade de São Paulo: 1996.

ALEIXO, A. Molecular systematics and the role of the "Várzea"-"Terra-Firme" ecotone in the diversification of Xiphorhyncus Woodcreepers (Aves:Dendrocolaptidae). The Auk, v. 119, n. 3, p. 621-640, 2002.

ALMEIDA, F. F. M. de. The system of continental rifts bordering the Santos Basin, Brazil. Anais da Academia Brasileira de Ciências, v. 48, p. 15-26, 1976.

ALVARENGA, H. M. F. Um primitivo membro da ordem Galliformes (Aves) do terciário Médio da bacia de Taubaté estado de São Paulo. Anais da Academia brasileira de Ciências, v. 67, p. 33-44, 1995.

AVISE, J. C.; NELSON, W. S. Molecular genetic relationships of the extinct dusky seaside sparrow. Science, v. 243, p. 646-648, 1989.

AVISE, J. C.; NELSON, W. S.; SIBLEY, C. G. DNA sequence support for a close Phylogenetic relationship between some storks and New World vultures. Proc. Natl. Acad USA, v. 91, n. 11, p. 5173-5177, 1994.

BirdLife International. Threatened Birds of the World. $1^{\mathrm{a}}$ ed. Barcelona e Cambridge: Lynx Editions and BirdLife International, 2000.

BLAKE, E. R. A Manual of Netropical Birds. Vol. 1 . Univ. de Chicago press. 1977.

BONAPARTE, P. L. Tableaux paralléliques de l'ordre des Gallinacés. Compt. Rendus Acad. Sci. Paris, v. 42, p. 874-884, 1856.

BRADLEY, R. D.; BAKER, R. J. A test of the genetic species concept: cytochrome-b sequences and mammals. J. Mammal. v. 82, p. 960-973, 2001.

BROOKS, M.; STRAHL, S. D. Curassows, Guans and Chalacas. Status Survey and Conservation Action Plans for Cracids 2000-2004. IUCN/SSC Cracid Specialist Group. Gland, Switzerland and Cambridge, UK: IUCN, 2000.

BROWN, W. M.; JUNIOR, G. M.; WILSON, A. C. Rapid evolution of animal mitochondrial DNA. Proc. Natl. Acad. Sci. USA, v. 76, p. 1967-1971, 1979.

CLAPPERTON, L. Quaternary geology and geomorphology of South America. Amsterdan: Elsevier, 1993.

COLLAR, N. J.; GONZAGA, L. P.; KRABBE, N.; MADRONÕ NIETO, A.; 
NARANJO, L.; PARKER III, T. A.; WEGE, D. C. Threatened birds of the Americas. The ICBPIIUCN red data book. 3rd edn, part 2. Washington D.C.: Smithsonian Institution Press, 1992.

COLLINS, A. C.; DUBACH, J. M. Biogeographic and ecological forces responsible for speciation in Ateles. Int. J. Primatol., v. 21, p. 421-444, 2000.

CORTÉS-ORTIZ, L.; BERMINGHAM, E.; RICO, C.; RODRIGUEZ-LUNA, E.; SAMPAIO, I.; RUIZ-GARCIA, M. Molecular systematics and biogeography of the Neotropical monkey genus, Alouatta. Molecular Phylogenetics and Evolution, v. 26, p. 64-81, 2003.

COSTA, L. P. The historical bridage between the Amazon and the Atlantic Forest of Brazil: a study with small mammals. Journal of Biogeography, v. 30, p. 71-86, 2003.

DARLINGTON, P. J. Jr. "Zoogeography: the Geographical Distribution of Animals". New york: Jonh Wiley \& Sons, inc , 1957.

DEL HOYO, J.; ELLIOTT, A.; SARGATA, J. (eds). Handbook of the Birds of the World. Vol. 2. New World Vultures to Guinafowl. Barcelona: Lynx Editions, 1994.

DELACOUR, J.; AMADON, D. Curassows and Related Birds. Milan: Amilcare Pizzi,1973.

DIMCHEFF, D. E.; DROVETSKI, S. V.; MINDELL, D. P. Phylogeny of Tetraoninae and other galliform birds using mitochondrial 12S and ND2 genes. Molecular Phylogenetics and Evolution, v. 24, p. 203-215, 2002.

DYKE, G. J.; GULAS, B. E.; CROWE, T. M. Suprageneric relationships of galliform birds (Aves, Galliformes): a cladistic analysis of morphological characters. Zool. J. Linn. Soc., v. 137, p. 227-244, 2003.

FELSENSTEIN, J. Confidence limits on phylogenies: an approach using the bootstrap. Evolution, v. 39, p. 783-791, 1985.

FFRENCH, R.; O'NEILL, P.; ECKELBERRY, D. R. A guide to the birds of Trinidad and Tobago. 2nd. ed. Ithaca: Cornell Univ. Press, 1991.

FOSTER, P. G.; HICKEY, D. A. Compositional bias may affect both DNAbased and protein-based phylogenetic reconstructions. Journal of Molecular Evolution, v. 48, p. 284-290, 1999.

FRANK-HOEFLICH, K.; SILVEIRA, L. F.; ESTUDILLO-LÓPEZ, J.; GARCÍA$\mathrm{KOCH}$, A. M.; ONGAY-LARIOS, L.; PIÑERO, D. Increased taxon and character sampling reveals novel intergeneric relationships in the Cracidae (Aves: Galliformes). J Zool Syst Evol Res, v. 45, n. 3, p. 242-254, 2007. 
GALEWSKI, T.; MAUFFREY, J. F.; LEITE, Y. L.; PATTON, J. L.; DOUZERY, E. J. Ecomorphological diversification among South American spiny rats (Rodentia: Echimyidae): a phylogenetic and chronological approach. Molecular Phylogenetics and Evolution, v. 34, p. 601-615, 2005.

GOLDMAN, N. Simple diagnostic statistical test of models of DNA substitution. Journal of Molecular Evolution, v. 37, p. 650-661, 1993a.

GOLDMAN, N. Statistical tests of models of DNA substitution. Journal of Molecular Evolution, v. 36, p. 182-198, 1993b.

GRAU, E. T.; PEREIRA, L. P.; SILVEIRA, L. F.; HÖFLING, E.; WAJNTAL, A. Molecular Phylogenetics and Biogeography of Neotropical piping guans (Aves: Galliformes): Pipile Bonaparte, 1856 is synonym of Aburria Reichenbach, 1853. Molecular Phylogenetics and Evolution, v. 35, p. 637645, 2005.

GRAU, E. T.; PEREIRA, S. L.; SILVEIRA, L. F.; WAJNTAL, A. Molecular markers contribute in the management of a breeding program of the extinct in the wild Alagoas Curassow Mitu mitu and confirm the validity of the species. Bird Conservation International, v. 13, p.115-126, 2003.

GUERRA, A. T. Estrutura geológica, relevo e litoral. In: Guerra, A.T. (Org.) Geografia do Brasil: Grande região norte. Rio de Janeiro IBGE, 1956, pp. 1760 .

HADDRATH, O.; BAKER, A. J. Complete mitochondrial DNA genome sequences of extinct birds: ratite phylogenetics and the vicariance biogeography hypothesis. Proc. R. Soc. Lond., v. 268, p. 939-945, 2001.

HAFFER, J. Avian speciation in tropical South America. With a systematic survey of the toucans (Ramphastidae) and jacamars (Galbulidae). Publ. Nuttall. Ornithol. Club 14, Cambridge, 1974.

HAFFER, J. Ciclos de tempo e indicadores de tempos na história da Amazônia. Estudos Avançados, v. 6, n. 15, p. 7-39, 1992.

HAFFER, J.; PRANCE, G. T. Climatic forcing of evolution in Amazonia during the Cenozoic: on the refuge theory of biotic differentiation. Amazoniana, v. 16, n. $3 / 4$, p. $579-607,2001$.

HAGELBERG, E. Mitochondrial DNA from ancient bones. In: Herrmann, B., Hummel, S., (Eds.) Ancient DNA. New York: Springer,1994, pp 195-204.

HAQ, B. U.; HARDENBOL, J.; VAIL, P. R. Chronology of fluctuating sea level since the Triassic. Science, v. 235, p. 1156-1167, 1987.

HEDGES, S. B. Molecular evidence for the origin of birds. Proc. Natl Acad Sci USA, v. 91, p. 2621-2624, 1994. 
HEDGES, S. B.; PARKER, P. H.; SIBLEY, C. G.; KUMAR, S. Continental breakup and the ordinal diversification of birds and mammals. Nature, v. 381, p. 266-299, 1996.

HELLMAYR, C. E.; CONOVER, B. Catalogue of birds of the Americas. Publ. field Mus. Nat. Hist, Zool. Ser., v. 13, n. 1, 1942.

HOOGHIEMSTRA, H.; VAN DER HAMMEN, T. Neogene and Quaternary development of the neotropical rain forest: the forest refugia hypotesis and a literature overview. Earth-science Reviews, v. 44, p. 147-183, 1998.

HOORN, C.; GUERRERO, J.; SARMIENTO, G. A.; LORENTE, M. A. Andean tectonics as a cause for changing drainage patterns in miocene northern South America. Geology, v. 23, n. 3, p. 237-240, 1995.

HUELSENBECK, J. P.; CRANDALL, K. A. Phylogeny estimation and hypothesis testing using maximum likelihood. Ann. Rev. Ecol. Syst.,v. 28, p. 437-466, 1997.

HUELSENBECK, J. P.; RANNALA, B. Phylogenetic methods come of age: testing hypothesis in an evolutionary context. Science, v. 276, p. 227-232, 1997.

International Commission on Zoological Nomenclature. International code of zoological nomenclature, London, International Trust for Zoological Nomenclature. 1999.

IRION, G. Sedimentation and sediments of the Amazonian rivers and evolution of the Amazonian landscape since Pliocene times. In: SIOLI, H. (Ed.), The Amazon: Limnology and landscape ecology of a mighty tropical river and its basin. Dordrecht: Dr. W. Junk Publishers, 1984, pp. 201-214.

JACQUIN, J. F. Beyträge zur Geschichte der Vögel. Vienna:1784.

KIMURA, R. K.; PEREIRA, S. L.; GRAU, E. T.; HÖFLING, E.; Wajntal, A. Genetic distances and phylogenetic analysis suggest that Baillonius Cassin, 1867 is a Pteroglossus Illiger, 1811 (Piciformes: Ramphastidae). Ornitología Neotropical, v. 15, p. 527-537, 2004.

KLAMMER, G. The relief of extra-andean amazon basin. In: SIOLI H. (Ed.), The Amazon: Limnology and Landscape Ecology of a Mightly Tropical River and Its Basin., Dordrecht: Dr. W. Junk, 1984, pp. 47-83.

KUMAR, S.; TAMURA, K.; JAKOBSEN, I. B.; NEI, M. MEGA2: Molecular Evolutionary Genetics Analysis software. Tempe, Arizona, USA: Arizona State University, 2001.

LEE, M. S. Y.; HUGALL, A. F. Partitioned likelihood support and the 
evaluation of data set conflict. Systematic Biology, v. 52, p. 15-22, 2003.

LESSON, R. P. Manuel d'ornithologie, ou description des genres etdes principales especes d'oiseaux. Paris: 1828.

LUNDBERG, J. G.; MARSHALL, L. G.; GUERRERO, J.; HORTON, B.; MALABARTA, M. C. S. L.; WESSELEINGH, F. The stage for neotropical fish diversification: a history of tropical South American rivers. In: Malabarba, L.R., Reis, R.E., Vaurie, R.P., Lucena, C.A.S. (Eds), Phylogeny and classification of Neotropical fishes. Part. 1. Porto Alegre: EDIPUC/RS, pp 13-48.

MADISON, D. R.; MADISON, W. P. MacClade 4.0. Sunderland, Mass: Sinauer Associates Inc., 2005.

MARROIG, G.; CERQUEIRA, R. Plio-pleistocene South American History and the Amazon Lagoon Hypotesis: a Piece in the Puzzle of Amazonian Diversification. J. Comp. Biol., v. 2, n. 2, p. 103-119, 1997.

MIYAKI, C. Y.; MATIOLI, S. R.; BURKE, T.; WAJNTAL, A.. Parrot evolution and paleogeographical events: mitochondrial DNA evidence. Molecular Biology and Evolution, v. 15, p. 544-551, 1998.

MOYLE, R. G. Phylogeny and Biogeographical history of Trogoniformes, a pantropical bird order. Biol. J. Linn. Soc., v. 84, p. 725-738, 2005.

NARDELLI, P. M. A preservação do Mutun-de-Alagoas, Mitu mitu. Queimados, RJ: Semana llustrada Editorial Ltda, 1993.

NORES, M. An alternative hypothesis for the origin of the Amazonian bird diversity. J Biogeography, v. 26, p. 475-485, 1999.

NORES, M. The implications of Tertiary and Quaternary sea level rise events for avian distribution patterns in the lowlands of northern South America. Global Ecol. Biogeogr., v. 13, p. 149-161, 2004.

OLMOS, F. The Pipile cumanensis grayi - P. cujubi nattereri contact zone in Mato Grosso, Brazil. In: Brooks, D.M., Olmos, F., Bergazo, A.J., (Eds), Biology and conservation of the Piping Guans (Aves: Cracidae). Special Publication of the Cracidae Specialist Group, Houston, pp. 24-30.

PAULA COUTO, C. de. Mamíferos fósseis do Cenozóico da Amazônia. Instituto Brasileiro de Bibliografia e Documentação, CNPq, Rio de Janeiro. Boletim 3, p. 1-121, 1956.

PELZELN, A. VON. Little-known birds. Sitz. K. Acad. Wiss. Wien., v. 31, p. 319-331, 1858.

PEREIRA, S. L. Filogenia Molecular e Evolução em Cracidae (Aves). Tese (Doutorado) - Instituto de Biociências da Universidade de São Paulo, 2000. 
PEREIRA, S. L.; BAKER, A. J. A vicariant hypothesis for the speciation of curassows (Aves, Cracidae) based on mithocondrial DNA phylogeny. Auk, v. 121, p. 682-694, 2004a.

PEREIRA, S. L.; BAKER, A. J. Low number of mitochondrial pseudogenes in the chicken (Gallus gallus) nuclear genome: implications for molecular inference of population history and phylogenetics. BMC Evolutionary Biology, v. 4, p. 17, 2004.

PEREIRA, S. L.; BAKER, A. J. A mitogenomics timescale for birds detects variable phylogenetic rates of molecular evolution and refutes the standard molecular clock. Molecular Biology and Evolution, v. 23, p. 1731-1740, 2006.

PEREIRA, S. L.; BAKER, A. J.; WAJNTAL, A. Combined nuclear and mitochondrial DNA Sequences Resolve Generic Relatioships within the Cracidae (Galliformes, Aves). Systematic Biology, v. 51, p. 946-958, 2002.

PEREIRA, S. L.; GRAU, E. T.; WAJNTAL, A. Molecular architecture and rates of DNA substitutions of the mitochondrial control region of cracid birds. Genome, v. 47, p. 535-545, 2004.

PETERS, J. L. Check List of Birds of the World. Cambridge: Harvard Univ. Press, 1934.

POSADA, D.; CRANDALL, A. MODELTEST: testing the model of DNA substitution. Bioinformatics, v. 14, p. 817-818, 1998.

REICHENBACH, H. G. L. Avium systema naturale. Leipzig: Friedrich Hofmeister, 1853.

RIBAS, C. C.; MOYLE, R. G.; MIYAKI, C. Y.; CRACRAFTT, J. The assembly of montane biotas: linking Andean tectonics and climatic oscillations to independent regimesof diversification in Pionus parrots. Proc. Biol. Sci., v. 274, p. 2399-2408, 2007.

RICCOMINI, C.; PELLOGGIA, A. U.; SALONI, J. C.; KOHNKE, M. W., FIGUEIRA, R. M. Neotectonic activity in the Serra do Mar rift system (southeastern Brazil). Journal of South American Earth Science, v. 2, p.191198, 1989.

RICHLY, E.; LEISTER, D. Numts in sequenced eukaryotic genomes. Mol. Biol. Evol., v. 21, p. 1081-1084, 2004.

RIDGELY, R. S.; GREENFIELD, P. J. The birds of Ecuador. Status, distribution and taxonomy. Ithaca: Cornell University Press, 2001.

RONQUIST, F. R.; HUELSENBECK, J. P. MRBAYES: Bayesian inference of phylogeny. Bioinformatics, v. 19, p. 1572-1574, 2003. 
SAFFORD, H. D. Brazilian páramos I. An introduction to the physical environment and vegetation of the campos de altitude. Journal of Biogeography, v. 26, p. 693-712, 1999.

SALAZAR-BRAVO, K.; DRAGOO, J. W.; TINNIN, D. S.; YATES, T. L. Phylogeny and evolution of the Neotropical rodent genus Calomys: inferences from mitochondrial DNA sequence data. Mol. Phylogenet. Evol., v. 20, p. 173184, 2001.

SALGADO-LABOURIAU, M. L. História Ecológica da Terra. São Paulo: Ed. Edgard Blücher Ltda, 1994.

SALVATORI. T. Le specie del genere "Pipile". Riv. Italiana di Ornit., v. 3, p. 48-58, 1914.

SANDERSON, M. J. Estimating absolute rates of molecular evolution and divergence times: a penalized likelihood approach. Mol. Biol. Evol., v. 19, p. 101-109, 2002.

SANDERSON, M. J. r8s: inferring absolute rates of evolution and divergence times in the absence of a molecular clock. Bioinformatics, v. 19, p. 301-302, 2003.

SIBLEY, C. G.; AHLQUIST, J. E. Phylogeny and Classification of Birds - a Study in Molecular Evolution. New Haven, Reino Unido: Yale University Press, 1990.

SIBLEY, C. G.; AHLQUIST, J. E.; MONROE, B. L. A classification of the living of the living birds of the world based on DNA-DNA hybridization studies. Auk, v. 105 , p. $409-423,1988$.

SICK, H. Birds in Brazil. New Jersey: Princeton University Press, 1993.

SILVEIRA, L. F. Filogenia dos Cracidae (Aves: Galliformes) com base em caracteres osteológicos. Tese (Doutorado) Instituto de Biociências da Universidade de São Paulo, 2003.

SILVEIRA, L. F.; OLMOS, F.; LONG, A. J. Birds in Atlantic forest fragments in North-east Brazil. Cotinga, v. 20, p. 32-46, 2003.

SIOLI, H. Sedimentation in Amazonasgerbiet. Geol. Rundschau, v. 45, p. 608633, 1957.

SHIMODAIRA, H. An approximately unbiased test of phylogenetic tree selection. Syst. Biol., v. 51, p. 492-508, 2002.

SHIMODAIRA, H.; HASEGAWA, M. "CONSEL: for assessing the confidence of phylogenetic tree selection," Bioinformatics, v. 17, p. 1246-1247, 2001. 
SPIX, J. B.. Avium species novae. Vol. 2. Munich: 1825.

STRAHL, S. D.; GRAJAL, A.; Conservation of large avian frugivorous and the management of neotropical protected areas. Oryx, v. 25, p. 50-55, 1991.

STRIMMER, K.; VON HAESELER, A. Quartet puzzling: a quartet maximum likelihood method for reconstructing tree topologies. Mol. Biol. Evol., v. 13, p. 964-969, 1996.

SWOFFORD, D. L. PAUP* - Phylogenetic Analysis Using Parsimony ( ${ }^{*}$ and related methods), version 4.0. Sunderland: Sinauer Associates, 2001.

TORDOFF, H. B.; MACDONALD, J. R. A new bird (Family Cracidae) from the early Oligocene of South Dakota. Auk, v. 74, p. 174-184, 1957.

VAN TUINEN, M.; SIBLEY, C. G.; HEDGES, S. B. Phylogeny and biogeography of ratites birds inferred from DNA sequences of the mithocondrial ribosomal genes. Mol. Biol. Evol., v. 15, p. 370-376, 1998.

VAURIE, C. Systematic Notes on the Bird Family Cracidae. $\mathrm{N}^{\circ}$ 1.Geographical Variation of Ortalis canicollis and Penelope marail. Amer. Mus. Novitates, v. 2197, p. 1-8, 1964.

VAURIE, C. Systematic Notes on the Bird Family Cracidae. N ${ }^{\circ}$ 5. Penelope purpuracens, Penelope jacquacu and Penelope obscura. Amer. Mus. Novitates, v. 2250, p. 1-23, 1966a.

VAURIE, C. Systematic Notes on the Bird Family Cracidae. $N^{\circ} 6$. Reviews of Nine Species of Penelope. Amer. Mus. Novitates, v. 2251, p. 1-30, 1966b.

VAURIE, C. Systematic Notes on the Bird Family Cracidae. $\mathrm{N}^{\circ} 7$. The genus Pipile. Amer. Mus. Novitates, v. 2296, p. 1-16, 1967.

VAURIE, C. Taxonomy of the Cracidae. Bull. Amer. Mus. Nat. hist., v. 138, p. 135-243, 1968.

VUILLEUMIER, F. Relatioships and Evolution within the Cracidae. Bull. Mus. Zool., v. 134, p. 1-27, 1965.

WHITMORE, T. C. An Introduction to Tropical Rain Forests. New York: Oxford University press, 1990.

WRIGHT, T. F.; WILKINSON, G. S. Population genetic structure and vocal dialects in an amazon parrot. Proc. R. Soc. Lond., v. 268, p. 609-616, 2001.

ZINK, R. M.; BLACKWELL-RAGO, R. C. Species limit and recent population history in the curve-billed trasher. The Condor, v. 102, p. 881-886, 2000. 